\title{
Growth/Differentiation Factor-15 and its role in peripheral nervous system lesion and regeneration
}

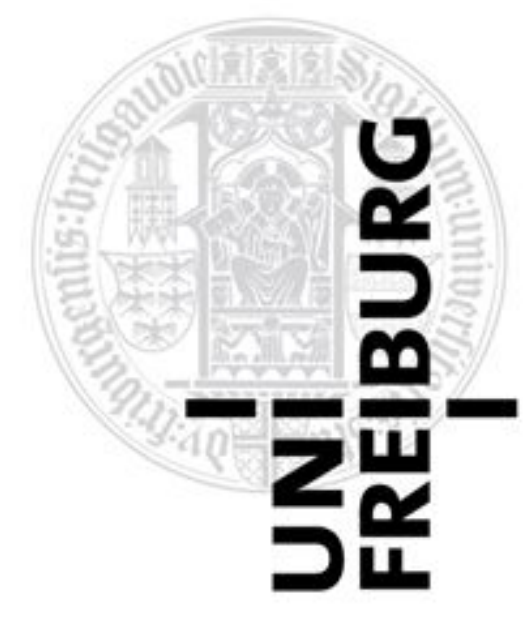

\section{INAUGURALDISSERTATION}

zur Erlangung des Doktorgrades

der Fakultät für Chemie und Pharmazie

der Albert-Ludwigs Universität Freiburg im Breisgau

\author{
vorgelegt von \\ Xiaolong Wang \\ aus Xi'an Shaanxi China
}

2014 

Vorsitzender des Promotionsausschusses: Herr Prof. Dr. Stefan Weber

Referent: Frau Prof. Dr. Irmgard Merfort

Korreferent: Herr Prof. Dr. Klaus Unsicker

Drittprüfer: Herr Prof. Dr. Andreas Bechthold

Datum der mündlichen Prüfung: 05.03.2015 

Publication from Ph.D. thesis:

Regulation and effects of GDF-15 in DRG and peripheral nerve after sciatic nerve injury. Manuscript under preparation.

Publications during Ph.D. study:

Local substitution of GDF-15 improves axonal and sensory recovery after peripheral nerve injury. Mensching L, Börger AK, Wang X, Charalambous $P$, Unsicker K, Haastert-Talini K. Cell Tissue Res. 2012 Nov; 350(2): 225-38.

Regulation and effects of GDF-15 in the retina following optic nerve crush. Charalambous P, Wang X, Thanos S, Schober A, Unsicker K. Cell Tissue Res. 2013 Jul; 353(1): 1-8.

Poster from Ph.D. thesis:

GROWTH DIFFERENTIATION FACTOR-15 (GDF-15) IN PERIPHERAL NERVE INJURY. P. Charalambous, W. Xiaolong Wang, A. Schober, J. Strelau, F. Bosse, H. W. Müller, K. Unsicker. Ninth Göttingen Meeting of the German Neuroscience Society, Poster. 



\section{Contents:}

Abstract---:--_-1

Zusammenfassung----o-s

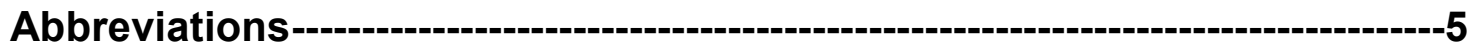

1. Introduction--

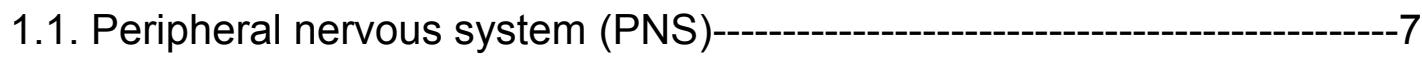

1.1.1. Origin and development of the PNS--

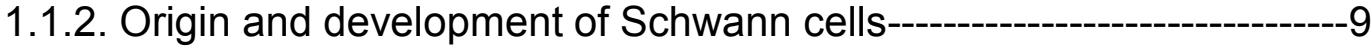

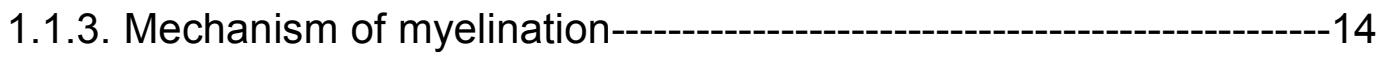

1.1.4. PNS can regenerate------------------------------------------------------16

1.1.5. Intrinsic signals in PNS regeneration--

1.1.6. Changes in poximal stump---20

1.1.7. Changes in distal stump--------------------------------------21

1.1.8. Post-lesion Schwann cell activity----------------------------------------22

1.1.9. Macrophage-Schwann cell interaction-----------------------------23

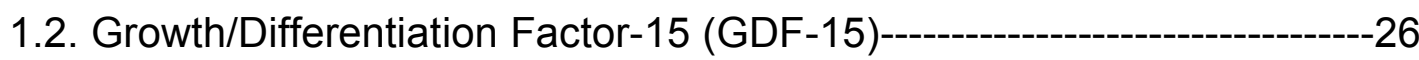

1.2.1. Discovery, structure and expression of GDF-15---------------------26

1.2.2. GDF-15 in the nervous system----------------------------------28

1.2.3. GDF-15 in cardiovascular functions------------------------------------30

1.2.4. GDF-15 in tumorigenesis----30

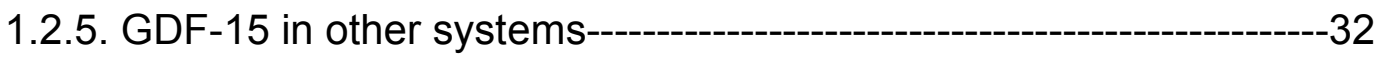

1.3. Research rationale and purpose---_-

2. Materials and Methods---35

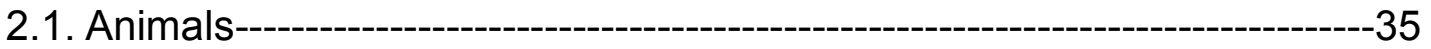

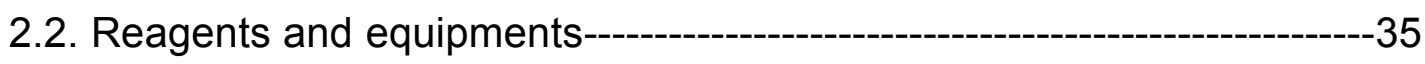

2.2.1. Chemicals, reagents and antibodies---------------------------35

2.2.2. Recipes-----------------------------------------------------------39

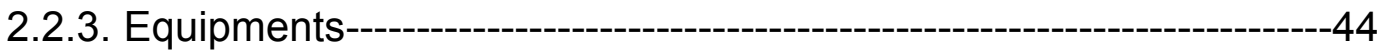

2.3. Methods--- 45 


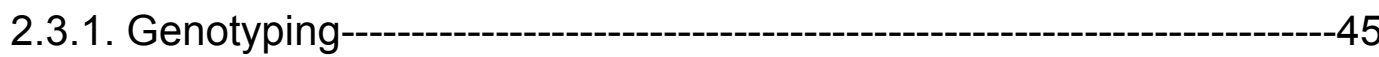

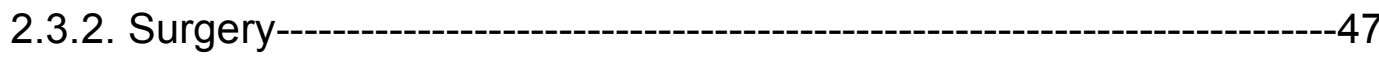

2.3.3. RNA and protein extraction----------------------------------------------------47

2.3.4. Reverse transcription and Real-time qPCR------------------------------49

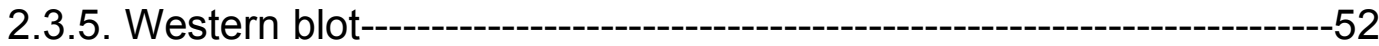

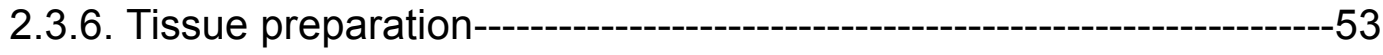

2.3.7. Paraffin embedding and sectioning-----------------------------------------53

2.3.8. Cryo-embedding and sectioning---------------------------------------------54

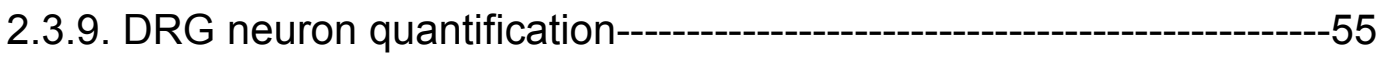

2.3.10. Immunohistochemistry-----------------------------------------------------55

2.3.11. Electron Microscopy----------------------------------------------------------56

2.3.12. Electromyography (EMG)--------------------------------------------------58

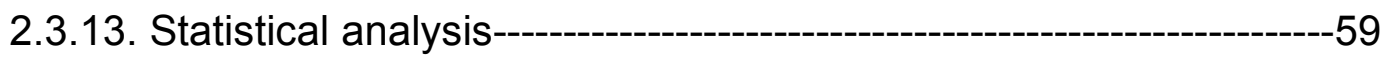

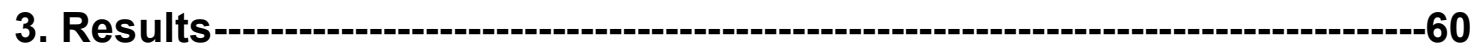

3.1. GDF-15 expression pattern---------------------------------------------------------60

3.1.1. GDF-15 in DRG after sciatic nerve lesion-------------------------------60

3.1.2. GDF-15 in sciatic nerve-------------------------------------------------------61

3.2. DRG neuron survival/death in WT and GDF-15 KO animals-------------66

3.2.1. Survival/death related genes in WT and GDF-15

KO animals--------------------------------------------------------------------------66

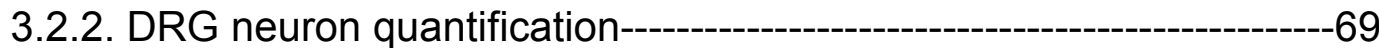

3.3. GDF-15 and axonal regeneration------------------------------------------------70

3.3.1. Demyelination and regeneration related genes

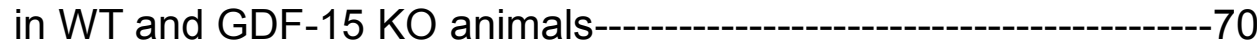

3.3.2. Inflammatory genes and macrophage recruitment in WT and GDF-15 KO animals

3.3.3. Fibroblast and Schwann cell activation in WT and GDF-15 KO animals

3.3.4. Remyelination analysis of regrowing axons in WT and GDF-15 KO animals 
3.3.5. Regenerating axon quantification in WT and GDF-15 KO animals 78

3.3.6. Regenerating axon diameter distribution in WT and GDF-15 KO animals $-80$

3.4. Functional recovery in WT and GDF-15 KO animals after $\mathrm{SN}$ crush lesion $-83$

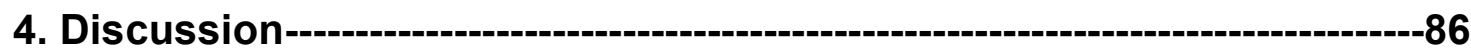

4.1. GDF-15 expression pattern-----------------------------------------------86

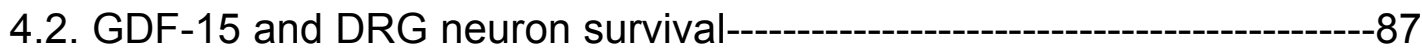

4.3. GDF-15 and SN regeneration---

4.3.1. GDF-15 and axon myelination/remyelination-------------------------90

4.3.2. GDF-15 and Schwann cells/fibroblasts/macrophages----------------91

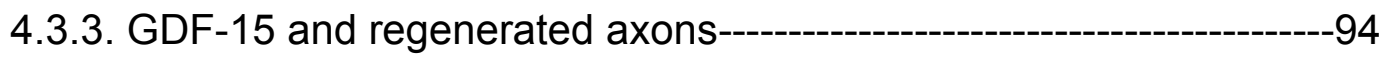

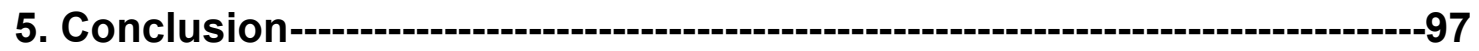

Acknowledgement---on

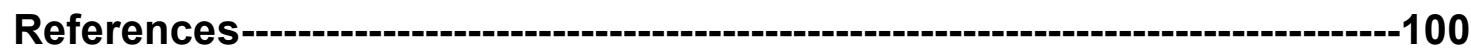

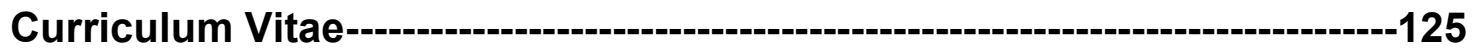





\section{Abstract:}

Growth/Differentiation Factor-15 (GDF-15) is a distant member of the TGF- $\beta$ superfamily, which is widely expressed in the body, most prominently in liver, lung, kidney and exocrine glands. Functions assigned to GDF-15 to date are mostly related to cancer biology and progression, inflammation and cardioprotection. In the field of the nervous system, several studies had shown that injured cortical neurons, microglia, Schwann cells and activated macrophages are the main producers of GDF-15. Exogenous GDF-15 has neurotrophic functions for cultured neurons, and can promote maturation of the regenerating axons. GDF-15 deficient mice exhibit postnatal progressive neuron loss. However, the functions and underlying signaling pathways of GDF-15 in the nervous system are largely unknown.

In this project, crush or transection lesion on the sciatic nerve was performed on GDF-15 knock out (KO) mice and wild type (WT) littermates. The main parameters and markers related to GDF-15 expression, neuron survival, nerve regeneration and functional recovery were analyzed.

GDF-15 mRNA levels in the dorsal root ganglia (DRG) were slightly upregulated at 3 and 7 days after sciatic nerve lesion, and returned to control level thereafter. GDF-15 expression in the sciatic nerve segments distal to the lesion peaked at 7 days after injury, which may be related to dedifferentiation of Schwann cells and infiltration of macrophages. GDF-15 was then downregulated after 7 days in the sciatic nerve crush model, but it remained at high level in the transection model. The potential neurotrophic factor Galanin was higher expressed in the GDF-15 deficient DRG than in the WT. The immunoreactivity of the survival-promoting molecule phospho-Bad was found to be constitutively expressed in the GDF-15 KO DRG, but was only seen in 
the WT DRG after lesion. In the GDF-15 KO mice, the myelination modulator Krox-20 was maintained at a high level in unlesioned nerve, which might account for the hypermyelination phenotype. However, it did not alter the remyelination during nerve regeneration. The macrophage attractor MAC-2, cytokines IL-1 $\beta$ and IL-6 were found to be more prominently expressed in the GDF-15 knock out nerve than in WT littermates. As a consequence, the levels of macrophage markers $\mathrm{CD} 11 \mathrm{~b}$ and $\mathrm{F} 4 / 80$ in $\mathrm{KO}$ mice were higher than in the WT; this was further substantiated by the staining of F4/80 in the nerve distal to the lesion. The alternative macrophage activation markers Arginase 1 and Ym1 were more prominently expressed in lesioned nerves from GDF-15 KO than in WT mice.

After sciatic nerve lesion, DRG neuron loss and axon remyelination showed no significant difference between the genotypes. However, regenerated axons in wild type animals gained a larger diameter at a later time point after sciatic nerve lesion, and showed a better improvement in terms of conduction velocity and amplitude in the electromyography test, meaning a better functional recovery.

In conclusion, GDF-15 does not alter DRG neuron death after sciatic nerve lesion; GDF-15 suppresses macrophage recruitment and alternative activation; finally, GDF-15 promotes the maturation of regenerated axons by enlarging the diameter. 


\section{Zusammenfassung:}

Growth/Differentiation Factor-15 (GDF-15) ist ein entferntes Mitgleid der TGF-ß Superfamilie und ist bei Säugern weit verbreitet; die höchste Expression findet man in den Organen Leber, Lunge, Niere und in exokrinen Drüsen. Bisher meist untersuchte Funktionen von GDF-15 betreffen die Biologie von Krebszellen, Metastasierung, Entzündung und das pathologische Herz. Für das Nervensystem ist in mehreren Studien gezeigt worden, dass GDF-15 im lädierten cerebralen Cortex, in Mikroglia, in Schwannzellen und in aktivierten Makrophagen synthetisiert und sekretiert wird. Exogen appliziertes GDF-15 wirkt neurotroph und kann die Regeneration lädierter Axone über einen Spalt hinweg fördern. GDF-15 Knockout-Mäuse zeigen einen progredienten postnatalen Verlust motorischer und sensorischer Neurone. Allerdings sind die meisten Funktionen von GDF-15 im Nervensystem noch nicht aufgeklärt.

In meiner Dissertationsarbeit habe ich an GDF-15 WIldtyp- und Knockout-Mäusen Quetschungs- und Durchtrennungs-Experimente am Nervus Ischiadicus durchgeführt und die morphologischen, molekularen und biochemischen Konsequenzen sowie die Nervenregeneration (nach Quetschung) untersucht.

GDF-15 wurde in Spinalganglien (dorsal root Ganglien, DRG) nach $3-7$ Tagen postläsional hochreguliert und normaliserte sich danach. Distal der Nervenläsionsstelle erreichte die GDF-15 Expression 7 Tage nach Verletzung ihren Gipfel; dies steht offenbar im Zusammenhang mit der Aktivierung/Dedifferenzierung von Schwannzellen und der Makrophageninfiltration. Nach Quetschung kehrten die GDF-15 Werte jenseits von Tag 7 auf Kontrollniveau zurück; nach Nerv-Durchtrennung blieben die 
Werte hoch. Galanin ist ein neurotropher Faktor und war in GDF-15 defizienten DRGs höher exprimiert als in Wlldtyp-Ganglien. GDF-15 Knockouts exprimierten phosphoryliertes Bad (das als Überlebenssignal funktioniert) konstitutiv; in Wlldtyp-Tieren wurde es nur nach Läsion beobachtet. Krox-20 ist ein positiver Regulator der Myelinisierung; es war prominent heraufreguliert in unlädierten Nerven von Knockout-Tieren; wir sehen dies im Zusammenhang mit dem Hypermyelinisierungs-Phänotyp dieser Tiere. Allerdings förderte hochreguliertes Krox-20 nicht die Remyelinisierung bei der Nervenregeneration. Der Makrophagen-Attractor MAC-2 sowie die Cytokine IL-1 $\beta$ und IL-6 waren höher exprimiert in GDF-15 knockout-nerven als in Wildtypen. Dies führte in Kockout-Tieren zu einer höheren Makrophagen-Invasion, erkennbar an hohen Werten der Makrophagen-Marker CD11b und F4/80. Dies entsprach auch den immuncytochemischen Resultaten. Arginase 1 und Ym1 sind Marker für den alternativen (M2) Aktivierungsweg für Makrophagen; beide Marker waren prominenter exprimiert in läsionierten Nerven von GDF-15 Knockout Tieren als in Wildtyp-Tieren. Nach Nervenläsion entwickelten sich DRG Neurontod und Axonremyeliniserung in Knockout- und Wildtyp-Tieren nahezu ohne Unterschied. Allerdings hatten regenerierte Wlldtyp-Axone größere Durchmesser und eine verbesserte Leitungsgeschwindigkeit, also eine bessere funktionelle Erholung.

Die Gesamt-Schlussfolgerung ist, dass GDF-15 nach Nervenläsion für das Überleben sensorischer Neurone in vivo unerheblich ist. Jedoch unterdrückt GDF-15 die Makrophagen-Aktivierung und ihre alternative (M2) Aktivierung. Wichtig ist schließlich, dass GDF-15 die Reifung regenerierender Axone durch Vergrößerung ihrer Durchmesser fördert. 


\section{Abbreviations:}

\begin{tabular}{|c|c|}
\hline $\mathrm{Bcl} 2$ & B-cell CLL/lymphoma 2 \\
\hline $\mathrm{Bcl}-\mathrm{xl}$ & BCL2-like 1 \\
\hline BDNF & Brain-derived neurotrophic factor \\
\hline cAMP & Cyclic adenosine monophosphate \\
\hline CCR2 & Chemokine ( $\mathrm{C}-\mathrm{C}$ motif) receptor 2 \\
\hline CNS & Central nervous system \\
\hline CNTF & Ciliary neurotrophic factor \\
\hline CREB & cAMP response element-binding protein \\
\hline CREM & cAMP-responsive element modulator \\
\hline DRG & Dorsal root ganglion \\
\hline Egr-3 & Early growth response protein 3 \\
\hline EMG & Electromyography \\
\hline ERK & Extracellular signal regulated kinases \\
\hline GALR & Galanin receptor \\
\hline GAP-43 & Growth associated protein 43 \\
\hline GDF-15 & Growth/Differentiation Factor-15 \\
\hline GDNF & Glial cell derived neurotrophic factor \\
\hline GFAP & Glial fibrillary acidic protein \\
\hline GM-CSF & Granulocyte-macrophage colony-stimulating factor \\
\hline GSK-3 & Glycogen synthase kinase 3 \\
\hline HIF & Hypoxia inducible factor \\
\hline Id 2 & Inhibitor of DNA binding 2 \\
\hline IFN-Y & Interferon gamma \\
\hline IGF1 & Insulin-like growth factor 1 \\
\hline IGF2 & Insulin-like growth factor 2 \\
\hline $\mathrm{IHC}$ & Immunohistochemistry \\
\hline IL-13 & Interleukin 13 \\
\hline IL-1 $\beta$ & Interleukin 1 beta \\
\hline JAK & Janus kinase \\
\hline JNK & C-Jun N-terminal kinases \\
\hline KO & Knock out \\
\hline LIF & Leukemia inhibitory factor \\
\hline LPC & Lysophosphatidylcholines \\
\hline MAG & Myelin associated glycoprotein \\
\hline MAPK & Mitogen-activated protein kinases \\
\hline MBP & Myelin basic protein \\
\hline MCP-1 & Monocyte chemotactic protein 1 \\
\hline
\end{tabular}




\begin{tabular}{|c|c|}
\hline $\mathrm{MIC}-1$ & Macrophage inhibitory cytokine 1 \\
\hline MIP-1a & Macrophage Inflammatory Proteins 1 alpha \\
\hline mTOR & Mammalian target of rapamycin \\
\hline NAG-1 & Nonsteroidal anti-inflammatory drug-activated protein-1 \\
\hline NCAM & Neural cell adhesion molecule \\
\hline $\mathrm{NF}-\mathrm{kB}$ & Nuclear factor kappa-light-chain-enhancer of activated B cells \\
\hline NGF & Nerve growth factor \\
\hline NMSC & Non-myelinating Schwann cell \\
\hline NPY & Neuropeptide Y \\
\hline NRG1 & Neuregulin 1 \\
\hline NT3 & Neurotrophin-3 \\
\hline Olig1 & Oligodendrocyte transcription factor 1 \\
\hline OMgP & Oligodendrocyte myelin glycoprotein \\
\hline ORF & Open reading frame \\
\hline P0 & Myelin protein zero \\
\hline $\mathrm{p} 75^{\mathrm{NTR}}$ & Low-Affinity Nerve Growth Factor Receptor \\
\hline PDGFB & Platelet-derived growth factor subunit B \\
\hline PKA & Protein kinase $\mathrm{A}$ \\
\hline PKB & Protein kinase B \\
\hline PLA2 & Phospholipase A2 \\
\hline PMP22 & Peripheral myelin protein 22 \\
\hline PNS & Peripheral nervous system \\
\hline SC & Schwann cell \\
\hline SCG & Superior cervical ganglion \\
\hline SCP & Schwann cell precursor \\
\hline $\mathrm{SHH}$ & Sonic hedgehog \\
\hline SN & Sciatic nerve \\
\hline Sox10 & SRY (sex determining region Y)-box 10 \\
\hline Sox2 & SRY (sex determining region Y)-box 2 \\
\hline STAT3 & Signal transducer and activator of transcription 3 \\
\hline TGF- $\beta$ & Transforming growth factor beta \\
\hline TLR & Toll-like receptor \\
\hline TNF- $\alpha$ & Tumor necrosis factor alpha \\
\hline VEGF & Vascular endothelial growth factor \\
\hline WT & Wild type \\
\hline
\end{tabular}




\section{Introduction}

\subsection{Peripheral nervous system (PNS)}

\subsubsection{Origin and development of the PNS}

The mammalian nervous system can be divided into two sub-systems: the central nervous system (CNS) and the peripheral nervous system (PNS). The CNS consists of the brain and the spinal cord, while the PNS encompasses the nerves and ganglia external to the CNS, mainly includes spinal nerves which derive from the spinal cord and cranial nerves which come from the brain. The PNS contains both the autonomic system and the somatic system, each with components locating within the CNS and the PNS. The autonomic system transfers information between the CNS and visceral organs (Irwin, 1993). The somatic system conducts information between the CNS and the skin, skeleton muscles, bones, and joints (Elenkov et al., 2000).

As reviewed extensively by numerous articles and books (e.g. Neuroscience, $3^{\text {rd }}$ edition, Dale Purves, et al.; Developmental Biology, $6^{\text {th }}$ edition, Scott $F$ Gilbert), during embryonic development, the ectoderm overlying the notochord thickens and becomes a temporary structure, the neural plate (Chang and Hemmati-Brivanlou, 1998; Duprat et al., 1990). The neural plate then begins to fold and forms a transitional structure, named neural tube (Bronner-Fraser, 1994). A group of cells locating between the neural plate and the ectoderm starts to differentiate and migrate laterally and dorsally to the neural tube. This group of cells is termed the neural crest (Bronner-Fraser, 1995) (Fig 1.1).

The marginal region of the neural tube consists of neural ectodermal cells which are named the neuroepithelium, and will later give rise to a subpopulation of cells called neuroblasts (Morest and Silver, 2003). The neuroblasts form the mantle layer locating peripherally to the neuroepithelial 
cells. The cells in the mantle layer finally become the gray matter of the spinal cord (McConnell, 1995; Tanabe and Jessell, 1996). Neuroblasts send out processes peripherally from the mantle layer and form the nerve fibers, which are then myelinated and become the white matter in the spinal cord (McConnell, 1995). Neuroepithelial cells also give rise to spongioblasts (gliablasts), which will finally become the glial cells in the CNS (Morest and Silver, 2003).

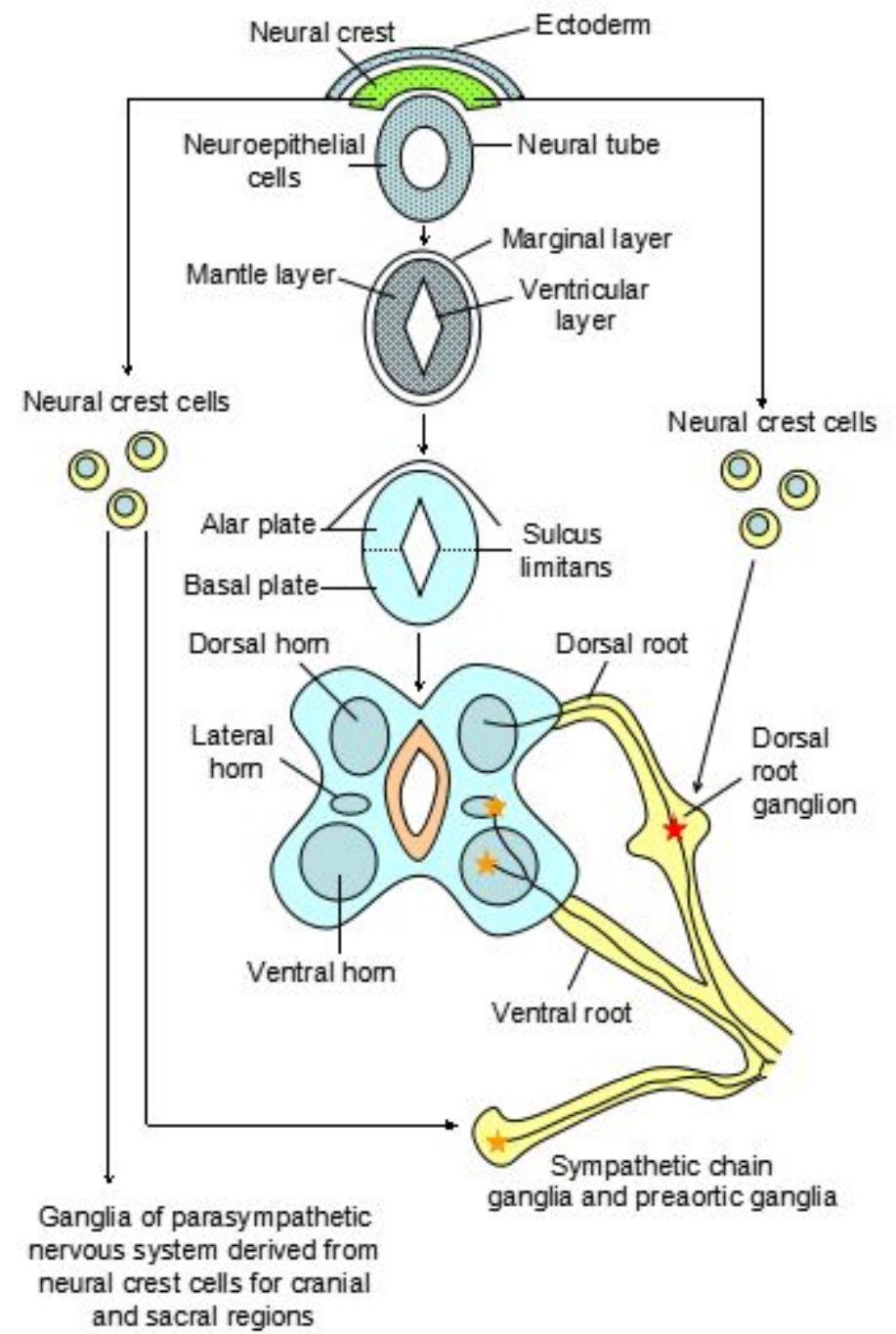

Fig 1.1 Development of spinal cord and peripheral nervous system.

Viewed transversely, the neural tube includes the central canal. The lateral corners of the canal are called the sulcus limitans (Miller et al., 2010). This 
sulcus forms the boundary between the cells located dorsally from the alar plate, and the cells located more ventrally, the latter are termed the basal plate. The cells located in the alar plate are connected to sensory function, while the cells from the basal plate are related predominently to motor function. During neural development, the intermediate region between the alar plate and the basal plate become an intermediolateral region of the gray matter, with the neurons showing autonomic function (Bronner-Fraser, 1994; McConnell, 1995; Tanabe and Jessell, 1996).

A group of neural crest cells, which locate dorsolaterally to the neural tube, will further divided into segments corresponding to the somites which develop in the mesoderm. Some of the neural crest cells go through epithelial/mesenchymal transitions and migrate to form ganglion primordial (finally form the dorsal root ganglia), in which the sensory neuron precursors undergo terminal differentiation and extend axons centrally to spinal cord and peripherally to various targets (muscle spindles, cutaneous receptors, sensory receptors) (Miller et al., 2010). Another group of neural crest cells, located in the margins of dorsal neural tube, migrate ventrally to a region near the dorsal aorta. They develop to a column of sympathetic ganglion primordia, and differentiate to obtain mainly noradrenergic properties. Finally, these cells become the sympathetic ganglia, some of which migrate rostrally to form, e.g., the superior cervical ganglion (SCG) and some migrate ventrally to establish the prevertebral ganglia, leaving the remaining cells in the column forming the sympathetic chain (Cowen and Gavazzi, 1998; Francis and Landis, 1999).

\subsubsection{Origin and development of Schwann cells}

Except neurons, there are two main types of glial cells in the PNS, satellite glia cells (SGCs) and Schwann cells (SCs). SGCs originate from the early cell pools, e.g. boundary cap cells in neural crest. They normally surround neuron 
bodies within ganglia, and are considered to have various functions, such as nutrients supply, protection, and microenvironment control (Fex et al., 2004; Nascimento et al., 2008; Pannese, 2010).

Besides SGCs, SCs are of particular importance. SCs are the myelinating and non-myelinating glial cells in the PNS. Depending on the formation of myelin sheath, SCs can be further divided into two subgroups, myelinating Schwann cells (produce myelin sheath) and non-myelinating Schwann cells (NMSCs), both derived from the neural crest (Griffin and Thompson, 2008; Woodhoo and Sommer, 2008) (Fig 1.1). Three developmental stages are involved in the formation of SCs: firstly, neural crest cells migrate to the nerve trunks and become Schwann cell precursors (SCPs) at mouse embryo day (E) 12/13; secondly, SCPS develop into immature Schwann cells at E15/16; finally, around birth, the immature Schwann cells differentiate into myelinating Schwann cells and the non-myelinating Schwann cells (Jessen and Mirsky, 2005; Jessen, 2005) (Fig 1.2).

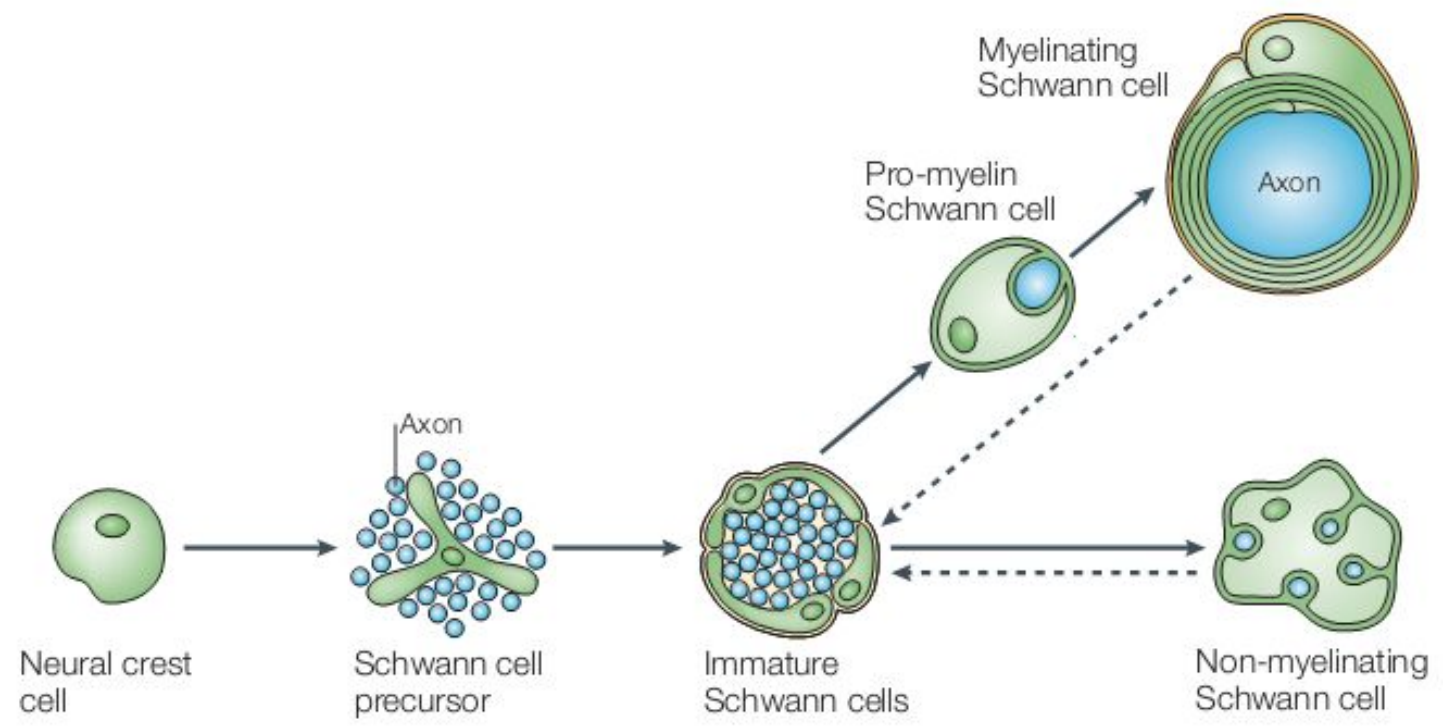

Fig 1.2 The Schwann cell lineage. Figure obtained from (Jessen and Mirsky, 2005).

Sox10 is thought to be critical for the formation of the glial lineage from the migrating neural crest cells. Sox10 is expressed in developing SGCs and 
SCPs, but downregulated in immature neurons. In mice lacking Sox10, the SGCs and SCPs are missing while neurons are in normal number. One possible function of Sox10 might be maintaining the response to Neuregulin 1 (NRG1) in early glial cells (Garratt et al., 2000; Jagalur et al., 2011; Kuspert et al., 2012) (Fig 1.3).

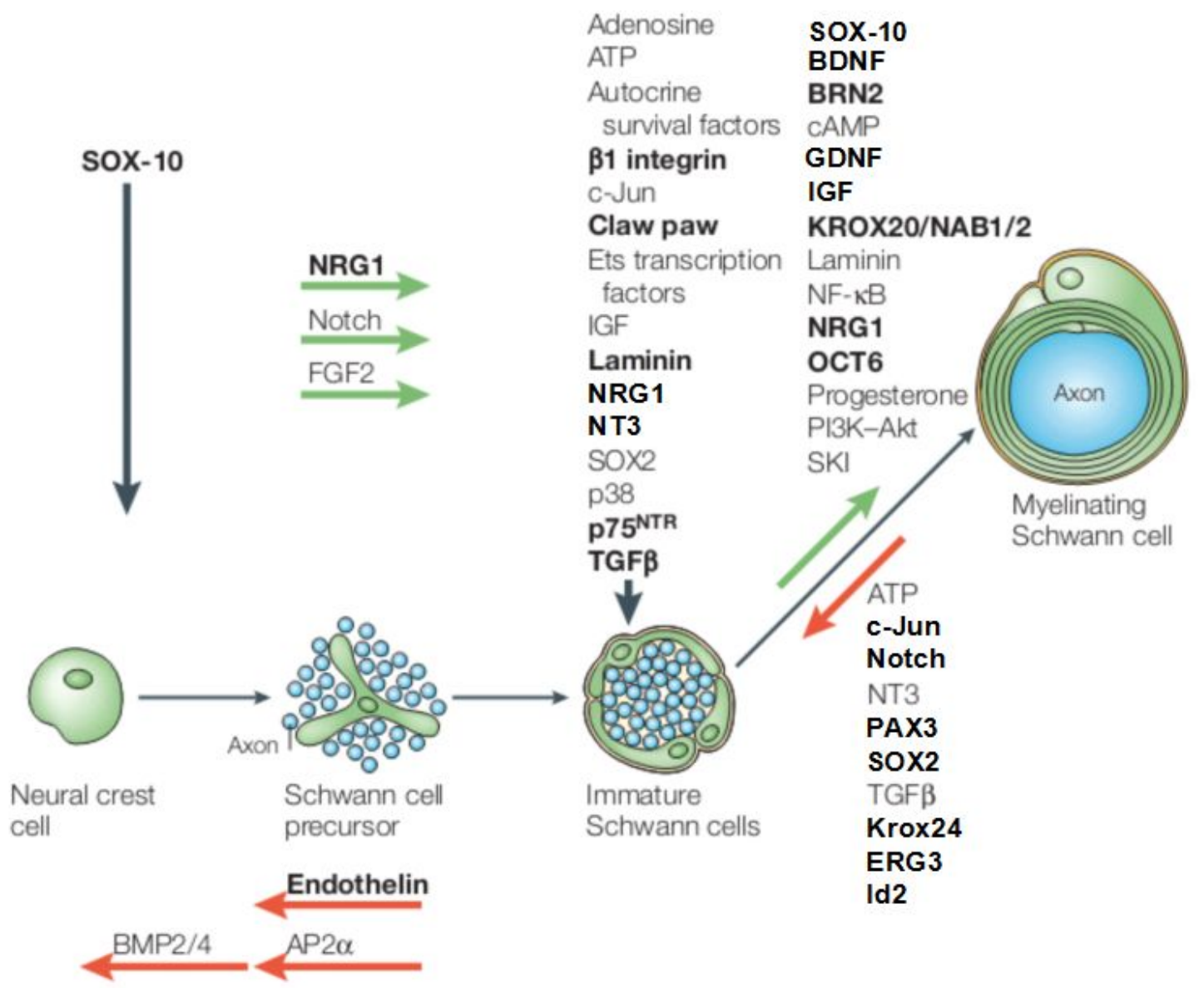

Fig 1.3 Factors involved in Schwann cell development and myelination. Figure adapted from (Jessen and Mirsky, 2005).

Early embryonic nerves are tightly associated with SCPs, forming a column structure without connective tissue, protective perineurium or blood supply. Thus SCPs are thought to be essential for trophic support and proper nerve fasciculation to immature neurons (Jessen and Mirsky, 2005). SCPs, in contrast of mature SCs, lack autocrine survival loops and largely depend on a 
NRG1 signaling, which is provided by axons, for survival (Chen and Strickland, 2003; Feltri et al., 2002; Meyer and Birchmeier, 1995; Wallquist et al., 2002). NRG1 is also a major regulator during the transition of SCPs to immature Schwann cells (Cornejo et al., 2010; Newbern and Birchmeier, 2010).

The formation of immature Schwann cell is, in time course, paralleled with the increase in vascularization, connective tissue spacing, and the formation of the perineurium in the peripheral nerve (Jessen and Mirsky, 2005). At this stage, immature Schwann cell processes surround large bundles of axons. Immature Schwann cells gain the ability to support their own vitality by autocrine survival factors, such as leukaemia inhibitory factor (LIF), neurotrophin 3 (NT3), insulin-like growth factor 2 (IGF2), and platelet-derived growth factor- $\beta$ (PDGFB) (Dowsing et al., 1999; Meier et al., 1999; Weiner and Chun, 1999). It is crucial that the autocrine circle could also promote self-survival after lesion and the regeneration of axons. On the other hand, excess immature Schwann cells need to be eliminated, this is probably controlled by the balance between survival and death factors (Jessen and Mirsky, 2005). Survival factors include axon associated NRG1, laminin from the basal lamina, as well as the autocrine factors mentioned above (Chen and Strickland, 2003; Feltri et al., 2002; Meyer and Birchmeier, 1995; Wallquist et al., 2002). At least two death factors have been identified: $p 75$ neurotrophin receptor $\left(p 75^{\mathrm{NTR}}\right)$, which is required for SCs cell death, probably activated by binding of nerve growth factor (NGF) (Syroid et al., 2000); and TGF- $\beta$, as the elevated cell death in neonatal SCs after lesion is suppressed by injection of TGF- $\beta$-blocking antibody (Einheber et al., 1995; Parkinson et al., 2001) (Fig 1.3).

During late embryo stages, individual immature Schwann cells gradually associate with single axons only to reach a $1: 1$ ratio, which is termed radial sorting, the pre-myelinating step (Webster et al., 1973). Around birth, immature Schwann cells begin to differentiate into myelinating Schwann cells and, 
subsequently, NMSCs (Jessen and Mirsky, 2005). This reversible process takes several weeks to complete in rodent nerves and is thought to be controlled by axonal signals, as random association with axons of different caliber determines subsequent maturation. Those SCs associated with large diameter axons $(>\sim 1 \mu \mathrm{m})$ will bacome myelinating $S C$ and those associated with small diameter axons become NMSCs (Griffin and Thompson, 2008; Woodhoo and Sommer, 2008) (Fig 1.2).

After radial sorting, myelinating Schwann cells go through comprehensive biochemical and morphological changes concerning lipids, protein and myelin synthesis and wrapping of lamellae to form myelin sheaths (Sherman and Brophy, 2005). Myelination offers several biological advantages such as a dramatic increase in conduction velocity, which directly correlates with total fiber diameter, as well as reduction in energy costs to generate an action potential (Gillespie and Stein, 1983; Nave, 2010). This structure increases conduction velocity in two known ways: saltatory conduction and an increase in axon diameter (Gillespie and Stein, 1983). Each myelinated segment of an axon is referred to as an internode and internodes are separated by nodes of Ranvier. Nodes of Ranvier are $\sim 1 \mu \mathrm{m}$ in length, rich in sodium channels, and are seperated by the insulating myelin sheath, therefore, the electric signal can "jump" from one node to the next (Lustig et al., 2001; Sakurai et al., 2001; Sherman and Brophy, 2005). Myelination can also induce the phosphorylation of neurofilament $\mathrm{M}$ (medium) and $\mathrm{H}$ (heavy), which enlarges the interfilament spacing and consequently, increase the axonal caliber (Hisanaga and Hirokawa, 1989; Julien and Mushynski, 1983). Myelination also offers axonal protection and limits collateral sprouting from myelinated shafts, the latter effect probably results from growth inhibitory molecules in the myelin, such as netrin, myelin-associated glycoprotein (MAG) and oligodendrocyte myelin glycoprotein (OMgP) (Gan et al., 1999; Gupta et al., 2006; Ji et al., 2008; Lim et al., 1999; Pagany et al., 2003; Willison et al., 1988). In the PNS, myelinating 
fibers are mainly A and B group fibers (Navarro et al., 2007).

The non-myelinating Schwann cells (NMSCs) consist of the Schwann cells in the Remak fibers, the terminal Schwann cells (tSCs) found at neuromuscular junctions, and specialized sensory transducers, e.g. Pacinian corpuscles and Meissner 's corpuscles (Griffin and Thompson, 2008; Vega et al., 2009). All of these NMSCs keep the ability to myelinate if they receive the appropriate axonal signal (Navarro et al., 2007; Stoll and Muller, 1999).

In contrast to the CNS, the PNS contains large population of unmyelinated axons, which are estimated to be 4 times more frequent than myelinated axons (Holland et al., 1998). In rodents, 85-90\% NMSCs usually ensheath more than one axon, while the remaining 10-15\% NMSCs enclose small axons in a 1:1 ratio. Interestingly, in human, all NMSCs associate with small axons in a 1:1 ratio (Sharghi-Namini et al., 2006). Non-myelinating fibers consist of postganglionic sympathetic fibers, C fiber nociceptors, as well as some preganglionic sympathetic and parasympathetic fibers (Griffin and Thompson, 2008). NMSCs are highly plastic, and have the ability to sprout out if necessary. This is due to the absence of myelin, which contains the inhibitory molecules for sprouting (Murinson and Griffin, 2004).

\subsubsection{Mechanism of myelination}

Myelination is a complex process and includes signals from microenvironment and axon (Jessen and Mirsky, 2005; Sherman and Brophy, 2005). Axon-associated neuregulin-1 controls the formation and thickness of the myelin sheath (Cornejo et al., 2010; Newbern and Birchmeier, 2010; Stassart et al., 2013; Wolpowitz et al., 2000). Many neurotrophic factors participate in the myelination process, including glial cell line-derived neurotrophic factor (GDNF) (Averill et al., 2004; Hoke et al., 2003; Piirsoo et al., 2010), 
brain-derived neurotrophic factor (BDNF)(Omura et al., 2005; Tolwani et al., 2004; Xiao et al., 2009; Yamauchi et al., 2004), and insulin-like growth factors (IGF-1/2)(Cheng et al., 2000; Silva et al., 2009). Schwann cells also produce myelin structrue proteins to construct myelin sheaths: myelin protein zero (P0)(Trapp, 1988), myelin basic protein (MBP)(Topilko et al., 1994), peripheral myelin protein 22 (PMP22)(Snipes et al., 1999), and myelin-associate-glycoprotein (MAG)(Trapp, 1988). Current evidence has shown that myelination is regulated by balancing the positive and negative transcriptional regulators. Positive transcription factors for myelin are normally upregulated in immature Schwann cells, which are essential for the initiation of myelination, inter alia, Sox10 (Britsch et al., 2001; Paratore et al., 2001), Krox-20 (Egr-2)(Topilko et al., 1997; Zorick et al., 1999), octamer-binding transcription factor 6 (Oct-6)(Ghazvini et al., 2002; Mandemakers et al., 2000; Smith et al., 2001) and brain 2 class III POU-domain protein (Brn-2) (Jaegle et al., 2003). Sox10, except its role in the transition from neural crest cells to SCPs, is critical for Oct- 6 expression and the induction of myelin genes in immature Schwann cells (Jagalur et al., 2011; Paratore et al., 2001). Krox-20 deficient mice show a 1:1 ratio of axon to immature Schwann cells, but fail to form myelin sheaths, indicating that Krox-20 is crucial for myelination but not radial sorting (Topilko et al., 1994). However, Krox-20 is shown to be essential to maintain the myelin sheath in physiological condition (Decker et al., 2006). Oct-6 has functional overlap with Brn-2 in terms of myelinogenesis, as Oct-6 conditional KO mice showed a delayed initiation of myelination compared with WT littermates (Ghazvini et al., 2002; Jaegle et al., 2003).

On the other hand, there are negative transcriptional regulators of myelination, which are generally activated in immature Schwann cells, deactivated in myelinating Schwann cells, re-activated upon denervating/lesion conditions to induce Schwann cell dedifferentiation, orchestrating suppression of myelin protein gene expression. After lesioning the nerve, the negative regulators are 
believed to induce the dedifferentiation program of SCs, which leads to a phenotype similar to immature Schwann cells and then remyelinate the regrowed axons (Jessen and Mirsky, 2008). Currently, several candidates of negative regulators have been documented, including the transcription factors C-Jun (Parkinson et al., 2008), Pax-3 (Blanchard et al., 1996), Sox2 (Le et al., 2005; Parrinello et al., 2010), Krox-24 (Grose et al., 2002; Topilko et al., 1997), Egr-3 (Mercier et al., 2001), Notch (Mirsky et al., 2008; Woodhoo et al., 2009) and Id2 (Le et al., 2005; Mager et al., 2008). c-Jun is a central member of the AP-1 transcription factor family and can be phosphorylated by Jun $\mathrm{N}$-terminal kinases (JNKs) (Raivich et al., 2004). c-Jun is actively expressed in Krox-20 deficient nerves, where axon myelination is restricted (Parkinson et al., 2004; Pham et al., 2009). c-Jun is essential for SC dedifferentiation: firstly, c-Jun is upregulated in denervated SCs following nerve lesion; secondly, C-Jun deficient SCs fail to phagocytose myelin debris; thirdly, c-Jun null SCs are unable to suppress myelin genes expression (Arthur-Farraj et al., 2012; Pham et al., 2009). Notch is a transmembrane receptor, and is cleaved after binding to the ligand. The Notch intra-cellular domain (NICD) is then released and passes the signal down and regulates downstream transcription ( $\mathrm{Li}$ et al., 2004). Notch is also known to control the developmental transition from SCPs to immature Schwann cells, as well as SC proliferation within embryonic nerves (Kubu et al., 2002; Morrison et al., 2000). Like c-Jun, Notch also acts as a negatively regulator of myelination postnatally (Woodhoo et al., 2009)(Fig 1.3).

\subsubsection{PNS can regenerate}

One of the most significant differences between the PNS and CNS is the fact that the PNS has the ability to spontaneously regenerate after lesion. Although in clinical cases in humans, the regenerative results are mostly suboptimal, the experiments on rodents have produced satisfactory results in many instances 
(Reyes et al., 2005). The major features leading to the regenerative difference in the PNS and CNS are well documented and include multiple facets of intrinsic growth programs, the inhibitory molecules associated with myelin, removal of myelin debris, glial scar formation, activation of phagocytic cells, and bridging for regeneration in lesion sites (Cafferty et al., 2008; Giger et al., 2010).

The major events in the PNS after lesion include: axon degradation, collapse of myelin sheaths, proximal neurite sprouting, Schwann cell proliferation forming the Bands of Büngner, invasion of circulating macrophages, removal of myelin debris, elongation of the axon distally, reconstruction of the myelin sheath, and reinnervation of the targets (Abe and Cavalli, 2008; Chen et al., 2007; Fawcett and Keynes, 1990; Navarro et al., 2007; Stoll and Muller, 1999) (Fig 1.4).

(A)

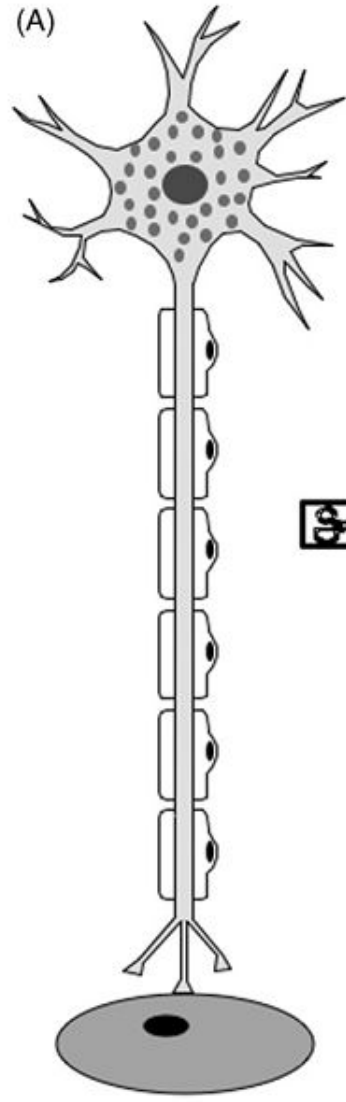

(B)
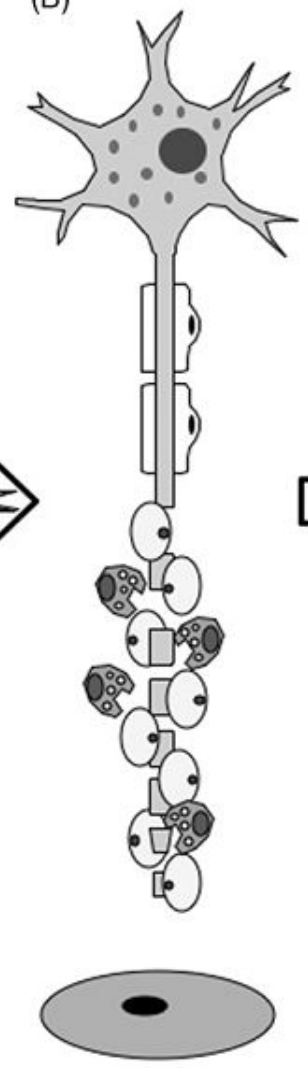

(C)
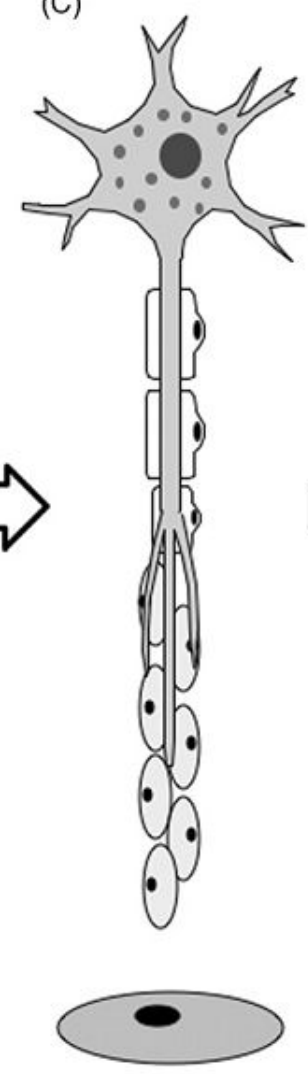

(D)

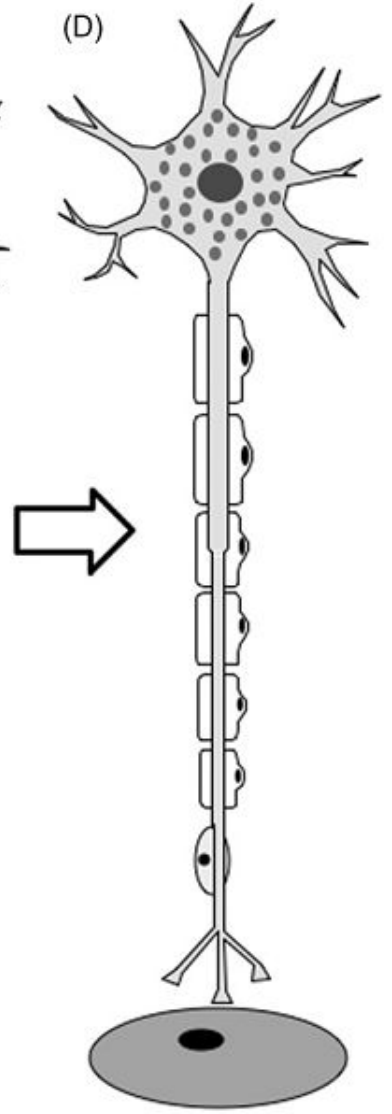

Fig 1.4 Major events after PNS lesion. Figure obtained from (Navarro et al., 2007). 
The most widely used methods for studying regeneration in the PNS in rodents are nerve transection (neurotmesis), crush injury (axonotmesis) and chronic constrictive injury (neuropraxia) (Chen et al., 2007; Navarro et al., 2007). Among these, crush injury and chronic constrictive injury, which normally leave the epineurium intact, allow fast regeneration and fully functional recovery; while in case of nerve transection, surgical or mechanical repair is necessary to obtain satisfactory regeneration (Fawcett and Keynes, 1990; Hudson et al., 2000).

\subsubsection{Intrinsic signals in PNS regeneration}

Axons are complex structures that require a combined support for the functional maintainance and regeneration from the neuronal cell bodies and the attached glial cells. Lesioning an axon leads to the loss of a large amount of axonplasmic volume and results in chromatolysis (dissolution of the Nissl bodies) of the neuron soma; furthermore, this intervention causes soma and nucleolar swelling, as well as nuclear eccentricity (Lieberman, 1971; Navarro et al., 2007; Stoll and Muller, 1999). The injured neurons switch their metabolic machinery from generating neural transmitters and nerve impulses to promoting self-survival and regenerating axons. The percentage of sensory neuron death in DRG after SN lesion has been reported to amount to between 10 and $30 \%$, affecting preferentially more the small than the large neuron populations (Groves et al., 1999; Shi et al., 2001; Tandrup et al., 2000). A slight loss of $0-10 \%$ motoneurons has been found after adult SN injury (Lowrie et al., 1994; Vanden et al., 1993). Neurons in the adult are less vulnerable to die than immature neurons, whereas lesions close to the cell bodies cause more neuronal death than distal lesions (Snider et al., 1992; Ygge, 1989).

Nerve injury also results in the activation of an intrinsic growth capacity which has been extensively studied: several molecules are strongly upregulated or 
reexpressed in neurons after nerve lesion. Cyclic adenosine monophosphate (cAMP) signaling functions through protein kinase $A(P K A)$ activity and switches on downstream genes via cAMP response element binding protein (CREB), to initiate and promote regeneration program (Cai et al., 2002; Gao et al., 2004). Downstream molecules of cAMP signaling include Arginase 1 (ARG1), neuropeptide $Y$ (NPY), protein kinase A (PKA), CREM (cAMP response element modulator), and IL-6 (Parlato et al., 2006; Spooren et al., 2010; Zhou et al., 2012). Lesion also upregulates trophic factors, such as BDNF, NGF, and NGF receptor (Averill et al., 2004; Delcroix et al., 2003; Meyer et al., 1992; Micera et al., 2007; Piirsoo et al., 2010; Wilhelm et al., 2012). C-Jun has been shown to contribute to regeneration, as the c-Jun null neurons fail to organize a proper regeneration program (Arthur-Farraj et al., 2012; Fontana et al., 2012; Yuan et al., 2012). c-fos, similar to c-Jun, also promotes neuron regeneration (Dai et al., 2009; Jergova et al., 2008; Yuan et al., 2009). ATF3 and signal transducer and activator of transcription 3 (STAT3) are induced in DRG neurons after peripheral injury, but not central lesion (Kiryu-Seo et al., 2008; Reid et al., 2010; Saul et al., 2010). STAT3 may promote the survival of motor neurons after peripheral nerve injury by activating some motor neuron survival factors, such as Reg-2 and Bcl-xl (Schwartz et al., 2002; Sekikawa et al., 2008). Other regeneration-associated genes upregulated in neurons following injury include Galanin, Integrin $\alpha 7 \beta 1$, CD44, and GAP-43 (Frey et al., 2000; Hirata et al., 2002; Lindwall et al., 2004; Raivich et al., 2004; Son et al., 2007). These genes differentially promote neuron survival or regeneration by enhancing neurite sprouting and cytoskeletal reconstruction (Fig 1.5). 


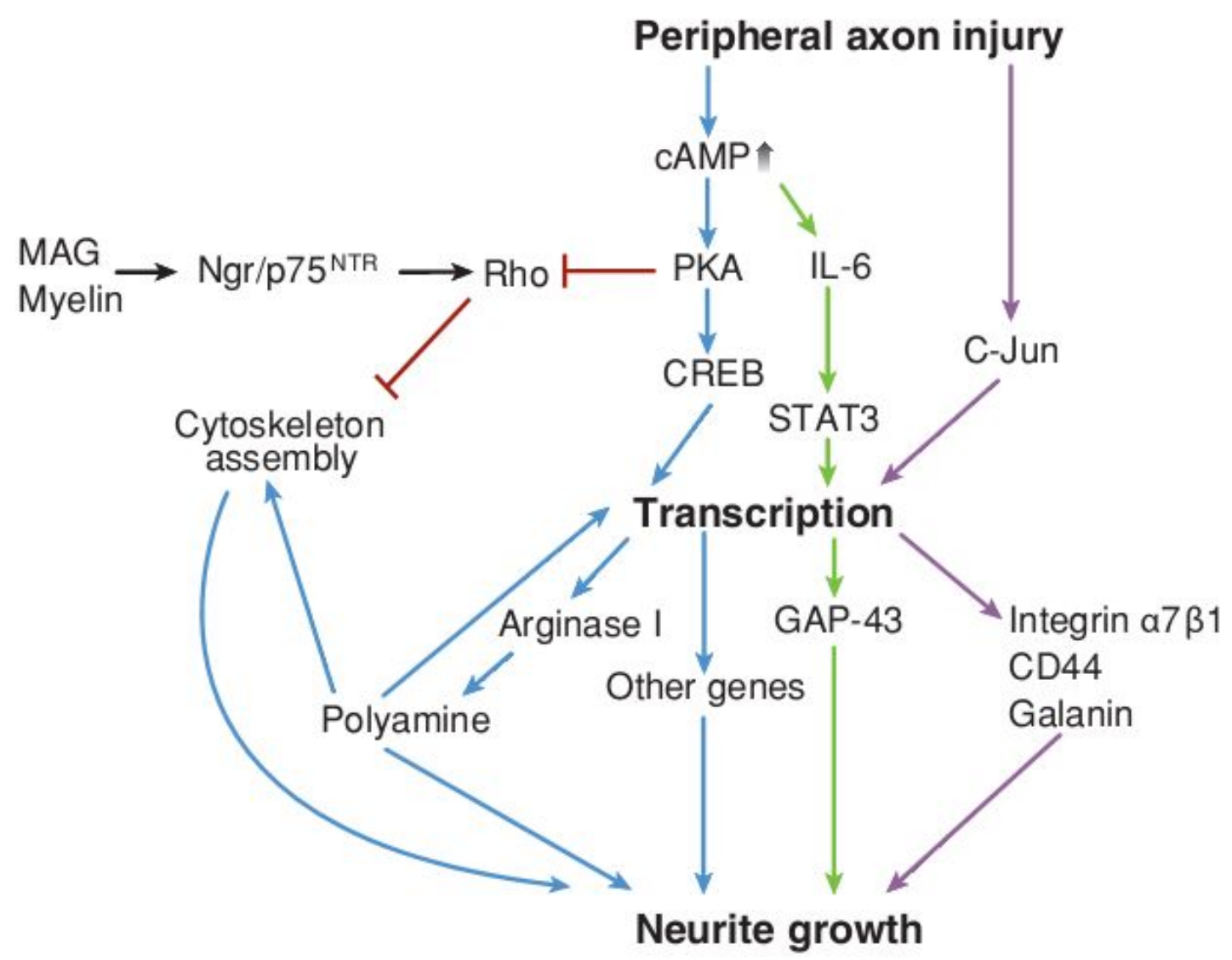

Fig 1.5 Intrinsic signals in PNS regeneration. (Chen et al., 2007).

\subsubsection{Changes in poximal stump}

Lesion leads to a retrogradely degeneration from the lesion site towards neuron body, but depends on the degree of injury, only one or a few intermodal lengths are affected, and certain amount of cytosol outflows before the opening reseals by the fusion of cellular membrane. Within hours, proximal axons start to regrow collaterally and distally inside of the basal lamina (Navarro et al., 2007; Stoll and Muller, 1999). The newly sprouted neurites are protruding through the injury and are decreased in numbers when they reach and contact the endoneurium in the distal stump (Fawcett and Keynes, 1990). This process is strongly dependent on the guidance of SCs which form physical contact to the regrowing axons (Donnerer, 2003). The regenerating sprouts will stay unmyelinated until a later stage, regardless of the previous 
myelination status of axons (Flores et al., 2000). Regrowing axons will preferentially reinnervate the endoneurial tubes in the distal stump over the neighboring tissues (Son and Thompson, 1995).

\subsubsection{Changes in distal stump}

Immediately after lesion, the axonal membranes proximal to the injury site fuse the opening ends to stop the cytosolic content from outflow (Fawcett and Keynes, 1990). On the contrary, the distal axonal segment will undergo Wallerian degeneration, a process first described by Augustus Waller in 1850. Wallerian degeneration involves the granular disintegration of the cytoskeleton systems and the breakdown of previous myelin sheath which is due to the calcium-mediated proteolysis triggered by the damage of membrane. Schwann cells and macrophages are activated and phagocytose the myelin breakdown products and axonal debris (Fu and Gordon, 1997; Makwana and Raivich, 2005; Navarro et al., 2007). This is a critical step for Wallerian degeneration that helps to provide a permissive microenvironment for axon regeneration. SCs form column-shaped structures (Bands of Büngner) which could guide axons to correct targets. Axons reconnected to the proper distal targets would benefit from trophic supply and finally enlarge their diameter to normal level in a late stage. On the contrary, axons that fail to reconnect with correct targets, may grow into connective tissue, and will later be eliminated (Hall, 1997; Liu, 1996).

Neurotrophic factors, such as NGF, NT-3 and BDNF, have all been shown to be upregulated after lesion and induce axon growth (Makwana and Raivich, 2005; Snider et al., 2002). Cytokines such as interleukin-6 (IL-6) are related to nerve regeneration, as mice with conditional knock out of IL-6 exhibit sensory defects and impaired DRG axons regeneration after lesion (Tofaris et al., 2002; Zhong et al., 1999). Another immune regulator, leukemia inhibitory factor (LIF) 
also shows its role in the nerve regeneration by studies using LIF knockout animals (Cafferty et al., 2001; Livesey et al., 1997). STAT3 has been shown to be not only essential for the survival of spinal motor neurons, but also critical for the expression of IL-6 and LIF (Dominguez et al., 2010; Haas et al., 1999; Ohbayashi et al., 2007). Extracellular matrix molecules and cell adhesion molecules, such as laminin, NCAM, fibronectin and L1 are also necessary for guiding axons to pass the injury site, to enter the distal stumps and finally to reach the targets (Chen et al., 2005; Chen and Strickland, 2003; Chernousov et al., 2008; Parrinello et al., 2010; Hansen et al., 2008; Schäfer and Frotscher, 2012; Schmid and Maness, 2008).

\subsubsection{Post-lesion Schwann cell activity}

Nerve lesion triggers dramatic morphological and physiological changes in the nerve segment distal to injury. Schwann cells transit to a status similar to immature Schwann cells, termed dedifferentiation (Arthur-Farraj et al., 2012). The SCs phagocytose axon and myelin debris and briefly proliferate, which peaks at 3-4 days post lesion (Navarro et al., 2007; Stoll and Muller, 1999). The molecular phenotype of immature Schwann cells and adult dedifferentiated Schwann cells is different (Arthur-Farraj et al., 2012; Jessen and Mirsky, 2005). Several molecules are well documented: the lipid antigen O4 is a marker of immature Schwann cells, also expressed in both myelinating and non-myelinating adult Schwann cells, but downregulated in dedifferentiated cells (Mirsky et al., 1990). Conversely, Integrin $\alpha 1 \beta 1$ is absent from immature cells but is expressed in denervated SCs (Stewart et al., 1997). In vivo, $\mathrm{N}$-cadherin is suppressed to a low level in immature cells, but is strongly activated in lesioned nerves (Thornton et al., 2005; Wanner et al., 2006). Furthermore, immature cells in developing nerves are known to be different from mature NMSCs, because NMSCs are PO mRNA negative, galactocerebroside positive and Integrin $\alpha 1 \beta 1, \alpha 7 \beta 1$ positive. The NMSCs also 
differ from dedifferentiated cells, as the latter express P0 mRNA, but lack of galactocerebroside and O4 (Mirsky et al., 2008).

Schwann cell dedifferentiation is a key step of successful regeneration. At the dedifferentiation stage, SCs downregulate genes related to myelin production and maintainance, including myelin structural proteins, P0, MBP, MAG, periaxin and cholesterol synthesizing enzymes (LeBlanc and Poduslo, 1990; Scherer et al., 1995; Stoll and Muller, 1999). Dedifferentiated Schwann cells also reprogram to express molecules normally found in immature SCs, such as L1, NCAM, p75 low affinity neurotrophin receptor ( $p 75^{\mathrm{NTR}}$ ), and glial fibrillary acidic protein (GFAP) (Johnson et al., 1988; Schmid and Maness, 2008; Tacke and Martini, 1990; Thornton et al., 2008; Triolo et al., 2006). Furthermore, dedifferentiated SCs upregulate trophic factors such as NGF, BDNF and GDNF, and cytokines, such as TNF- $\alpha$, IL-1 $\beta$, IL-6, LIF and MCP-1, to facilitate the regenerative program (Flugel et al., 2001; Nadeau et al., 2011; Piirsoo et al., 2010; Taskinen and Roytta, 2000; Wilhelm et al., 2012). Although the details of transcriptional control of the phenotype transition are still unclear, a recent study has demonstrated that c-Jun is actually the major controller of the dedifferentiation phenotype (Arthur-Farraj et al., 2012).

\subsubsection{Macrophage-Schwann cell interaction}

During Wallerian degeneration, products of degenerated neural tissue could stimulate monocyte chemotactic protein-1 (MCP-1) expression in SCs partially through Toll-like receptor 2/3 (TLR2/3) (Boivin et al., 2007; Karanth et al., 2006; Lee et al., 2006). Other cytokines such as tumor necrosis factor alpha (TNF- $\alpha$ ), $\mathrm{IL}-1 \alpha$ and macrophage inflammatory protein 1 alpha (MIP-1 $\alpha$ ) are also found in SCs immediately after SN injury. IL-1 $1 \beta$ expression is then induced by TLRs and related to the early response to injury (Taskinen and Roytta, 2000). After macrophages have infiltrated into the nerve, they also express TNF- $\alpha, \mathrm{IL}-1 \alpha$, 
and IL-1 $\beta$ (Gordon and Martinez, 2010; Martini et al., 2008; Tofaris et al., 2002). Those molecules mentioned above stimulate the expression of the phospholipase A2 (PLA2) family members, which consist of both intracellular and secretory forms (Murakami et al., 1997). PLA2s hydrolyze membrane phosphotidylcholine, which is a main component of the myelin membranes, resulting in the production of lysophosphotidylcholine (LPC), which has potential myelinolytic activity. Injection of LPC into the $\mathrm{SN}$ could induce demyelination within short time, which probably results from the activation of the classic complement pathway, since LPC could bind to C-reactive protein (Larsen et al., 2003; Ousman and David, 2000). Thus, the PLA2s induced LPC generation has the ability of stimulating myelin breakdown at the beginning of Wallerian degeneration. Myelin-derived lipids are also reabsorbed for regeneration and remyelination. Lipid binding proteins, such as Apolipoproteins $D$ and $E(A p o D, A p o E)$, accumulate in the distal nerve portion after injury. ApoD is mainly expressed by endoneural fibroblasts, while ApoE is primarily produced by infiltrating macrophages (Li et al., 2010; Spreyer et al., 1990; Stoll and Muller, 1986).

Macrophages play an important role in the processes of removing myelin and axonal debris in the lesioned nerve, especially the ones from hematogenous origin (Hu and McLachlan, 2003; Rosenberg et al., 2012; Shibata et al., 2003). They invade into the lesioned loci within the first 48 hours and spread to the whole distal part of the nerve by no later than day 4 , and their quantity peaks by 14 days (Bendszus and Stoll, 2003). In vitro studies have demonstrated that $\mathrm{IL}-1 \beta$ and TNF- $\alpha$ promote myelin phagocytosis by recruiting infiltrating macrophages (Shamash et al., 2002). In vivo evidence shows that functional blocking antibodies neutralizing MCP-1/MIP-1 $\alpha$ or IL-1 $\beta$ dramatically reduce the number of phagocytic macrophages (Perrin et al., 2005). Macrophage surface marker, MAC-2 (galactin-3) participates in myelin phagocytosis and has been reported to be induced by Granulocyte-macrophage 
colony-stimulating factor (GM-CSF) in peripheral nerve (Reichert et al., 1994; Saada et al., 1996). GM-CSF is found to be expressed predominantly by active fibroblasts in the lesioned nerve, pointing out the involvement of non-neural cells in the process of Wallerian degeneration (Mirski et al., 2003). Nevertheless, fibroblasts can also form a bridge connecting the nerve stumps in transection lesions and, through ephrin-B/EphB2 signaling, guide the SC migration and direct the axon regrowth (Parrinello et al., 2010). SCs express MAC-2 and surprisingly, are able to phagocytose myelin debris; thus, before macrophages infiltrating into the distal stump, SCs are the main contributor of phagocytosis (Saada et al., 1996)(Fig 1.6).

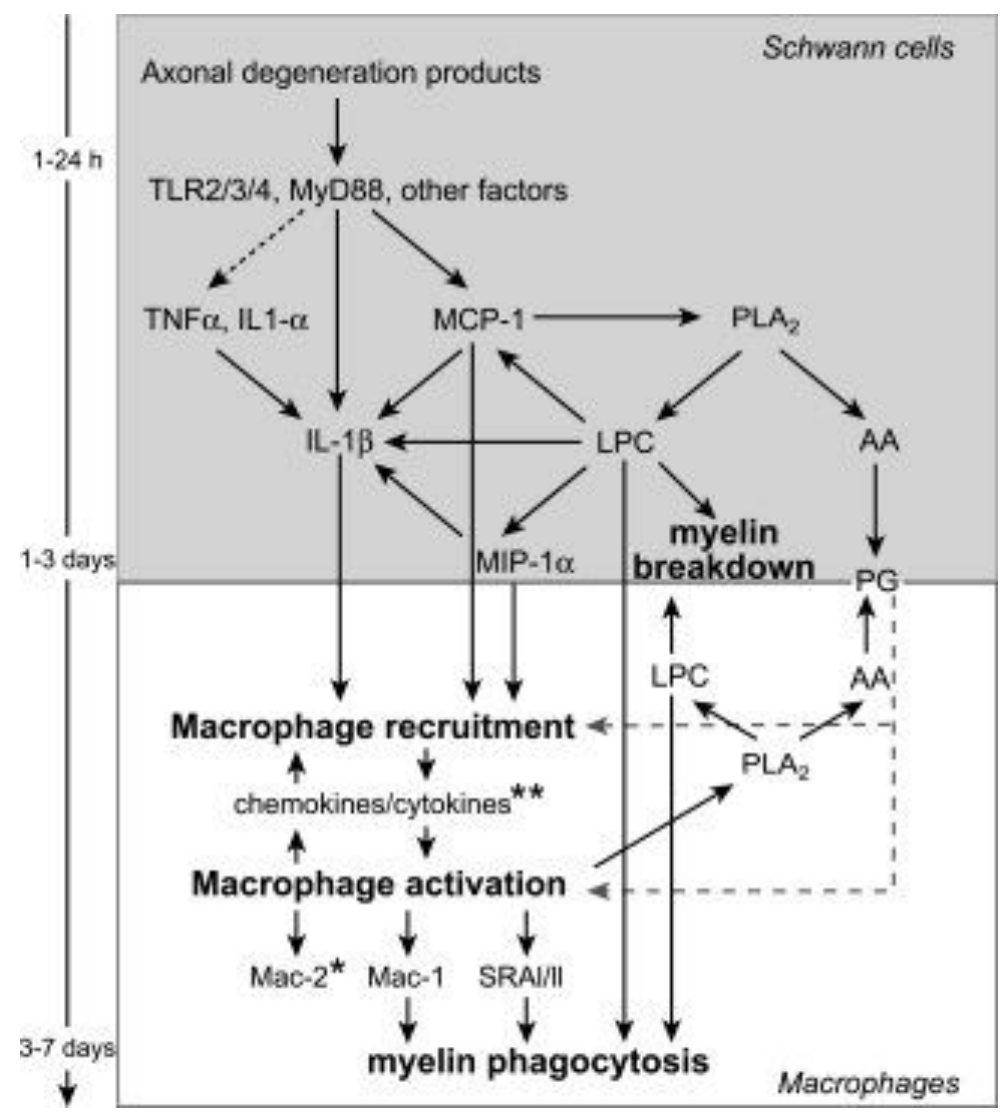

Fig 1.6 A pathway map of Schwann cell-Macrophage interaction during PNS regeneration. Figure obtained from (Martini et al., 2008).

Macrophages exhibit an anti-inflammatory phenotype after they have started phagocytosing myelin. NgR1, which is found to be a common receptor for all three axonal regrowth inhibitory molecules in myelin (Nogo-A, MAG and 
OMgp), could lead to the growth cone collapse in the CNS and impair neurite growth (Martini et al., 2008). NgR2 is also found in peripheral nerve, and has a higher affinity binding to MAG than to Nogo-A or OMgp (Venkatesh et al., 2005). NgR1 is downregulated in axons after nerve lesion, but is highly expressed in phagocytic macrophages. The proportion of all macrophages expressing $\mathrm{NgR} 1$ and $\mathrm{NgR} 2$ increases after lesion and reaches a peak by day 7 (Fry et al., 2007). On the contrary, only a few (12\%) circulating monocytes express NgR1 and NgR2 (Fry et al., 2007). Circulating macrophages have to infiltrate into the basal lamina of SCs for phagocytosis, and afterwards, at the end stage of Wallerian degeneration, they have to migrate out of the basal lamina (Martini et al., 2008). NgR plays an essential role on the outward migration of macrophages after clearance of debris, as $\mathrm{NgR}$ expressing macrophages are pushed away when they contact with the $\mathrm{NgR}$ ligands (MAG and OMgp) in newly synthesized myelin of regenerated axon. This repulsion is believed to be induced by the Rho-A pathway (David et al., 2008; Fry et al., 2007).

\subsection{Growth/Differentiation Factor-15 (GDF-15)}

\subsubsection{Discovery, structure and expression of GDF-15}

Growth/Differentiation Factor-15 (GDF-15) is a distant member in the transforming growth factor beta (TGF- $\beta$ ) superfamily and was discovered in the late 1990s almost simultaneously by several different laboratories (Bootcov et al., 1997; Böttner et al., 1999; Fairlie et al., 1999). According to the different screening/cloning methods and functions involved, GDF-15 has received various names, such as Nonsteroidal anti-inflammatory drug (NSAID) activated gene-1 (NAG-1)(Baek et al., 2001), macrophage inhibitory cytokine-1 (MIC-1)(Bootcov et al., 1997), placental transformation growth factor- $\beta$ (PTGFB)(Lawton et al., 1997), prostate-derived factor (PDF)(Paralkar et al., 1998) and placental bone morphogenetic protein (PLAB)(Hromas et al., 1997). 
The GDF-15 gene consists of two exons seperated by a single intron. This pattern resembles closely GDF- 9 and inhibin $\alpha$ and $\beta$ in the TGF- $\beta$ superfamily. The rat and mouse GDF-15 preproprotein contains 303 amino acids (aa), compared to human which has 308 amino acid, including a 29 aa signal peptide, a 167 aa propeptide and a 112 aa mature protein (Böttner et al., 1999)(Fig 1.7). The preproprotein contains an RXXR dibasic cleavage site at the C-terminal. The generation of active mature protein, which is a $25 \mathrm{KDa}$ secreted dimer, needs the removal of a signal sequence, disulfide-linked dimerization of GDF-15 monomers, and the furin-like protease cleavage at the RXXR site (Böttner et al., 1999). Nevertheless, recent evidence also suggests that GDF-15 can be secreted in both processed and unprocessed form, using different secretory pathways (Bootcov et al., 1997). The mature peptides from the three species all contain two cysteine residues in addition to the seven cysteines required to form the cystine knot, which is also the conserved feature among TGF- $\beta$ superfamily members. Unlike the other members, GDF-15 shows the lowest conservation between species, as the mature protein from human and rat only share 70\% conserved residues (Böttner et al., 1999). The analysis of the promoter region has identified many regulatory sites upstream of the ORF region, including several AP-1 and SP-1 sites, as well as WT-1, NF-KB, AP-2, PUR factor, HiNF-c and MIG-1 binding sites, suggesting that GDF-15 can be regulated by various upstream molecules (Böttner et al., 1999). 


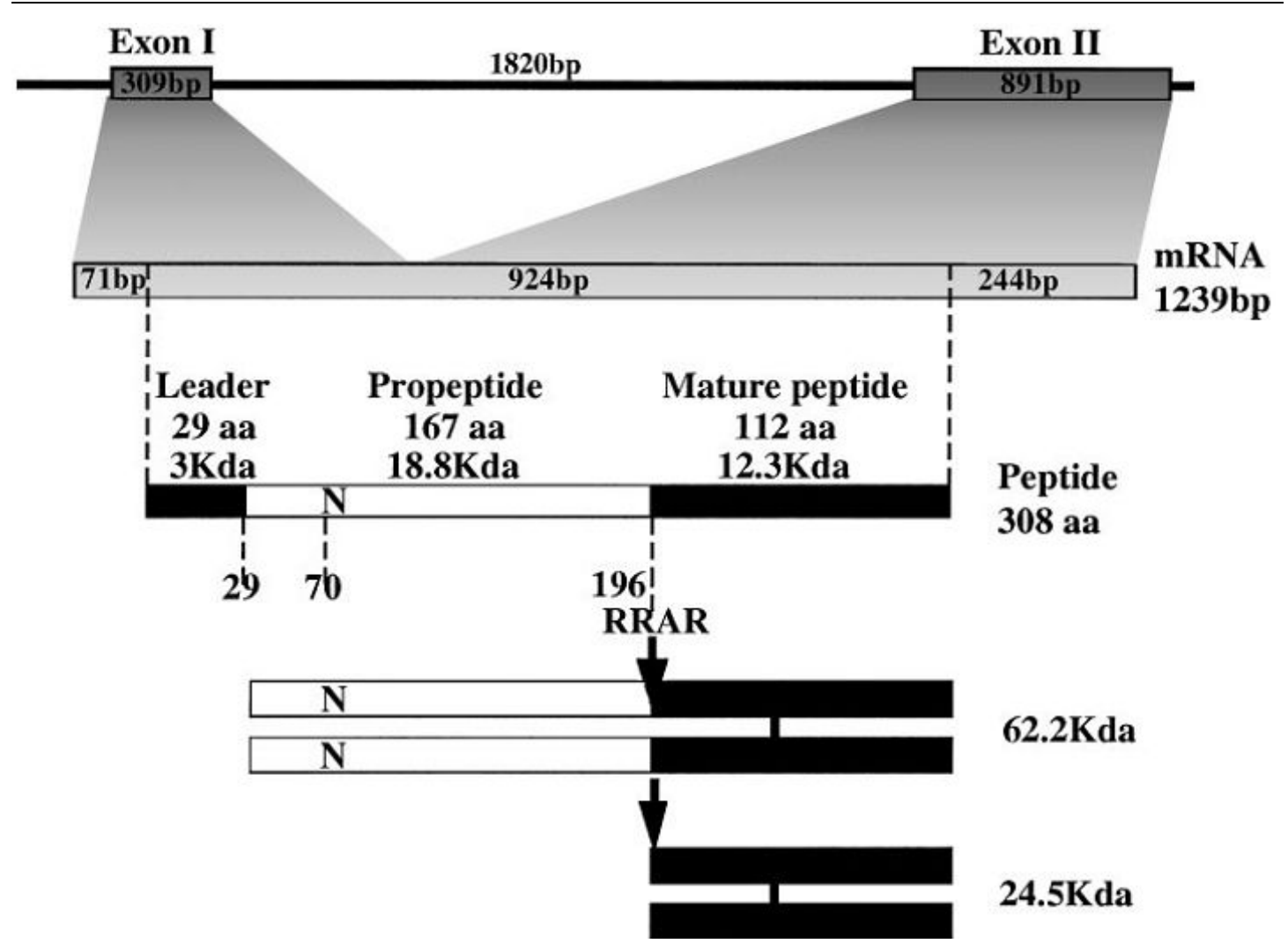

Fig 1.7 Gene structure of gdf-15. Figure obtained from (Fairlie et al., 1999).

GDF-15 has been shown to be expressed ubiquitously in adult tissues, with relatively higher expression in prostate, placenta, bronchi, bronchioli, exocrine glands, macrophages, brain choroid plexus, kidney, lung, liver and spleen, and with comparably lower expression in heart, gut, skeletal muscle, thymus and pituitary, suggesting its multiple functionality (Böttner et al., 1999; Kadara et al., 2006; Nakamura et al., 2003; Unsicker et al., 2013; Xu et al., 2006). GDF-15 is also found in mouse embryo, e.g. in skin and cartilaginous tissue, indicating that it has a role in developmental control (Paralkar et al., 1998).

\subsubsection{GDF-15 in the nervous system}

GDF-15 has been shown to have a neurotrophic function in in vitro experiments, as it could promote the survival of cultured midbrain dopaminergic neuron, cerebellar granule neurons, sensory, sympathetic and spinal cord motor neurons (Strelau et al., 2009). Furthermore, GDF-15 KO 
mice exhibit a postnatal progressive neuron loss phenotype, including spinal cord, trigeminal, facial motoneurons and DRG sensory neurons, with a reduction of $\sim 20 \%$ in quantity from postnatal day 90 (P90) to P180. Neuron loss is accompanied by impaired behavioral function and rotarod performance (Strelau et al., 2009). GDF-15 KO mice also upregulate myelin-related genes, including MBP, PO and PMP22, leading to hypermyelination in the PNS (Strelau et al., unpublished data). SCs have been identified as a producer of GDF-15, which can be retrogradely transported along the axons (Strelau et al., 2009). The GDF-15 KO phenotype partially resembles the CNTF KO phenotype, but exact underlying mechanisms are still uncovered (Sendtner et al., 1994).

In normal physiological conditions, GDF-15 expression is found ubiquitously in all regions of rodent CNS and PNS, with the highest mRNA levels in the choroid plexus, where GDF-15 protein is secreted into the cerebrospinal fluid (Strelau et al., 2000). Current studies show that GDF-15 is regulated after lesioning the nervous system. In the cold-lesioned cerebral cortex, GDF-15 mRNA is found to be upregulated in the region adjacent to the lesion and peaks at 36-48h (Schober et al., 2001). Interestingly the main source of GDF-15 are the lesioned neurons as well as a moderate number of microglia, this is in contrast to the notion that activated macrophages are the major producer of GDF-15 in other tissue (de Jager et al., 2011; Fairlie et al., 1999; Schlittenhardt et al., 2004). A more recent experiment on mouse optic nerve lesions has shown GDF-15 to be upregulated post lesion, together with some important cell-death/survival related molecules, such as ATF-3, Bad, and Bcl-2 (Charalambous et al., 2013; Subramaniam et al., 2003). Galanin and Caspase 8 were shown to be differentially regulated in GDF-15 KO and WT mice. However, cell death of retinal ganglion cells in GDF-15 KO and WT mice follows identical quantitative and temporal patterns (Charalambous et al., 2013). 
Local application of GDF-15 into the gap after a sciatic nerve transection has been shown to result in an improved sensory, but not motor regeneration. Additionally, in the GDF-15 treated animal, less but more mature regenerated axons were found suggesting that GDF-15 may be involved in the scenarios of PNS regeneration (Mensching et al., 2012).

\subsubsection{GDF-15 in cardiovascular functions}

The largest portion of all publications related to GDF-15 is concentrated on its cardiovascular functions. After myocardial infarction, GDF-15 is rapidly upregulated in the infarcted myocardium in both mouse models and human patients, and can keep this high expression level for a prolonged period (Kempf et al., 2006; Kempf et al., 2007; Kempf et al., 2011). GDF-15 has been reported to be increased in atherosclerotic lesions, colocalized with macrophages. GDF-15 deficient mice have a decreased macrophage infiltration, chemokine receptor 2 (CCR2) expression, apoptosis and necrotic core formation (Bonaterra et al., 2012; de Jager et al., 2011). Increased levels of GDF-15 in circulating blood have been observed in patients with acute myocardial infarction (Kempf et al., 2006). GDF-15 also shows a protective effect on cultured cardiomyocytes in reducing apoptosis (Kempf et al., 2006). In patients with heart failure, levels of GDF-15 and increases in GDF-15 over time have been linked to an adverse outcome (Kehl et al., 2012). Collectively, GDF-15 is viewed as a marker and predictor of cardiometabolic risk and heart failure. GDF-15 has also been identified as a novel autocrine/endocrine molecule that antagonizes the hypertrophy and loss of ventricular function, possibly via the SMAD 2/3 pathway (Xu et al., 2006).

\subsubsection{GDF-15 in tumorigenesis}

Elevated GDF-15 expression has been characterized as a feature of various 
tumors, including breast, gastric, colon, ovarian and prostate cancer. Serum GDF-15 levels are significantly increased in metastatic cancers, particularly colorectal cancer (Baek et al., 2009; Brown et al., 2003; Dubey et al., 2012; Kim et al., 2005; Welsh et al., 2003). During epithelial neoplastic transformation, GDF-15 is upregulated in response of many antitumorigenic stimuli e.g. anti-inflammatory chemicals and gamma irradiation. During the early stages of carcinogenesis, anti-cancer reagent-induced GDF-15 can result in tumor cell apoptosis, cell cycle arrest and inhibition of blood vessel formation (Unsicker et al., 2013).

The specific role of GDF-15 in tumorgenesis is still not fully understood, but some clues give a preliminary idea about it. GDF-15 is shown to be stimulated on the activation of the MAPK-ERK1/2 or PKB/Akt pathway by SP-1 family transcription factors in breast or gastric cancer (Wollmann et al., 2005). GDF-15 can also activate HIF-1 and VEGF by phosphorylation and activate the ErbB receptor, mTOR, and ERK1/2 pathways, while downregulating ErbB2 can lead to the suppression of GDF-15-mediated downstream signaling (Kim et al., 2008). GDF-15 is also found to be induced by hepatitis $C$ virus and in hepatocellular carcinoma, where the GDF-15 autocrine signaling of infected hepatocytes mediates GSK-3/ $\beta$ catenin, Akt and Raf phosphorylation (Si et al., 2011). This is followed by cell-cycle regulation by e.g. cyclins A2, D2 and E1, or cell adhesion molecules, such as E-cadherin (Si et al., 2011). In malignant glioblastomas, GDF-15 is upregulated following anoxia, indicating its role in angiogenesis (Boyle et al., 2009; Huh et al., 2010). GDF-15 is highly expressed in malignant melanomas and leads to the formation of new vessels affecting the tumor tissue size (Huh et al., 2010).

The effect of GDF-15 in tumorgenesis is also related to immunoregulation. Studies based on GDF-15 deletion or knock down show an enhanced natural killer T cell mediated cytotoxicity, and delayed growth of glioma cells, which 
resembles the phenotype of TGF- $\beta$ downregulation (Friese et al., 2004; Roth et al., 2010). p53 has been reported to be necessary for GDF-15 expression. Tumor cell migration decreased in response to GDF-15, with unaffected proliferation (Cheng et al., 2011; Song et al., 2012). Furthermore, in a model of prostate cancer, GDF-15 has been shown to influence tumor invasion through the Rho GTPase network, however, the underlying mechanisms are still unclear (Cheng et al., 2011).

\subsubsection{GDF-15 in other systems}

Because of its ubiquitous tissue distribution, GDF-15 is involved in diverse functions and in multiple processes. GDF-15 can serve as an anti-inflammatory cytokine in the model of heart infarction, by inhibiting the recruitment of macrophage towards the lesion loci (Kempf et al., 2011). This is achieved by the activation of $\mathrm{Cdc} 42$, repression of Rap 1, and clustering of $\beta 2$ integrin on leukocytes. GDF-15 has also been verified as an acute phase mediator of the CCR2/TGF $\beta$ RII dependent inflammation, and as a regulator of the IL-6 dependent inflammation in response of vascular injury (Kempf et al., 2011). GDF-15 also has an impact on metabolic control, such as appetite, obesity, and body weight change (Johnen et al., 2007). Obese patients express high levels of GDF-15, especially patients suffering from type II diabetes (Lajer et al., 2010). GDF-15 is associated with keratinocyte differentiation and several skin diseases, such as skin sclerosis and melanoma (Ichikawa et al., 2008; Kluger et al., 2011; Yanaba et al., 2012). GDF-15 also regulates osteoclastic differentiation through inhibiting carbonic anhydrase II and cathepsin K (Hinoi et al., 2012; Vanhara et al., 2009). 


\subsection{Research rationale and purpose}

The probably most fascinating feature of the peripheral nervous system is its ability to spontaneously regenerate after lesion. This regeneration requires a complex orchestration of different physiological processes, including the retrograde transfer of lesion signal(s), transcriptional transition, morphological changes, neuron survival, axon degeneration, Schwann cell/macrophage/fibroblast activation, neurite regrowth, axon remyelination and target reinnervation, finally leading to functional recovery. Research on PNS regeneration has a great and profound significance: firstly, to better understand the mechanisms of PNS regeneration provides new approaches to promote CNS regeneration; secondly, research on rodent models may eventually lead to improvements for the therapy of human patients.

GDF-15 has been shown to have ubiquitous origins and involvement in different biological processes. Our particular interests focuses on nervous system regeneration: firstly, GDF-15 may be expressed by macrophages and Schwann cells, both of which are the most important participants in PNS regeneration; secondly, GDF-15 is related to the trophic support of cultured neurons and maintenance of adult neuron in vivo, which might be applied to the in vivo situation following injury; thirdly, GDF-15 has a role in the regulation of cell adhesion molecules and recruitment of macrophages, as well as in the suppression of inflammation. These facts revealed by previous research have generated the hypothesis that GDF-15 might be involved in the orchestration of PNS regeneration.

We used GDF-15 knock out mice and respective wild types as model animals, applied sciatic nerve crush or transection+stump ligation, to investigate: firstly, whether GDF-15 plays a role in PNS regeneration; secondly, what is the expression pattern of GDF-15 during PNS regeneration; thirdly, which are the 
Introduction

targets and interacting molecules within the GDF-15 network. 


\section{Materials and Methods}

\subsection{Animals}

All animal treatments were performed with permission from the responsible authority of the University Clinic Freiburg. C57BL6/J WT mice were provided by the animal facility of the BioMed Zentrum, University Clinic Freiburg. The GDF-15 $5^{\text {laczllacz }}$ mouse colony was established in Heidelberg (Strelau et al., 2009) on a C57BL6/J background and was reestablished in Freiburg by embryo transfer. The animals were held under standard conditions, with a 12/12 hours day/night cycle. Food and water were provided ad libitum. All experiments were done on the mice of 5 6 months old.
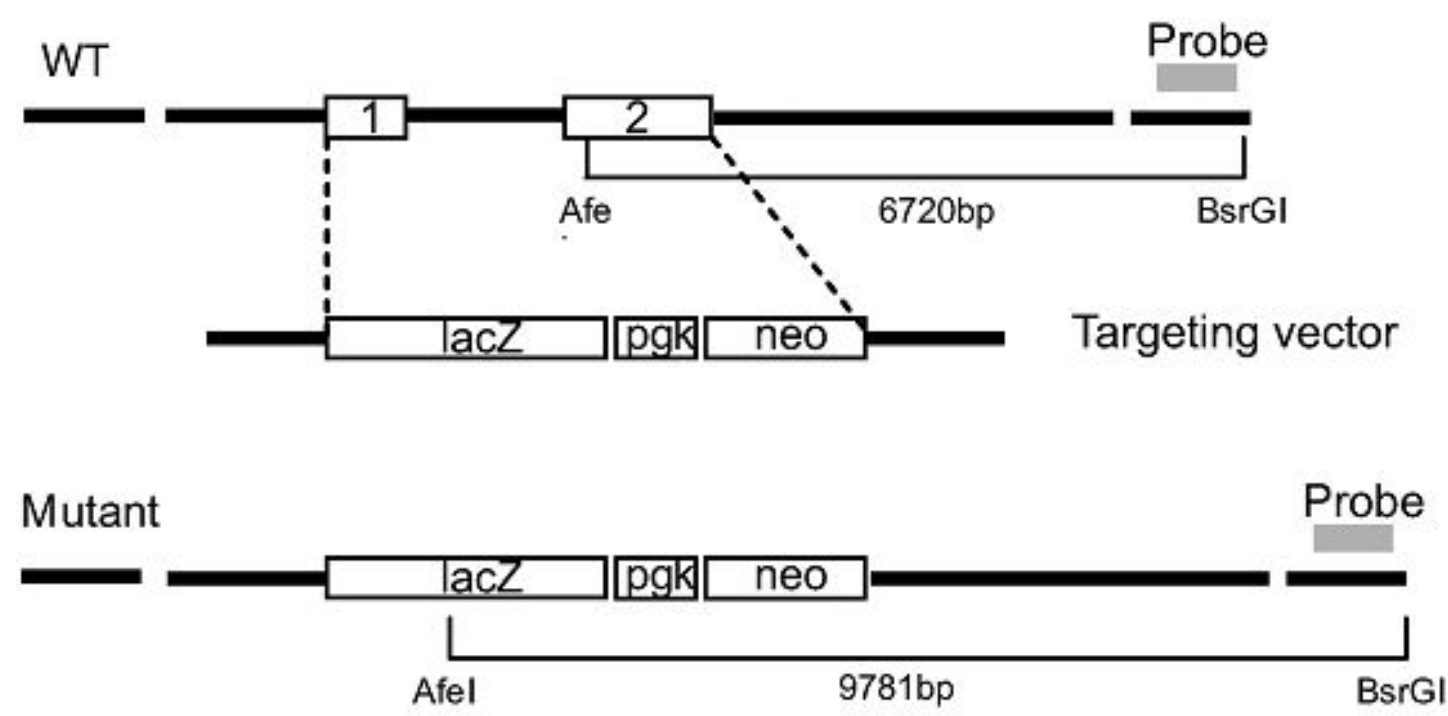

Fig 2.1 Structure of the GDF-15 gene and strategy for knock out this gene. Figure obtained from (Strelau et al., 2009).

\subsection{Reagents and equipments}

\subsubsection{Chemicals, reagents and antibodies}

All chemicals used in the present study are listed below in Table 2.1. 
Table 2.1 Chemicals

\begin{tabular}{|c|c|c|}
\hline Chemicals & Catalog \# & Company \\
\hline Acetic acid & 20104.334 & VWR \\
\hline Ammonium persulfate (APS) & 9592.2 & Carl Roth \\
\hline Bromochloropropane & B9673-200ML & Sigma \\
\hline Citric acid monohydrate & C7129-500G & Sigma \\
\hline Cresyl echt violet & $1 \mathrm{~A} 396$ & Chroma \\
\hline Glutaraldehyde & 1.12179 .0025 & VWR \\
\hline Hydrogen chloride & $30271-1 \mathrm{~L}$ & Sigma \\
\hline Isopropanol & $\mathrm{P} / 7500 / 17$ & Fisher Scientific \\
\hline $\mathrm{K}_{2} \mathrm{HPO}_{4}$ & 1.05104 & Merck \\
\hline $\mathrm{KCl}$ & 1.04936 .1000 & Merck \\
\hline $\mathrm{KH}_{2} \mathrm{PO}_{4}$ & 3904.1 & Carl Roth \\
\hline Methanol & 20847.320 & VWR \\
\hline $\mathrm{Na}_{2} \mathrm{HPO}_{4}$ & P030.3 & Carl Roth \\
\hline $\mathrm{Na}_{2} \mathrm{HPO}_{4} \cdot 2 \mathrm{H}_{2} \mathrm{O}$ & 4984.1 & Carl Roth \\
\hline $\mathrm{NaH}_{2} \mathrm{PO}_{4} \cdot 2 \mathrm{H}_{2} \mathrm{O}$ & 6345.1000 & Merck \\
\hline $\mathrm{NaCl}$ & 9265.1 & Carl Roth \\
\hline Osmium tetraoxide & 8088.1 & Carl Roth \\
\hline Paraformaldehyde (PFA) & 1.04005 .1000 & Merck \\
\hline Propylene oxide & $00236-1$ & Polysciences \\
\hline SDS pellets & $\mathrm{CN} 30.2$ & Carl Roth \\
\hline Sodium hydroxide & 1.06498 .1000 & Merck \\
\hline Sucrose & 4621.1 & Carl Roth \\
\hline TEMED & T9281-25ML & Sigma \\
\hline Toluidin blue & 1B481 & Chroma \\
\hline Triton X-100 & X100-100ML & Sigma \\
\hline Trizma base & T6066-1KG & Sigma \\
\hline Tween-20 & P9416-100ML & Sigma \\
\hline
\end{tabular}


All reagents and kits used in the present study are listed below in Table 2.2.

Table 2.2 Reagents and Kits

\begin{tabular}{|c|c|c|}
\hline Reagents & Catalog \# & Company \\
\hline Agarose & M3044.0500 & GENAXXON \\
\hline BCA Protein Assay Kit & 23227 & Thermo Scientific \\
\hline Blue film & $30-100$ & Genesee Scientific \\
\hline Bovine serum albumin (BSA) & 3737.2 & Carl Roth \\
\hline DNA Extraction Solution & QE09050 & Epicentre \\
\hline DNA Ladder & SM0241 & Thermo Scientific \\
\hline dNTP Mix & U1511 & Promega \\
\hline Durcupan $^{\mathrm{TM}}$ ACM A & 44611-100ML & Sigma \\
\hline Durcupan $^{\mathrm{TM}}$ ACM B & 44612-100ML & Sigma \\
\hline Durcupan $^{\mathrm{TM}}$ ACM C & 44613-100ML & Sigma \\
\hline Durcupan $^{\mathrm{TM}}$ ACM D & 44614-100ML & Sigma \\
\hline ECL Prime & RPN2232 & Life Sciences \\
\hline Entellan & 1.07691 & VWR \\
\hline Fluoromount-G & 0100-01 & SouthernBiotech \\
\hline GelRed $^{\mathrm{TM}}$ Nucleic Acid Gel Stain & 41003 & Biotium \\
\hline GoTaq® qPCR Master Mix & A6001 & Promega \\
\hline Hyperfilm ECL & $28-9068-37$ & Life Sciences \\
\hline Inhibitorcocktail Plus & 3751.1 & Carl Roth \\
\hline Isofluran & CDS019936 & Sigma \\
\hline Ketamine & 400203.00 .00 & Cp-pharma \\
\hline M-MLV Reverse Transcriptase & M1701 & Promega \\
\hline Non-fat milk & $\mathrm{T} 145.2$ & Carl Roth \\
\hline Paraffin & 39502004 & McCormick \\
\hline Protein ladder & $7711 \mathrm{~s}$ & NEB \\
\hline PVDF membrane 0.2 um & $39-4010$ & PeqLab \\
\hline PVDF membrane 0.45 um & NEF1002001PK & Pekin Elmer \\
\hline
\end{tabular}




\begin{tabular}{lll}
\hline Random Primers & C1181 & Promega \\
RedTaq Mastermix (2x) & M3029.0100 & GENAXXON \\
RNA Clean \& Concentrator ${ }^{\mathrm{TM}}-25$ & R1018 & ZYMO Research \\
RNAlater Stabilization Solution & AM7020 & Life Technologies \\
RNasin® Plus RNase Inhibitor & N2611 & Promega \\
Rotihistol & 6640.1 & Carl Roth \\
Rotiphorese® Gel 30 (37.5:1) & 3029.1 & Carl Roth \\
RQ1 RNase-Free DNase & M6101 & Promega \\
Tissue freezing medium & 020108926 & Leica \\
TriFast & $30-2020$ & PeqLab \\
Xylazine & 6293841.00 .00 & BAYER \\
\hline
\end{tabular}

All antibodies used in the present study are listed below in Table 2.3.

Table 2.3 Antibodies

\begin{tabular}{lllll}
\hline Antibody & Host & Catalog \# & Company & Dilution \\
\hline F4/80 & Rat & ab6640 & Abcam & 1:1000 WB \\
Galanin & Goat & sc-16411 & Santa Cruz & 1:200 IHC/1:500 WB \\
GAPDH & Mouse & ab8245 & Abcam & 1:10000 WB \\
GDF-15 & Rabbit & custom made & ImmunoGlobe & 1:200 IHC/1:500 WB \\
Iba-1 & Rabbit & \#019-19741 & WAKO & $1: 500 \mathrm{IHC}$ \\
NF-kB & Rabbit & 4765 & Cell Signaling & 1:2000 WB \\
phospho-Bad & Rabbit & AB10423 & Millipore & $1: 125 \mathrm{IHC}$ \\
S100ß & Rabbit & Z0311 & DAKO & $1: 500 \mathrm{IHC}$ \\
Tuj-1 & Mouse & MMS-435P & Covance & $1: 1500 \mathrm{IHC}$ \\
Ym1 & Rabbit & 01404 & Stemcell & 1:1000 WB \\
anti-mouse-HRP & Horse & 7076 & Cell Signaling & $1: 5000 \mathrm{WB}$ \\
anti-goat-HRP & Rabbit & P0449 & DAKO & $1: 5000 \mathrm{WB}$ \\
anti-rabbit-HRP & Goat & 7074 & Cell Signaling & 1:5000 WB
\end{tabular}




\begin{tabular}{lllll}
\hline anti-rat-HRP & Goat & 7077 & Cell Signaling & $1: 5000 \mathrm{WB}$ \\
DaM-Dylight405 & Donkey & $715-475-151$ & Dianova & $1: 500 \mathrm{IHC}$ \\
DaM-Alexa488 & Donkey & $715-545-151$ & Dianova & $1: 500 \mathrm{IHC}$ \\
DaM-Cy3 & Donkey & $715-165-151$ & Dianova & $1: 500 \mathrm{IHC}$ \\
DaR-Dylight405 & Donkey & $711-475-152$ & Dianova & $1: 500 \mathrm{IHC}$ \\
DaR-Alexa488 & Donkey & $711-545-152$ & Dianova & $1: 500 \mathrm{IHC}$ \\
DaR-Cy3 & Donkey & $711-165-152$ & Dianova & $1: 500 \mathrm{IHC}$ \\
DaR-Alexa594 & Donkey & $711-585-152$ & Dianova & $1: 500 \mathrm{IHC}$ \\
DaG-Alexa488 & Donkey & A-11055 & Life & $1: 500 \mathrm{IHC}$ \\
& & & Technologies & \\
DaG-Cy3 & Donkey & $705-165-147$ & Dianova & $1: 500 \mathrm{IHC}$ \\
DaM-Biotin & Donkey & $715-065-151$ & Dianova & $1: 500 \mathrm{IHC}$ \\
DaR-Biotin & Donkey & $711-065-152$ & Dianova & $1: 500 \mathrm{IHC}$ \\
DaG-Biotin & Donkey & $705-065-147$ & Dianova & $1: 500 \mathrm{IHC}$ \\
Streptavidin-Cy2 & & $016-220-084$ & Dianova & $1: 500 \mathrm{IHC}$ \\
Streptavidin-Cy3 & & $016-160-084$ & Dianova & $1: 500 \mathrm{IHC}$ \\
Donkey Serum & Donkey & $\mathrm{C} 065 \mathrm{HZ}$ & AbD serotec & $10 \% \mathrm{IHC}$ \\
\hline & & &
\end{tabular}

\subsubsection{Recipes}

All recipes used in the present study are listed below in Table 2.4-Table 2.20.

Table 2.4 10X PBS:

\begin{tabular}{ll}
\hline Components & Amount \\
\hline $\mathrm{NaCl}$ & $80 \mathrm{~g}$ \\
$\mathrm{KCl}$ & $2 \mathrm{~g}$ \\
$\mathrm{Na}_{2} \mathrm{HPO}_{4}$ & $14.4 \mathrm{~g}$ \\
$\mathrm{KH}_{2} \mathrm{PO}_{4}$ & $2.4 \mathrm{~g}$ \\
\hline
\end{tabular}

Add $\mathrm{ddH}_{2} \mathrm{O}$ to $800 \mathrm{ml}$. Adjust $\mathrm{pH}$ to 7.4 .

Add $\mathrm{ddH}_{2} \mathrm{O}$ to $1 \mathrm{~L}$. 
Table 2.5 1X PBST:

\begin{tabular}{ll}
\hline Components & Amount \\
\hline $10 X$ PBS & $100 \mathrm{ml}$ \\
$\mathrm{H}_{2} \mathrm{O}$ & $900 \mathrm{ml}$ \\
Triton X-100 & $1 \mathrm{ml}$
\end{tabular}

Stir to dissolve Triton $\mathrm{X}-100$.

Table 2.6 0.1M PB

\begin{tabular}{ll}
\hline Components & Amount \\
\hline $\mathrm{Na}_{2} \mathrm{HPO}_{4} \cdot 2 \mathrm{H}_{2} \mathrm{O}$ & $14.24 \mathrm{~g}$ \\
$\mathrm{NaH}_{2} \mathrm{PO}_{4} \cdot 2 \mathrm{H}_{2} \mathrm{O}$ & $3.12 \mathrm{~g}$ \\
\hline
\end{tabular}

Add $\mathrm{ddH}_{2} \mathrm{O}$ to $1 \mathrm{~L}$.

Table 2.7 10X TBS:

\begin{tabular}{lll}
\hline Components & Concentration & Amount \\
\hline Tris-Base & $0.2 \mathrm{M}$ & $24.23 \mathrm{~g}$ \\
$\mathrm{NaCl}$ & $1.5 \mathrm{M}$ & $87.66 \mathrm{~g}$ \\
\hline
\end{tabular}

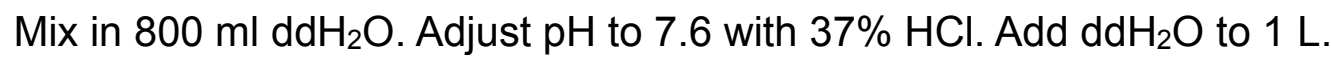

Table 2.8 1X TBST:

\begin{tabular}{ll}
\hline Components & Amount \\
\hline $10 x$ TBS & $100 \mathrm{ml}$ \\
$\mathrm{ddH}_{2} \mathrm{O}$ & $900 \mathrm{ml}$ \\
Tween 20 & $1 \mathrm{ml}$ \\
\hline
\end{tabular}

Stir to dissolve Tween 20.

Table 2.9 4X Tris buffer, $\mathrm{pH}=6.8$ :

\begin{tabular}{lll}
\hline Components & Concentration & Amount \\
\hline Tris-Base & $0.5 \mathrm{M}$ & $6.06 \mathrm{~g}$
\end{tabular}


$\mathrm{ddH}_{2} \mathrm{O}$

$80 \mathrm{ml}$

Adjust $\mathrm{pH}$ to 6.8 with $10 \mathrm{~N}$ or $6 \mathrm{~N} \mathrm{HCl}$. Add $\mathrm{ddH}_{2} \mathrm{O}$ to $100 \mathrm{ml}$.

Table 2.10 4X Tris buffer, $\mathrm{pH}=8.8$ :

\begin{tabular}{lll}
\hline Components & Concentration & Amount \\
\hline Tris-Base & $1.5 \mathrm{M}$ & $45.4 \mathrm{~g}$ \\
$\mathrm{ddH}_{2} \mathrm{O}$ & & $200 \mathrm{ml}$ \\
\hline
\end{tabular}

Adjust $\mathrm{pH}$ to 8.8 with $10 \mathrm{~N}$ or $6 \mathrm{~N} \mathrm{HCl}$. Add ddH $\mathrm{dH}_{2} \mathrm{O}$ to $250 \mathrm{ml}$.

Table 2.11 10X Western blot electrophoresis buffer:

\begin{tabular}{lll}
\hline Components & Concentration & Amount \\
\hline Tris-Base & $250 \mathrm{mM}$ & $30.3 \mathrm{~g}$ \\
Glycine & $1.92 \mathrm{M}$ & $144.1 \mathrm{~g}$ \\
SDS & $1 \%$ & $10 \mathrm{~g}$ \\
\hline
\end{tabular}

Add $\mathrm{ddH}_{2} \mathrm{O}$ to $1 \mathrm{~L}$. Do not adjust $\mathrm{pH}$, it should be $\sim 8.3$.

Table 2.12 10X Western blot transblot buffer:

\begin{tabular}{lll}
\hline Components & Concentration & Amount \\
\hline Tris-Base & $250 \mathrm{mM}$ & $30.3 \mathrm{~g}$ \\
Glycine & $1.92 \mathrm{M}$ & $144.1 \mathrm{~g}$ \\
\hline
\end{tabular}

Add $d_{d d} \mathrm{H}_{2} \mathrm{O}$ to $1 \mathrm{~L}$. Do not adjust $\mathrm{pH}$, it should be $\sim 8.3$.

Table 2.13 Western blot transblot working buffer:

\begin{tabular}{ll}
\hline Components & Amount \\
\hline $10 x$ Transblot buffer & $100 \mathrm{ml}$ \\
Methanol & $200 \mathrm{ml}$ \\
$\mathrm{ddH}_{2} \mathrm{O}$ & $700 \mathrm{ml}$ \\
\hline
\end{tabular}

Pre-cool before use. 
Table 2.14 5X Western blot sample loading buffer:

\begin{tabular}{lll}
\hline Components & Concentration & Amount \\
\hline SDS & & $1 \mathrm{~g}$ \\
DTT & $2.5 \mathrm{M}$ & $2 \mathrm{ml}$ \\
Tris buffer $\mathrm{pH}=6.8$ & $2 \mathrm{M}$ & $1.5 \mathrm{ml}$
\end{tabular}

Mix well to dissolve SDS in a $15 \mathrm{ml}$ tube, incubate in $37^{\circ} \mathrm{C}$ if necessary.

\begin{tabular}{lll}
\hline BPB & $5 \%$ & $100 \mathrm{ul}$
\end{tabular}

Add $\mathrm{ddH}_{2} \mathrm{O}$ to $5 \mathrm{ml}$ and mix thoroughly.

Add $5 \mathrm{ml}$ prewarmed glycerol and mix thoroughly.

Table 2.15 Western blot stripping buffer:

\begin{tabular}{ll}
\hline Components & Amount \\
\hline Glycine & $7.5 \mathrm{~g}$ \\
$\mathrm{ddH}_{2} \mathrm{O}$ & $800 \mathrm{ml}$
\end{tabular}

Adjust $\mathrm{pH}$ to 2.5 by $6 \mathrm{~N}$ or $10 \mathrm{~N} \mathrm{HCl}$.

Add $\mathrm{ddH}_{2} \mathrm{O}$ to $1 \mathrm{~L}$.

Table 2.16 SDS-PAGE separating gel:

\begin{tabular}{lllll}
\hline Components & $8 \%$ & $12 \%$ & $15 \%$ & $18 \%$ \\
\hline 4X Tris buffer $\mathrm{pH}=8.8$ & $5 \mathrm{ml}$ & $5 \mathrm{ml}$ & $5 \mathrm{ml}$ & $5 \mathrm{ml}$ \\
$\mathrm{ddH}_{2} \mathrm{O}$ & $9.7 \mathrm{ml}$ & $7 \mathrm{ml}$ & $5 \mathrm{ml}$ & $3 \mathrm{ml}$ \\
$30 \%$ Acrylamide $(37.5: 1)$ & $5.3 \mathrm{ml}$ & $8 \mathrm{ml}$ & $10 \mathrm{ml}$ & $12 \mathrm{ml}$ \\
$10 \%$ SDS & $200 \mu \mathrm{l}$ & $200 \mu \mathrm{l}$ & $200 \mu \mathrm{l}$ & $200 \mu \mathrm{l}$ \\
TEMED & $25 \mu \mathrm{l}$ & $25 \mu \mathrm{l}$ & $25 \mu \mathrm{l}$ & $25 \mu \mathrm{l}$ \\
$10 \%$ APS & $62.5 \mu \mathrm{l}$ & $62.5 \mu \mathrm{l}$ & $62.5 \mu \mathrm{l}$ & $62.5 \mu \mathrm{l}$ \\
\hline
\end{tabular}

Table 2.17 SDS-PAGE 4\% stacking gel:

\begin{tabular}{ll}
\hline Components & Amount \\
\hline 4X Tris buffer $\mathrm{pH}=6.8$ & $1.25 \mathrm{ml}$
\end{tabular}




$\mathrm{ddH}_{2} \mathrm{O} \quad 3.05 \mathrm{ml}$

$30 \%$ Acrylamide (37.5:1) $\quad 0.65 \mathrm{ml}$

$10 \%$ SDS $\quad 50 \mu \mathrm{l}$

TEMED $15 \mu \mathrm{l}$

$10 \%$ APS $\quad 37.5 \mu \mathrm{l}$

Table 2.18 0.1M Citric acid buffer:

\begin{tabular}{ll}
\hline Components & Amount \\
\hline Citric acid monohydrate & $21.01 \mathrm{~g}$
\end{tabular}

Add $\mathrm{ddH}_{2} \mathrm{O}$ to $800 \mathrm{ml}$. Adjust $\mathrm{pH}$ to 6.0 by $\mathrm{NaOH}$.

Add $\mathrm{ddH}_{2} \mathrm{O}$ to $1 \mathrm{~L}$.

Table $2.190 .5 \%$ Cresyl violet for NissI staining:

\begin{tabular}{ll}
\hline Components & Amount \\
\hline $1 \mathrm{M} \mathrm{Na}$-acetate & $40 \mathrm{ml}$ \\
$100 \%$ Acetic acid & $9.6 \mathrm{ml}$ \\
\hline Add ddH $\mathrm{H}_{2} \mathrm{O}$ to $1 \mathrm{~L}$. & \\
\hline Cresyl violet & $5 \mathrm{~g}$ \\
\hline
\end{tabular}

Stir overnight.

Table 2.20 Resin for Electron Microscope sample embedding:

\begin{tabular}{ll}
\hline Components & Amount \\
\hline Durcupan $^{\mathrm{TM}}$ ACM A & $24 \mathrm{ml}$ \\
Durcupan $^{\mathrm{TM}}$ ACM B & $36 \mathrm{ml}$ \\
Durcupan $^{\mathrm{TM}}$ ACM C & $0.3 \mathrm{ml}$ \\
Durcupan $^{\mathrm{TM}}$ ACM D & $0.9 \mathrm{ml}$ \\
\hline
\end{tabular}




\subsubsection{Equipments}

All equipments used in the present study are listed below in Table 2.21.

Table 2.21 Equipments:

\begin{tabular}{|c|c|c|}
\hline Equipments & Catalog \# & Company \\
\hline Balance & BP4100S & Sartorius \\
\hline CCD camera & 2K Sharp-eye & Troendle \\
\hline Centrifuge & $5804 \mathrm{R}$ & Eppendorf \\
\hline Cryo-microtome & cm3050s & Leica \\
\hline DAKO Pen & S200230-2 & DAKO \\
\hline Data acquisition device & PowerLab26T & AD Instruments \\
\hline DNA electrophoresis chamber & Horizo 11.14 & Life Technologies \\
\hline DNA electrophoresis power supply & EPS601 & Amersham \\
\hline Electron microscope & LEO 906E & Carl Zeiss \\
\hline EMG electrode & MLA1204 & $A D$ instruments \\
\hline FC Multiscan plate reader & 357 & Thermo Fisher \\
\hline Fluorescence microscope & Axioplan 2 & Carl Zeiss \\
\hline Heating rack & $2-2515$ & Neolab \\
\hline Horizontal shaker & KS250 basic & $\mathrm{IKA}$ \\
\hline $\mathrm{iQ}^{\text {TM }}$ 96-Well PCR Plates & $223-9441$ & Bio-Rad \\
\hline Laboratory temperature controllers & LTR 2055 & Jucheim Solingen \\
\hline Michel suture clips & $12040-01$ & F.S.T \\
\hline Microtome & 2050 & Reichert Jung \\
\hline PCR cycler & Mastercycler & Eppendorf \\
\hline $\mathrm{pH}$ meter & FEP20 & Mettler Toledo \\
\hline Precellys Keramik-Kit 1.4 mm & 91-PCS-CK14S & PeqLab \\
\hline Precellys 24 homogenisator & 91-PCS24 & PeqLab \\
\hline Real-time PCR cycler & iQ5 System & Bio-Rad \\
\hline Silk Suture Thread & $18020-60$ & F.S.T \\
\hline
\end{tabular}




\begin{tabular}{lll}
\hline Stereoscope & Stemi DV4 & Carl Zeiss \\
Superfrost Plus slide & J1800AMNZ & Thermo Scientific \\
Ultramicrotome & EM UC6 & Leica \\
Westernblot chember & Mini Trans-Blot & Bio-Rad \\
Westernblot power supply & PowerPac HC & Bio-Rad \\
X-Clear Advanced Polyolefin StarSeal E2796-9795 & StarLab \\
\hline
\end{tabular}

\subsection{Methods}

\subsubsection{Genotyping}

Total genomic DNA was extracted by the QuickExtract ${ }^{\mathrm{TM}}$ DNA Extraction Solution from Epicenter. Briefly, $50 \mu \mathrm{l}$ extraction buffer was added into tubes containing mouse tail tips, vortexed for $15 \mathrm{sec}$ and incubated at $65^{\circ} \mathrm{C}$ for $6 \mathrm{~min}$. Then samples were vortexed again for $15 \mathrm{sec}$ and incubated at $98^{\circ} \mathrm{C}$ for $2 \mathrm{~min}$. Resulting DNA was processed immediately or stored at $-20^{\circ} \mathrm{C}$ until use.

2 sets of primers for genotyping were used, as listed in Table 2.22 (Strelau et al., 2009).

Table 2.22 Primers for GDF-15 knock out mice genotyping:

\begin{tabular}{lll}
\hline Set & Name & Sequence 5'--3' \\
\hline Set 1 & F21 & GCAGAGAGGCTGAGGAACTT \\
& LacZR4 & GTTCTTGTTGGTCAAAGTAAACGAC \\
& F30 & TTGGGAAAAGGTTGGAGAGA \\
& R18 & GATACAGGTGGGGACACTCG \\
\hline Set 2 & NeoF1 & TCGCCTTCTTGACGAGTTCT \\
& R20 & CCCAGTCTTGTAGACAGAGCAA \\
& F26 & ATGCGCACCCAAGAGACT \\
& R21 & GGCCACCAGGTCATCATAAG \\
\hline
\end{tabular}


All primers were ordered from Metabion, and diluted to $50 \mu \mathrm{M}$ with $\mathrm{dd}_{2} \mathrm{O}$.

The RedTaq Mastermix (2x) from Genaxxon was used for PCR. Each reaction had a total volume of $25 \mu \mathrm{l}$, including $8.5 \mu \mathrm{l} \mathrm{H} \mathrm{H}_{2} \mathrm{O}, 12.5 \mu \mathrm{l}$ RedTaq Mastermix (2x), $3 \mu \mathrm{l}$ DNA, $1 \mu \mathrm{l}$ primer set 1 or $2(0.25 \mu$ l of each individual primer). The programs are listed below (Table 2.23).

Table 2.23 Programs for genotyping:

\begin{tabular}{l|l}
\hline Reaction for primer Set 1 & Reaction for primer Set 2 \\
\hline $94^{\circ} \mathrm{C}$ hot start & $94^{\circ} \mathrm{C}$ hot start \\
$94^{\circ} \mathrm{C} 3 \mathrm{~min}$ & $94^{\circ} \mathrm{C} 3 \mathrm{~min}$ \\
$94^{\circ} \mathrm{C} 1 \mathrm{~min}$ & $94^{\circ} \mathrm{C} 30 \mathrm{sec}$ \\
$61^{\circ} \mathrm{C} 2 \mathrm{~min}$ & $59^{\circ} \mathrm{C} 30 \mathrm{sec}$ \\
$72^{\circ} \mathrm{C} 3$ min & $72^{\circ} \mathrm{C} 1 \mathrm{~min}$ \\
Repeat for another 39 cycles & Repeat for another 39 cycles \\
$72^{\circ} \mathrm{C} 10$ min & $72^{\circ} \mathrm{C} 5 \mathrm{~min}$ \\
$8^{\circ} \mathrm{C}$ & $8^{\circ} \mathrm{C}$ \\
\hline
\end{tabular}

The PCR products were then loaded onto $1 \%$ agarose gels and detected by Gel Red. The outcome of genotyping was the following (Fig 2.1):

Primer set 1:

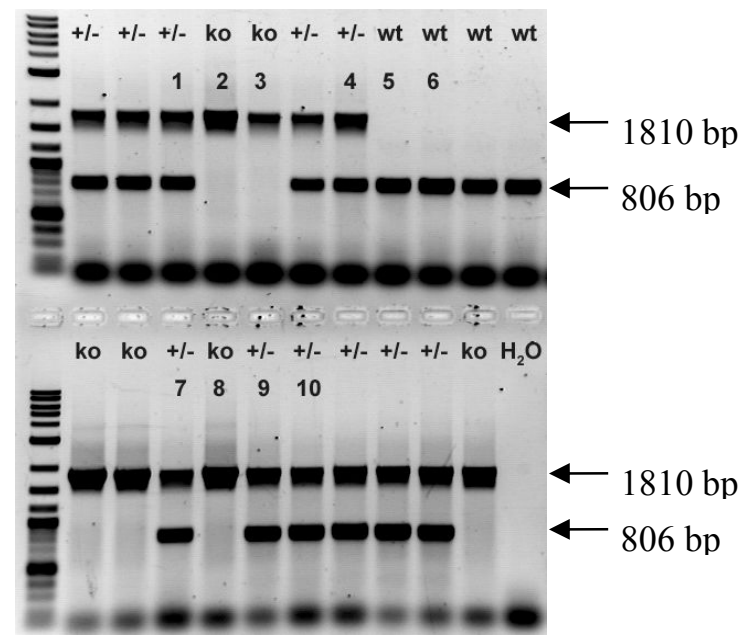

\section{Primer set 2:}

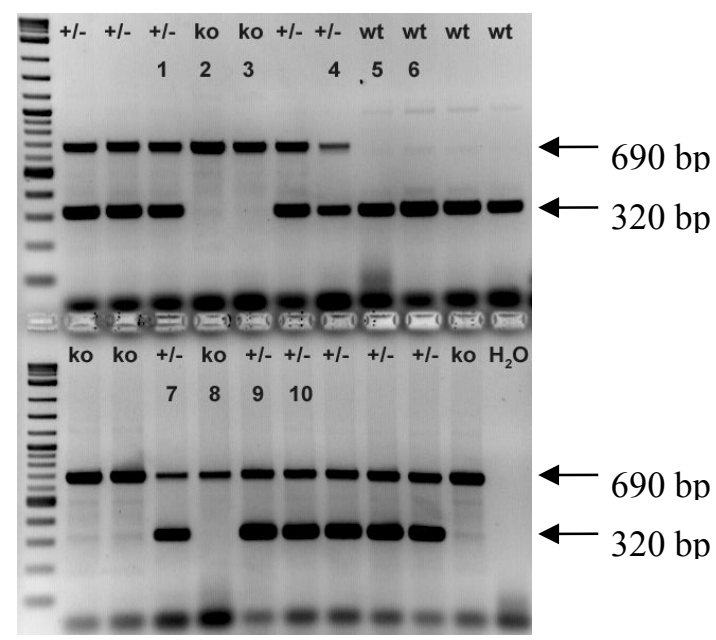

Fig 2.1 Genotyping results using the 2 sets of primers. 


\subsubsection{Surgery}

Animals were anesthetized with $2.5 \%$ (v/v with oxygen) Isoflurane (Forane) through inhalation. When the respiration became deep and slow ( 1 time per second), the toe tips were pinched to check the reflection. After reaching deep anesthesia, the animal was placed onto a heating plate with constant $39^{\circ} \mathrm{C}$, cornea gel was applied, hair on the limb was shaved and the skin was disinfected by $70 \%$ isopropanol. The skin and muscle was opened by scissors at mid-thigh level, until reaching the sciatic nerve. Lesions were introduced at a locus $1 \mathrm{~cm}$ proximal to the branching point of tibial nerve and common fibular nerve. For crush lesion, 5/45 forceps, with graphite powder sticking on it, was used to crush the sciatic nerve for 15 seconds; for transection lesion, 2 knots were made by $6 / 0$ suture silk with a $1 \mathrm{~mm}$ interval, followed by the transection of nerve between the 2 knots. The wound was then closed by wound clips. Animals were kept on the heating plate until wakeup, and then put back to the standard condition mentioned above.

\subsubsection{RNA and protein extraction}

The animals were sacrificed by cervical translocation. The tissues needed (e.g. sciatic nerve, DRG) were dissected, briefly washed in pre-cooled PBS, and then kept in RNALater reagent. After shaking overnight at $4^{\circ} \mathrm{C}$, the tissue could be used for RNA extraction or for long-term storage at -20 or $-80^{\circ} \mathrm{C}$. Tissue from 2 animals of same treatment were pooled and transferred from RNALater to homogenesis tube containing ceramic beads and $400 \mu \mathrm{l}$ Trifast reagent. Tissues were smashed by bead-beating in homogeniser (5000 rpm $15 \mathrm{sec}$ x 2 for nerve, $5000 \mathrm{rpm} 15 \mathrm{sec} \times 3$ for DRG). The RNA extraction protocol was modified from literature (Chey et al., 2011), basically, after homogenesis in 400 $\mu \mathrm{l}$ Trifast, $80 \mu \mathrm{l}$ bromochloropropane was added and samples were shaked vigorously by hand for $15 \mathrm{sec}$, kept at room temperature (RT) for $5 \mathrm{~min}$, 
followed by centrifugation at $12000 \mathrm{~g} 4^{\circ} \mathrm{C}, 15 \mathrm{~min}$. Then the colorless supernate $(\sim 200 \mu \mathrm{l})$ was transferred to a new $0.5 \mathrm{ml}$ tube, with $200 \mu \mathrm{l}$ isopropanol added, while the remaining intermediate white layer and red-colored organic layer was for the protein extraction later. The compound was invert-mixed by hand and kept at $-20^{\circ} \mathrm{C}$ for at least 10 min to precipitate RNA. The tubes were then centrifuged at $12000 \mathrm{~g} 4^{\circ} \mathrm{C}, 10 \mathrm{~min}$, followed by discarding the supernate, adding $300 \mu \mathrm{l} 75 \%$ ethanol, inverting the tube and centrifuged at $7500 \mathrm{~g} 4^{\circ} \mathrm{C}, 5 \mathrm{~min}$. The ethanol was completely removed by pipette, and the remaining RNA pellet at the bottom of tube was air-dried in the hood for 3 5 min, then 80 ul RNase-free water was added to dissolve the RNA. RNA solution was then purified by RNA Clean \& Concentrator ${ }^{\mathrm{TM}}-25$ kit, from Zymo Research. This procedure was exactly followed the instruction of the kit. The purified RNA was measured by Nanodrop N-1000 spectrophotometer.

The white layer and red organic phase bearing protein was mixed with $120 \mu$ l ethanol, inverted by hand, kept at RT for $5 \mathrm{~min}$, then centrifugated at $2000 \mathrm{~g}$ $4^{\circ} \mathrm{C}, 5 \mathrm{~min}$. The supernate was then transferred into a new $2 \mathrm{ml}$ tube, followed by adding $700 \mu \mathrm{l}$ ethanol and vortex, then by adding $200 \mu \mathrm{l}$ bromochloropropane and vortex, furthermore, by adding $600 \mu \mathrm{l}$ water and vortex. The mixture was left at RT for $5 \mathrm{~min}$, followed by $12000 \mathrm{~g} 10 \mathrm{~min}$ centrifugation for phase seperation. The upper colorless layer was discarded while the intermediate white layer and bottom red organic phase was transferred into a new $1.5 \mathrm{ml}$ tube. $700 \mu$ l ethanol was added to the $1.5 \mathrm{ml}$ tube, and mixed by vortex, centrifuged at $12000 \mathrm{~g}$ for $15 \mathrm{~min}$. All the liquid phase was then discard, the pellet was air-dried in the hood for 10 min. 4\% SDS solution containing proteinase inhibitor (1\% inhibitorcocktail plus) was added to dissolve the pellet, by shaking at RT. The protein concentration was determined by BCA kit. 


\subsubsection{Reverse transcription and Real-time qPCR}

Total RNA concentration was determined, and $1 \mu \mathrm{g}$ RNA was used for reverse transcription. The reaction was listed below (Table 2.24).

Table 2.24 Reaction for reverse transcription:

\begin{tabular}{ll}
\hline Components & Volume $\mu \mathrm{l}$ \\
\hline Total RNA $+\mathrm{H}_{2} \mathrm{O}$ & 20 \\
Ribonuclease Inhibitor $(40 \mathrm{u} / \mu \mathrm{l})$ & 0.5 \\
$\mathrm{RQ1}$ DNase & 0.5 \\
\hline
\end{tabular}

Incubate at $37^{\circ} \mathrm{C} 20 \mathrm{~min}, 70^{\circ} \mathrm{C} 10 \mathrm{~min}$

$5 \times$ reaction buffer 8

dNTP (10 mM each)

Random primers

$\mathrm{H}_{2} \mathrm{O}$

M-MLV reverse transcriptase

0.7

Incubate at $37^{\circ} \mathrm{C} 2$ hours, $90^{\circ} \mathrm{C} 5 \mathrm{~min}$

cDNA product could be used for Real-time qPCR immediately or stored at $-20^{\circ} \mathrm{C}$.

For Real-time qPCR, each well in 96 wells plate contained $10 \mu$ GoTaq ${ }^{\circledR}$ qPCR Master Mix, $4.8 \mu \mathrm{l} \mathrm{H} \mathrm{H}_{2} \mathrm{O}, 0.1 \mu \mathrm{l}$ forward primer $(50 \mathrm{mM}), 0.1 \mu \mathrm{l}$ reverse primer (50 mM) and $5 \mu \mathrm{l}$ cDNA (diluted according to the gene expression). The reaction was the following (Table 2.25).

Table 2.25 Real-time qPCR reaction:

\begin{tabular}{ll}
\hline Components & Volume $\mu \mathrm{l}$ \\
\hline GoTaq® qPCR Master Mix & 10 \\
Forward primer $(50 \mu \mathrm{M})$ & 0.1 \\
Reverse primer $(50 \mu \mathrm{M})$ & 0.1
\end{tabular}




\begin{tabular}{ll}
$\mathrm{H}_{2} \mathrm{O}$ & 4.8 \\
cDNA (diluted) & 5 \\
\hline Total & 20 \\
\hline
\end{tabular}

The Real-time PCR program is the following (Table 2.26).

Table 2.26 Real-time PCR program:

\begin{tabular}{ll}
\hline Temperature & Time \\
\hline $95^{\circ} \mathrm{C}$ start & $3 \mathrm{~min}$ \\
$95^{\circ} \mathrm{C}$ cycle & $10 \mathrm{sec}$ \\
$61^{\circ} \mathrm{C}$ cycle & $30 \mathrm{sec}$ \\
$72^{\circ} \mathrm{C}$ cycle & $30 \mathrm{sec}$ \\
\hline
\end{tabular}

Total 40 cycles.

All Real-time PCR primers were ordered from Metabion or Eurofins, listed below (Table 2.27).

Table 2.27 primers for Real-time qPCR:

\begin{tabular}{lll}
\hline Gene & Sequence 5'--3' & Product length \\
\hline a-SMA Fw & CTCTCTTCCAGCCATCTTTCAT & 60 \\
a-SMA Rv & TATAGGTGGTTTCGTGGATGC & \\
Arginase 1 Fw & TCATGGAAGTGAACCCAACTCTTG & 127 \\
Arginase 1 Rv & TCAGTCCCTGGCTTATGGTTACC & \\
Caspase 8 Fw & TTGAACAATGAGATCCCCAAA & 70 \\
Caspase 8 Rv & CCATTTCTACAAAAATTTCAAGCAG & \\
CD11b Fw & TGTCCCTGGCTGTTTCTACTG & 77 \\
CD11b Rv & ATTCTCCTTGCAGTTTTGGTG & \\
c-Jun Fw & CCAGAAGATGGTGTGGTGTTT & 63 \\
c-Jun Rv & CTGACCCTCTCCCCTTGC & \\
Collagen 1 Fw & CATGTTCAGCTTTGTGGACCT & 94 \\
Collagen 1 Rv & GCAGCTGACTTCAGGGATGT &
\end{tabular}




\begin{tabular}{|c|c|c|}
\hline $\mathrm{F} 4 / 80 \mathrm{Fw}$ & ATGGACAAACCAACTTTCAAGGC & 95 \\
\hline $\mathrm{F} 4 / 80 \mathrm{Rv}$ & GCAGACTGAGTTAGGACCACAA & \\
\hline Fibronectin Fw & CGGAGAGAGTGCCCCTACTA & 77 \\
\hline Fibronectin Rv & CGATATTGGTGAATCGCAGA & \\
\hline Fizz 1 Fw & TCCTGCCCTGCTGGGATGACTGCTA & 125 \\
\hline Fizz $1 \mathrm{Rv}$ & CAGCGGGCAGTGGTCCAGTCAA & \\
\hline Galanin Fw & TTTCTCAGTTTCTTGCACСTTAAA & 110 \\
\hline Galanin Rv & CAGTGGACATGGTCTCAGGA & \\
\hline GAPDH Fw & GGCATTGCTCTCAATGACAA & 97 \\
\hline GAPDH Rv & ATGTAGGCCATGAGGTCCAC & \\
\hline GDF-15 Fw & GAGCTACGGGGTCGCTTC & 130 \\
\hline GDF-15 Rv & GGGACCCCAATCTCACCT & \\
\hline Iba-1 Fw & ATGAGCCAAAGCAGGGATTT & 169 \\
\hline Iba-1 Rv & ACTCCATGTACTTCACCTTG & \\
\hline 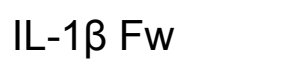 & CGTGGACCTTCCAGGATGAG & 111 \\
\hline IL-1 R Rv & CGTCACACACCAGCAGGTTA & \\
\hline IL-6 FW & GCTGGTGACAACCACGGCCT & 158 \\
\hline IL-6 Rv & TGCACAACTCTTTTCTCATTTCCACGA & \\
\hline Krox-20 Fw & CTACCCGGTGGAAGACCTC & 112 \\
\hline Krox-20 Rv & AATGTTGATCATGCCATCTCC & \\
\hline MAC-2 Fw & GCCTACCCCAGTGCTCCT & 82 \\
\hline MAC-2 Rv & GGTCATAGGGCACCGTCA & \\
\hline MCP-1 Fw & TTAAAAACCTGGATCGGAACCAA & 121 \\
\hline MCP-1 Rv & GCATTAGCTTCAGATTTACGGGT & \\
\hline NCAM Fw & CCAGTGGACAAGCCTCTGA & 106 \\
\hline NCAM Rv & GGGGGCTCAGACTTTGTTT & \\
\hline$N F-k B F w$ & GGGTCTGGGGATACTGAACA & 108 \\
\hline$N F-k B R v$ & GCCTCCATCAGCTCTTTGAT & \\
\hline NGF Fw & TATACTGGCCGCAGTGAGGT & 109 \\
\hline
\end{tabular}




\begin{tabular}{lll}
\hline NGF Rv & GGACATTGCTATCTGTGTACGG & \\
Olig1 Fw & CTCGCCCAGGTGTTTTGTTG & 149 \\
Olig1 Rv & TAAGTCCGAACACCGATGGC & \\
S100 $\beta \mathrm{Fw}$ & AACAACGAGCTCTCTCACTTCC & 66 \\
S100 $\beta \mathrm{Rv}$ & CTCCATCACTTTGTCCACCA & \\
SHH Fw & TGGAAGCAGGTTTCGACTGG & 165 \\
SHH Rv & CGGGACGTAAGTCCTTCACC & \\
Ym $1 \mathrm{Fw}$ & AGACTTGCGTGACTATGAAGCATTG & 96 \\
Ym $1 \mathrm{Rv}$ & GCAGGTCCAAACTTCCATCCTC & \\
\hline
\end{tabular}

\subsubsection{Western blot}

25 or $50 \mu \mathrm{g}$ total proteins (depending on the expression level) were loaded onto SDS-PAGE gels; the concentration of gel differed according to the molecular weight of the target protein. Electrophoresis was performed under a condition of constant $120 \mathrm{~V}$, for $100 \mathrm{~min}$. Then proteins in the gel were transblotted onto $0.2 \mu \mathrm{m}$ or $0.45 \mu \mathrm{m}$ PVDF membrane (depending on the molecular weight of protein) under $100 \mathrm{~V}$, for $100 \mathrm{~min}$. After a brief washing by TBST, the membrane was blocked by $5 \%$ non-fat milk for 1 hour at RT, followed by TBST washing and primary antibody (dissolved in 3\% BSA) incubation at $4^{\circ} \mathrm{C}$ overnight with shaking. Generally, following 3 times 5 min washing by TBST, the secondary antibody conjugated with HRP (in 5\% non-fat milk) was then applied onto the membrane for $1 \mathrm{~h}$ at RT. Subsequently, the membrane was washed and incubated with the substrate of HRP for enhanced chemiluminescence $(E C L)(500 \mu \mathrm{l}+500 \mu \mathrm{l}$ /membrane) for $5 \mathrm{~min}$ and the signals were visualized by film. The optical density of the Bands on the film was measured by Image $\mathrm{J}$ software and used for quantification (GAPDH was used in all cases as a reference gene). 
For stripping the membrane was incubated with stripping buffer at RT for $1.5 \mathrm{~h}$ with shaking, and then further incubated with $1 \%$ SDS at RT for $1.5 \mathrm{~h}$ with shaking. To detect proteins, whose molecular weights differed from the reference protein GAPDH ( $\sim 37 \mathrm{KDa})$, the membrane could also be cut and incubated with different primary antibodies simultaneously, avoiding re-blotting.

\subsubsection{Tissue preparation}

Animals were anesthetized by an intraperitoneal injection of Ketamine (187.5 $\mathrm{mg} / \mathrm{kg}$ body weight). Nervous reflexes were checked by pinching the toe tip. The thorax was opened and animals were transcardially perfused with $20 \mathrm{ml}$ of pre-cooled $0.1 \mathrm{M} \mathrm{PB}$, followed by $20 \mathrm{ml}$ pre-cooled 4\% PFA (in $0.1 \mathrm{M} \mathrm{PB}$ ), with a speed of 3 3.5 $\mathrm{ml} / \mathrm{min}$. The tissues were then carefully dissected and immersed in $4 \%$ PFA (in $0.1 \mathrm{M} \mathrm{PB}$ ) at $4{ }^{\circ} \mathrm{C}$ with shaking for post-fixation (for DRG and nerve, 4 hours post-fixation).

\subsubsection{Paraffin embedding and sectioning}

After post-fixation, the tissues underwent a dehydration process as the follows (Table 2.28).

Table 2.28 Dehydration process for paraffin embedding:

\begin{tabular}{llll}
\hline Reagents & Sciatic nerve & DRG & Tibial nerve \\
\hline $50 \%$ Ethanol & $5 \mathrm{~min}$ & $3 \mathrm{~min}$ & $3 \mathrm{~min}$ \\
$70 \%$ Ethanol & $5 \mathrm{~min}$ & $3 \mathrm{~min}$ & $3 \mathrm{~min}$ \\
$80 \%$ Ethanol & $5 \mathrm{~min}$ & $3 \mathrm{~min}$ & $3 \mathrm{~min}$ \\
$90 \%$ Ethanol & $5 \mathrm{~min}$ & $3 \mathrm{~min}$ & $3 \mathrm{~min}$ \\
$95 \%$ Ethanol & $5 \mathrm{~min}$ & $3 \mathrm{~min}$ & $3 \mathrm{~min}$ \\
$100 \%$ Ethanol & $5 \mathrm{~min} \times 2$ & $3 \mathrm{~min} \times 2$ & $3 \mathrm{~min}$ X2 \\
Rotihistol & $5 \mathrm{~min}$ X2 & $3 \mathrm{~min}$ X2 & $3 \mathrm{~min}$ X2
\end{tabular}




\begin{tabular}{|c|c|c|c|}
\hline Paraffin & $15 \mathrm{~min}$ & $15 \min$ & $15 \min$ \\
\hline Paraffin & $30 \min \times 2$ & $30 \min \times 2$ & $30 \min \times 2$ \\
\hline
\end{tabular}

The tissues were then embedded in paraffin and left at RT overnight for solidification. After microtome sectioning at the desired thickness, the sections were mounted onto Superfrost slides and left on the heating plate $\left(\sim 40^{\circ} \mathrm{C}\right)$ overnight. Before staining, sections went through a de-paraffinization procedure as follows (Table 2.29).

Table 2.29 De-paraffin procedure:

\begin{tabular}{ll}
\hline Reagents & Time \\
\hline Rotihistol & $5 \mathrm{~min}$ X4 \\
100\% Ethanol & $5 \mathrm{~min}$ X2 \\
$95 \%$ Ethanol & $5 \mathrm{~min}$ \\
$90 \%$ Ethanol & $5 \mathrm{~min}$ \\
$80 \%$ Ethanol & $5 \mathrm{~min}$ \\
$70 \%$ Ethanol & $5 \mathrm{~min}$ \\
PBS & $5 \mathrm{~min}$ \\
\hline
\end{tabular}

For antigen retrieval, sections were immersed in boiling $0.1 \mathrm{M}$ citric acid buffer $(\mathrm{pH}=6.0)$ for $3 \mathrm{~min}$. Sections could then be used for staining immediately or stored in PBS at $4^{\circ} \mathrm{C}$ for $1 \sim 2$ days if preferred.

\subsubsection{Cryo-embedding and sectioning}

After post-fixation, DRG and sciatic nerve were immersed in $15 \%$ sucrose (dissolved in PBS) solution at $4^{\circ} \mathrm{C}$ for 6 8 hours with shaking, and subsequently transferred to $30 \%$ sucrose (in PBS) solution at $4^{\circ} \mathrm{C}$ overnight with shaking for cryo-protection. After carefully absorbing the excess sucrose, with cooling of dry ice and a metal plate, tissues were embedded in tissue 
freezing medium and then stored at $-20^{\circ} \mathrm{C}$ (short term) or $-80^{\circ} \mathrm{C}$ (long term).

Cryo-embedded tissue was cut on a cryotome to the preferred thickness and mounted onto superfrost slides, then kept at $-20^{\circ} \mathrm{C}$ (short term) or $-80^{\circ} \mathrm{C}$ (long term). Before staining, sections were brought to RT and re-hydrated in PBS for 3 times 5 min prior to further processing.

\subsubsection{DRG neuron quantification}

DRG neuron quantification was down as previously described (Strelau et al., 2009). Briefly, DRGs were cut into serial sections of $8 \mu \mathrm{m}$ thickness, Nissl stained (see Table 2.30), and mounted with Entellan. Neuronal profiles with a visible nucleolus were counted in every fifth section using the Image J program. Total numbers were corrected by Abercrombie's formula.

Table 2.30 Nissl staining for DRG section:

\begin{tabular}{ll}
\hline Reagents & Time \\
\hline $0.5 \%$ Cresyl Echt Violet & $7 \sim 8 \mathrm{~min}$ \\
$\mathrm{H}_{2} \mathrm{O}+250 \mu$ l acetic acid & $5 \mathrm{sec}$ \\
$\mathrm{H}_{2} \mathrm{O}$ & $5 \mathrm{sec}$ \\
$70 \%$ Ethanol & $5 \mathrm{sec}$ \\
$80 \%$ Ethanol & $5 \mathrm{sec}$ \\
$90 \%$ Ethanol & $5 \mathrm{sec}$ \\
$95 \%$ Ethanol & $5 \mathrm{sec}$ \\
$100 \%$ Ethanol & $5 \mathrm{~min}$ X2 \\
Rotihistol & $5 \mathrm{~min}$ X3 \\
\hline
\end{tabular}

\subsubsection{Immunohistochemistry}

Generally, cryo- or paraffin embedded tissues were cut at $10 \mu \mathrm{m}$ thickness. 
After pre-staining procedures (re-hydration or de-paraffin) as mentioned above in 2.3.7. and 2.3.8., the sections were encircled by DAKO pen with its water repellence property. 10\% normal donkey serum in PBST (300 $\mu$ l per slide) was used for antigen blocking at RT for 1 hour, followed by 3 times 5 min PBS washing. Then primary antibody/antibodies (antibodies from different animal source could be used together) diluted in PBST (200 $\mu$ l per slide) was/were applied onto the slides and incubated at $4^{\circ} \mathrm{C}$ overnight. After 3 times $5 \mathrm{~min}$ PBS washing, secondary antibody/antibodies diluted in PBS (200 $\mu$ per slide, antibodies with different species reactivity could be used together) conjugated with fluorescent tags was/were incubated at RT for 1 hour. After washing by PBS, 1:500 Hoechst or 1:1000 DAPI in PBS was utilized to stain the nucleus at RT for 10 min. Finally, after washing, slides were mounted with fluoromount-G medium.

For proteins with very low expression, e.g. GDF-15, modification in the protocol was helpful. Basically, the secondary antibody was not conjugated with fluorescent group, but with biotin. Subsequently, streptavidin linked with fluorescent tag was used to visualize the signal.

\subsubsection{Electron Microscopy}

After perfusion with 4\% PFA, the sciatic nerve/tibial nerve was dissected and attached to a piece of thick filter paper to maintain the shape. Then the nerve piece with the filter paper was incubated in $2.5 \%$ glutaraldehyde solution (in $0.1 \mathrm{M} \mathrm{PB}$ ) for $2 \mathrm{~h}$ at RT. Tissue was then washed 3 times for 5 min each with $0.1 \mathrm{M} \mathrm{PB}$, and incubated in $1 \% \mathrm{OsO}_{4}$ in $0.05 \mathrm{M} \mathrm{PB}$ in the dark, at $\mathrm{RT}$ for $2 \mathrm{~h}$, followed by 3 times 5 min washing with 0.05 M PB. Samples could then be stored at $4^{\circ} \mathrm{C}$ overnight, and were dehydrated as described in Table 2.31. 
Table 2.31 Dehydration procedure for Electron Microscopy embedding:

\begin{tabular}{ll}
\hline Reagents & Time \\
\hline $50 \%$ Ethanol & $10 \mathrm{~min}$ \\
$70 \%$ Ethanol & $10 \mathrm{~min}$ \\
$80 \%$ Ethanol & $10 \mathrm{~min}$ \\
$90 \%$ Ethanol & $10 \mathrm{~min}$ \\
$95 \%$ Ethanol & $10 \mathrm{~min}$ \\
$100 \%$ Ethanol & $10 \mathrm{~min} \times 3$ \\
Propylene oxide & $10 \mathrm{~min}$ X3 \\
$1: 1$ Propylene oxide:Resin & 2 hours \\
Resin & 2 hours \\
\hline
\end{tabular}

After dehydration, the nerve was carefully seperated from filter paper, and embedded into Epoxy resin in a rubber mold, polymerized at $58^{\circ} \mathrm{C}$ in the oven for $\sim 3$ days.

The tissue was then transversely cut into semi-thin sections $(500 \mathrm{~nm})$ on an ultramicrotome and stained with $1 \%$ toluidin blue to check the quality of fixation. To measure the g-ratio, samples were cut into ultra-thin sections (60 nm) at 0.5 $\mathrm{cm}$ distal to the lesion site, mounted onto copper slot grids coated with Formvar, and photos were taken at 1670x fold magnificantion on a Zeiss electron microscope. Random photos were chosen and all intact myelinated axons on the screen were measured in two directions (long axis and short axis) for the diameter of the axon, the axon plus myelin, as shown in Fig 2.2. The g-ratio was then calculated by the formula: $g=((A / B)+(C / D)) / 2$. 


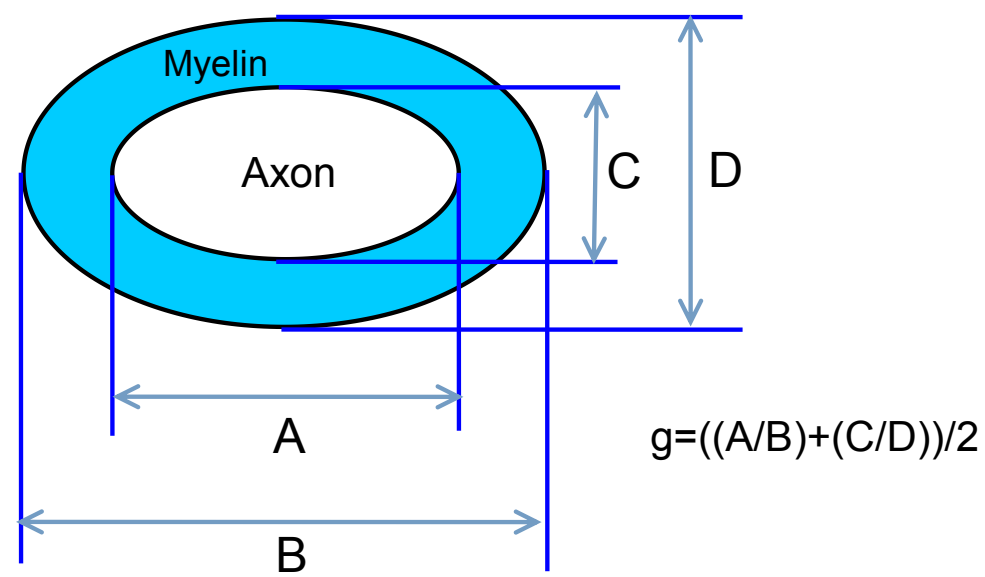

Fig 2.2 g-ratio measurement.

\subsubsection{Electromyography (EMG)}

5 and 9 weeks after the unilateral sciatic nerve crush, WT or GDF-15 KO mice, were anesthetized by intraperitoneal injection of $187.5 \mathrm{mg} / \mathrm{kg}$ ketamine and $12.5 \mathrm{mg} / \mathrm{kg}$ xylazine in physiological saline. Reflexes were checked by pinching the toe tip. One grounding electrode was subcutaneously injected into the tail. To stimulate the sciatic nerve, skin and muscles were opened at mid-thigh level and two stimulation needle electrodes were placed next to the sciatic nerve. Two recording needle electrodes were injected subcutaneously above the musculus digitorum brevis. The sciatic nerve was stimulated by increasing current pulses with a duration of $200 \mathrm{~ms}$, and the resulting EMG signals were recorded at the musculus digitorum brevis.

First, the left unlesioned control site was measured and then the EMG of the right lesioned site was recorded. For the analysis of latency and amplitude, only signals triggered by supramaximal stimuli were evaluated. Amplitude was defined as voltage interval between minimal and maximal peak of the recorded signal. The latency was defined as the time interval between the given stimulus and the maximal peak of the recorded signal. The conduction velocity (CV) was calculated by distance from stimulation to recording site divided by 
latency.

\subsubsection{Statistical analysis}

Data are shown as mean \pm SEM (only in EMG test) or mean \pm SD (all the other tests). Significant differences were determined by unpaired t-test (neuron quantification, g-ratio, EMG test) or by One-Way ANOVA followed by Tukey post test using GraphPad software. P value was shown as: ns ( $p>0.05$, not significant $),{ }^{*}(0.05>P>0.01$, significant $),{ }^{* *}(0.01>P>0.001$, very significant $),{ }^{* * *}$ $(P<0.001$, extremely significant). 


\section{Results}

\subsection{GDF-15 expression pattern}

It has previously been shown that GDF-15 is upregulated in cerebral cortical neurons following a "cold lesion" of the cortex and in retinal ganglion cells (RGCs) after optic nerve crush (Charalambous et al., 2013; Schober et al., 2001; Unsicker et al., 2013). One question addressed in the present study concerns whether in the peripheral nervous system (PNS) GDF-15 is similarly regulated in lesion paradigms. We used sciatic nerve (SN) crush and transection lesions.

\subsubsection{GDF-15 in DRG after sciatic nerve lesion}

Since the two types of lesion to SN (crush and transection) were previously shown to have different effects on dorsal root ganglia (DRG) neuron survival (Navarro et al., 2007), both lesion methods were initially applied to wild type (WT) animals in the present study. At different time points post lesion, animals were sacrificed and total RNA from DRGs was isolated and GDF-15 mRNA transcriptional levels were determined by quantitative Real-Time qPCR (qRT-PCR). After crush lesion, GDF-15 mRNA levels were slightly increased, reaching the maximum at 3 and 7 days post crush, followed by a decrease to control levels after 28 days (Fig $3.1 \mathrm{~A}$ ). In the transection model, GDF-15 showed a similar pattern as in the crush model, however, with a slight increase in the size of the peaks at 3 and 7 days, respectively ( 2 fold in crush, 3 fold in transection) (Fig 3.1 B). Western blots of GDF-15 failed to mimic the mRNA study (Fig 3.1 C D); possibly, the transcriptional elevation was not high enough to produce a steady translational change. 


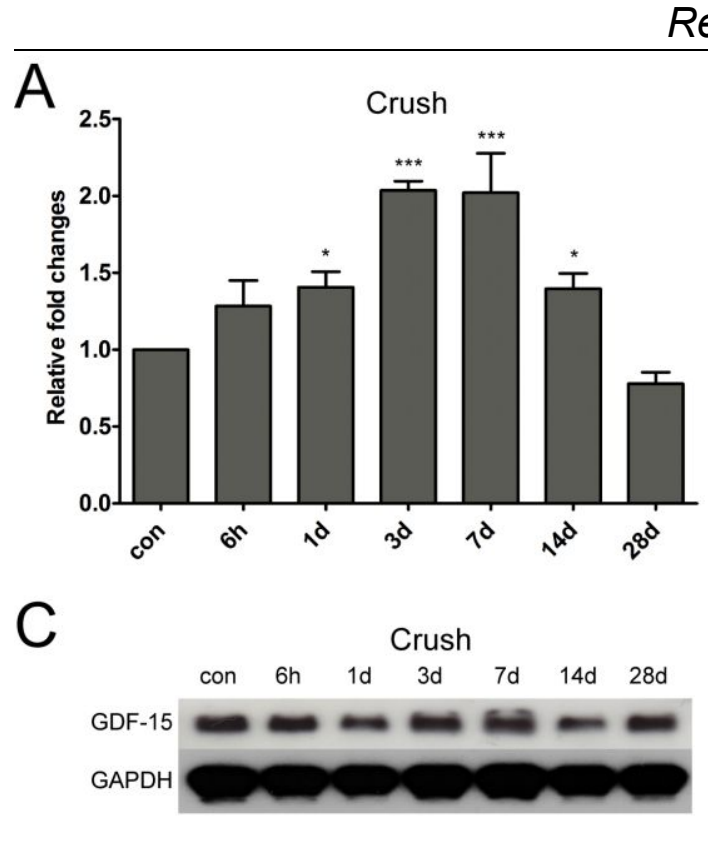

$\mathrm{E}$
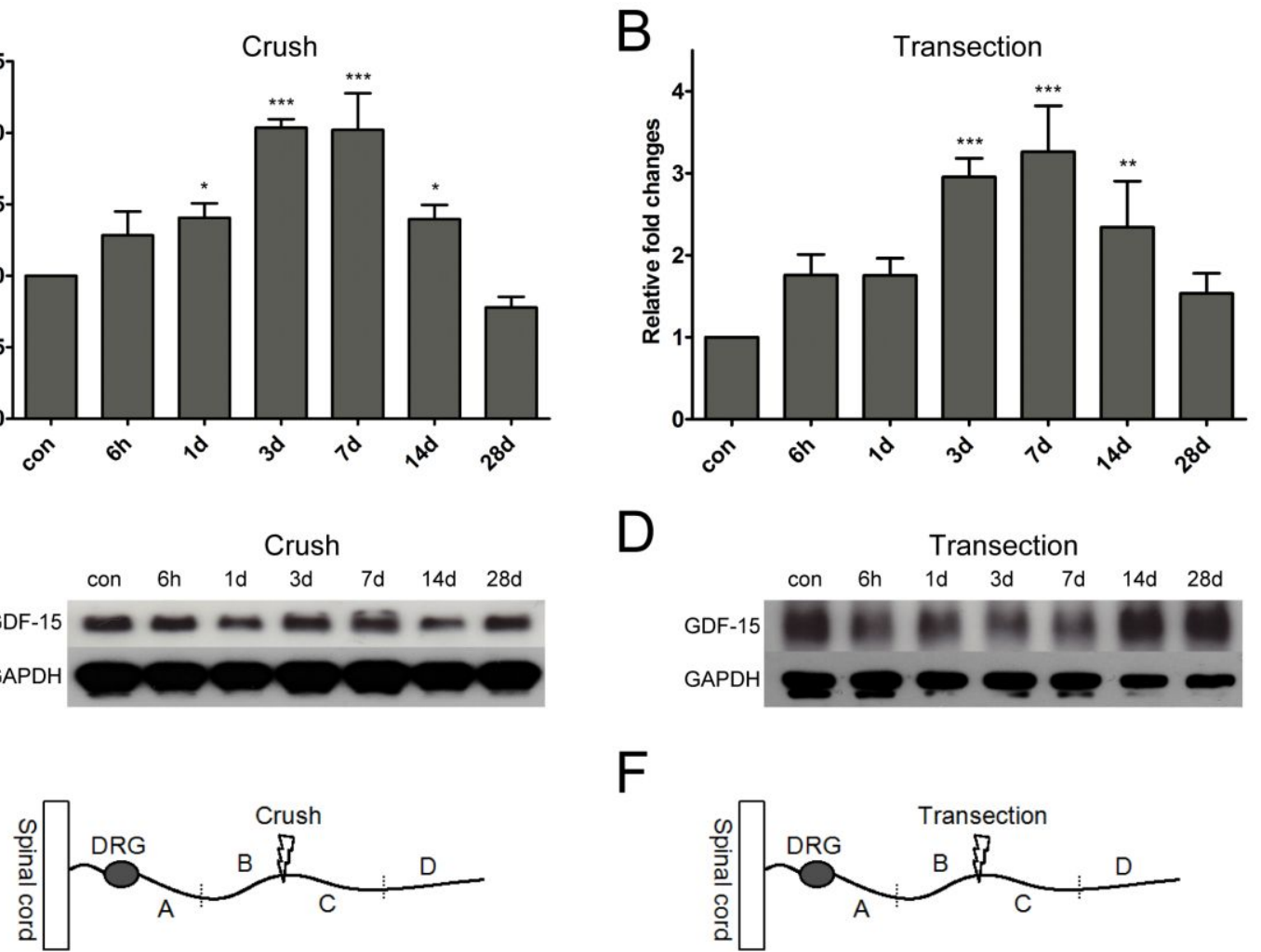

$\mathrm{D}$

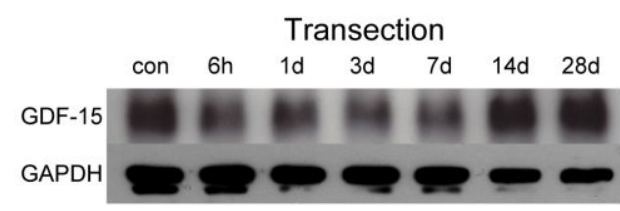

$\mathrm{F}$

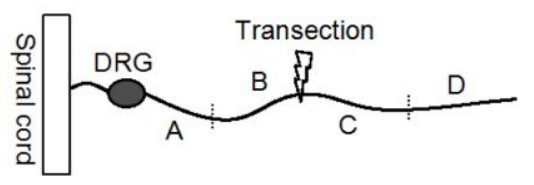

Fig 3.1 GDF-15 expression in DRG. GDF-15 mRNA levels were quantified by qRT-PCR at different time points after crush (A) or transection (B) lesion of SN (normalized to GAPDH, n=3). Representative Western blots of GDF-15 protein in DRG at different time points after crush (C) or transection (D) lesion of $S N$ are shown. (E, F) Schematic diagrams of lesion and tested tissue showing the different segments of the nerve for analysis. Data are shown as mean \pm SD. P-values were calculated by One-Way ANOVA followed by Turkey post-hoc test, ${ }^{*} p<0.05,{ }^{* *} p<0.01,{ }^{* * *} p<0.001$.

\subsubsection{GDF-15 in sciatic nerve}

As shown in previous studies, Schwann cells (SCs) and macrophages (Charalambous et al., 2013; de Jager et al., 2011; Strelau et al., 2009) can synthesize and release GDF-15 under certain physiological and pathological conditions. My specific interest was to determine the GDF-15 expression in the lesioned SN. Following crush, GDF-15 mRNA in segment B (proximal to lesion) gradually increased and reached levels $\sim 6$ times higher than control at 7 days, and subsequently returned to levels $\sim 2$ times higher than control at 28 days (Fig 3.2 A). In segment C (distal to lesion), GDF-15 mRNA showed a similar pattern of up- and downregulation, but surprisingly peaked at 7 days with $\sim 25$ 
times higher than basal level, followed by stabilization at 14/28 day with 10 15 times higher than control (Fig 3.2 B). The dramatic increase of GDF-15 mRNA in the distal part of the nerve was confirmed by Western blot (Fig 3.2 D), which, after quantification, showed that protein expression was $\sim 8$ times higher than control at 7 days (Fig $3.2 \mathrm{C}$ ).

A

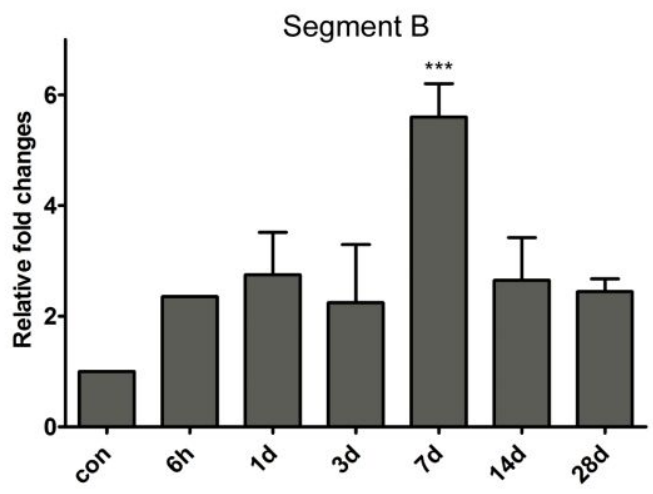

C

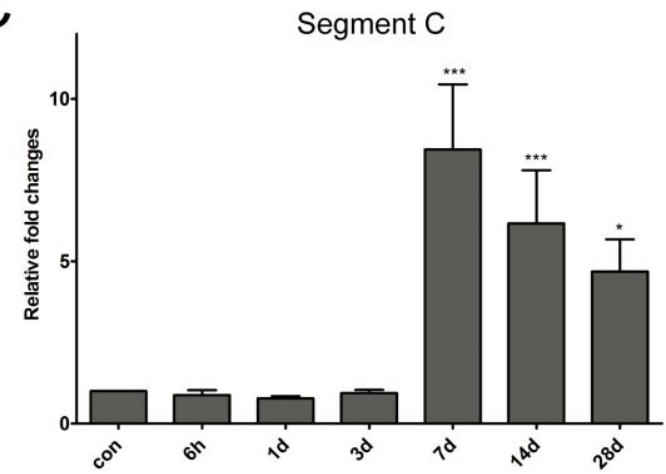

B

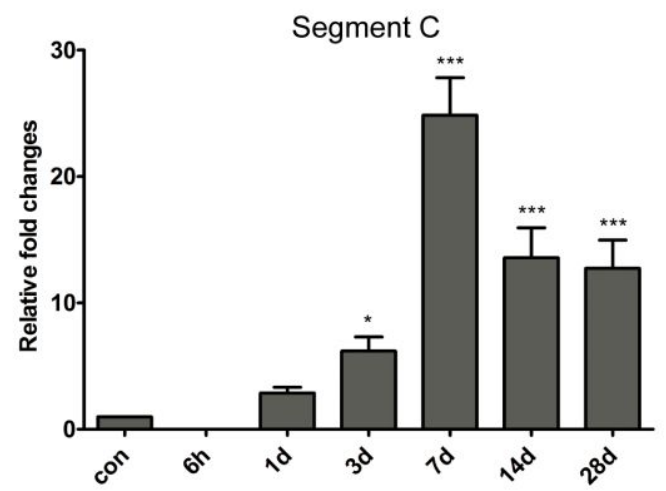

$D$

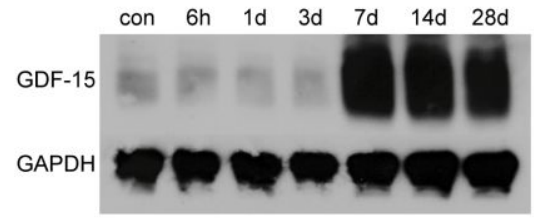

$E$

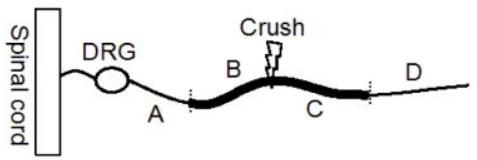

Fig 3.2 GDF-15 expression in sciatic nerve (SN) after crush lesion. GDF-15 mRNA levels in Segment B (A) or Segment C (B) were shown by qRT-PCR at different time points after crush lesion of $\mathrm{SN}$ (normalized by GAPDH, $n=3$ ). (C) GDF-15 protein regulation in Segment $C$ after crush was quantified based on Western blot (normalized by GAPDH, n=3). (D) Representative Western blot graphs of GDF-15 protein in Segment C at different time point after crush lesion of $S N$ are shown. (E) Schematic diagrams of lesion and tested tissue. Data are shown as mean \pm SD. P-values were calculated by One-Way ANOVA followed by Turkey post-hoc test, ${ }^{*} p<0.05,{ }^{* *} p<0.01,{ }^{* * *} p<0.001$.

The same measurement was done in the transection model. GDF-15 mRNA in Segment B slightly increased and reached levels $\sim 3$ times higher than control at $7 / 14$ day, and stayed at a basal level at 28 days (Fig 3.3 A). In Segment C, GDF-15 mRNA reached a $\sim 12$ times increase at 7 days, followed by stabilization at $14 / 28$ day being $\sim 10$ times higher than control levels (Fig $3.3 \mathrm{~B}$ ). 
Western blot of GDF-15 in Segment C lent further support to lesion-dependent regulation, there was a $\sim 8$-fold change at 7 days, and 5-fold at 28 days (Fig 3.3 C D).

A

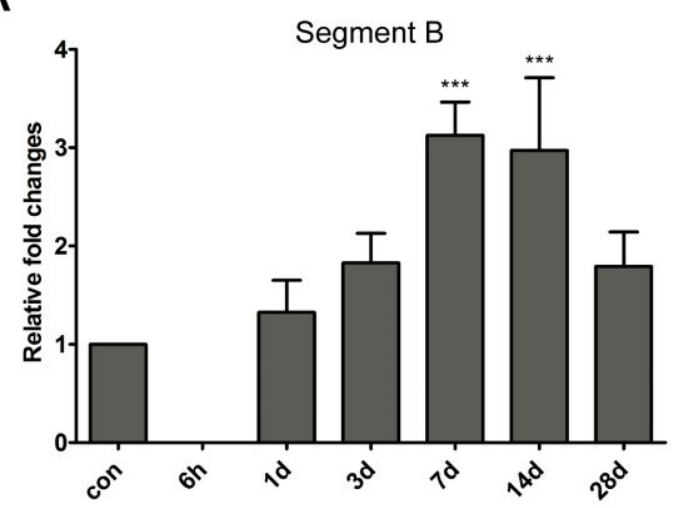

C

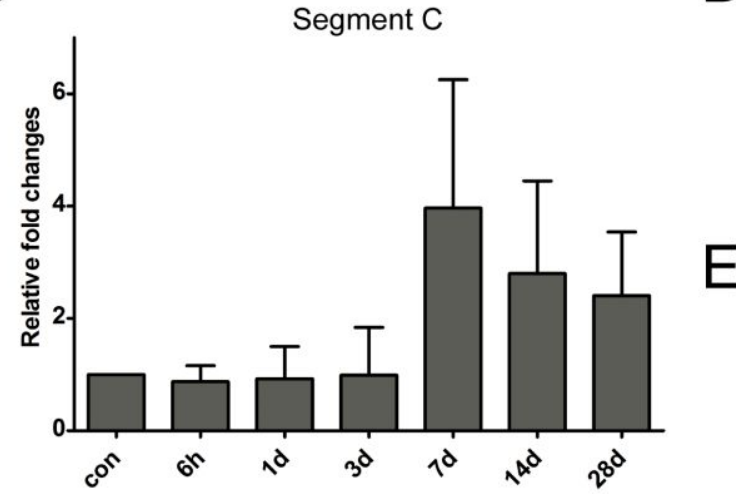

B

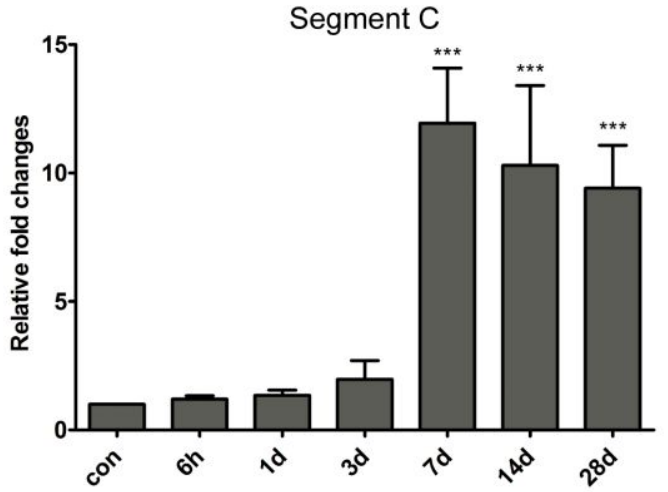

D
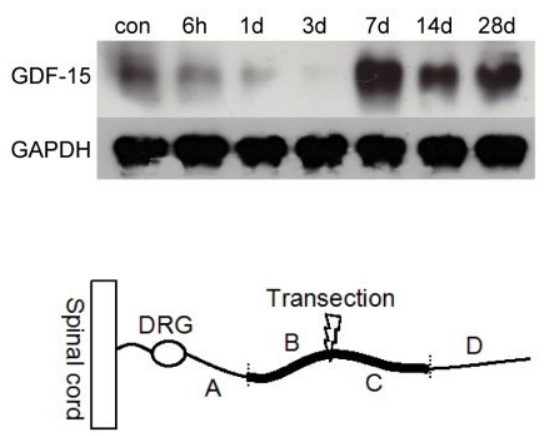

Fig 3.3 GDF-15 expression in SN after transection. GDF-15 mRNA levels in Segment B (A) or Segment $C(B)$ were shown by qRT-PCR at different time points after transection of SN (normalized by GAPDH, n=3). (C) GDF-15 protein regulation in Segment $C$ after transection was quantified based on Western blot (normalized by GAPDH, n=3). (D) Representative Western blot graphs of GDF-15 protein in Segment $C$ at different time points after transection of $\mathrm{SN}$ are shown. (E) Schematic diagrams of lesion and tested tissue. Data are shown as mean $\pm \mathrm{SD}$. P-values were calculated by One-Way ANOVA followed by Turkey post-hoc test, ${ }^{*} p<0.05,{ }^{* *} p<0.01,{ }^{* *} p<0.001$.

GDF-15 expression was also checked at a histological level. For wild type (WT) and knock out (KO) animals, $\mathrm{SN}$ segments both proximal and distal to the crush lesion, were dissected at 7 days, cryo-sectioned $(10 \mu \mathrm{m})$, and stained with GDF-15 and S100ß (marking Schwann cells) antibodies. In WT, both proximal (Fig 3.4 A a-c) and distal (Fig 3.4 A d-f) segments in crushed nerve exhibited increased GDF-15 immunoreactivity (ir) compared to unlesioned 
nerves (Fig 3.4 A g-i). In the proximal part, GDF-15 ir displayed a special pattern approximately vertical to the fibers, pointing out it might locate at the node of Ranvier. However, the staining with Ankyrin G antibodies (node of Ranvier marker) failed to show the co-localization of GDF-15 and node region (data not shown). In the distal part, GDF-15 ir was strongly upregulated, which further confirmed the above qRT-PCR and Western blot results. For the KO nerve, no GDF-15 ir was detected in any proximal (Fig 3.4 B a-c), distal (Fig 3.4 B d-f) and unlesioned parts (Fig 3.4 B g-i). 


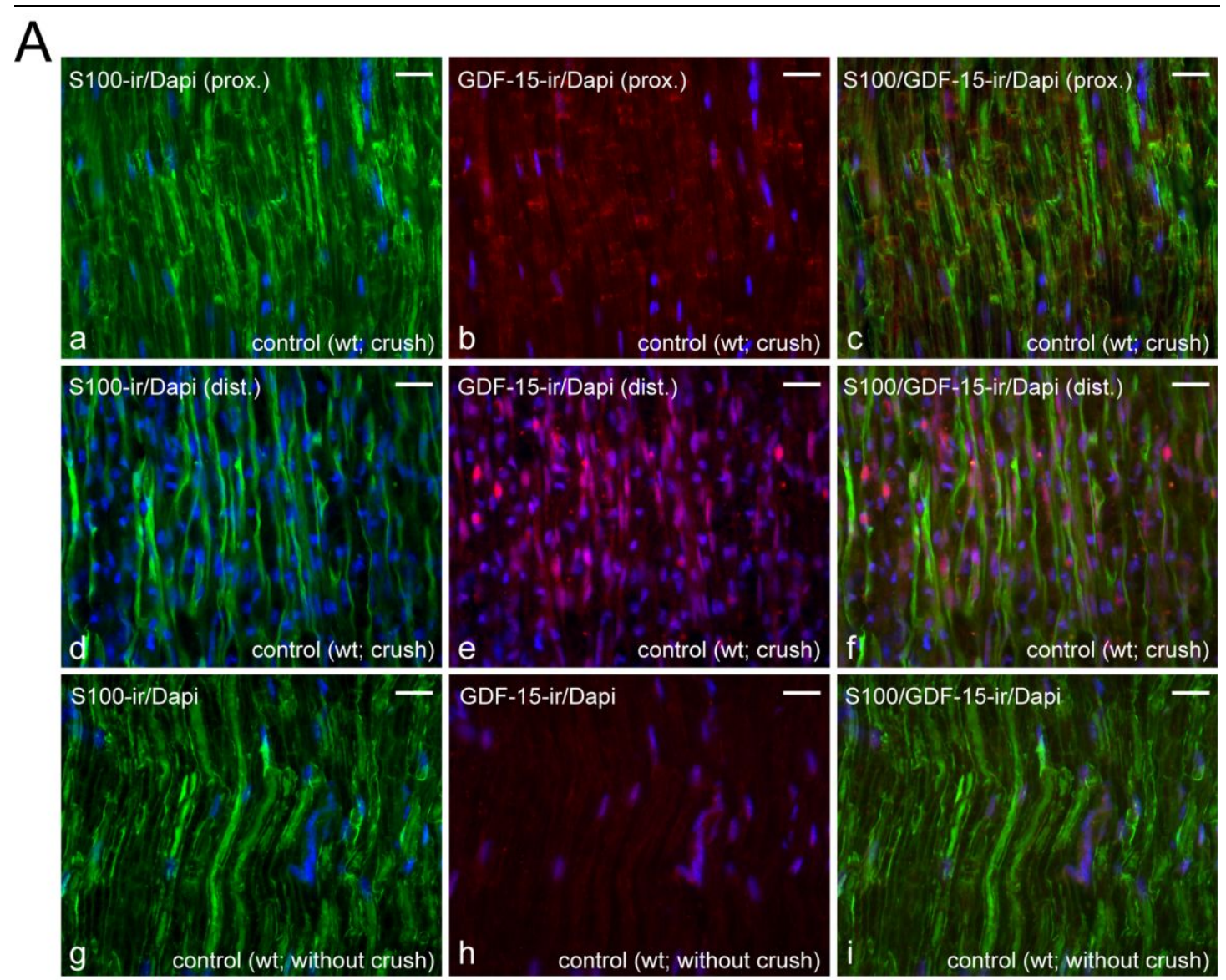

B
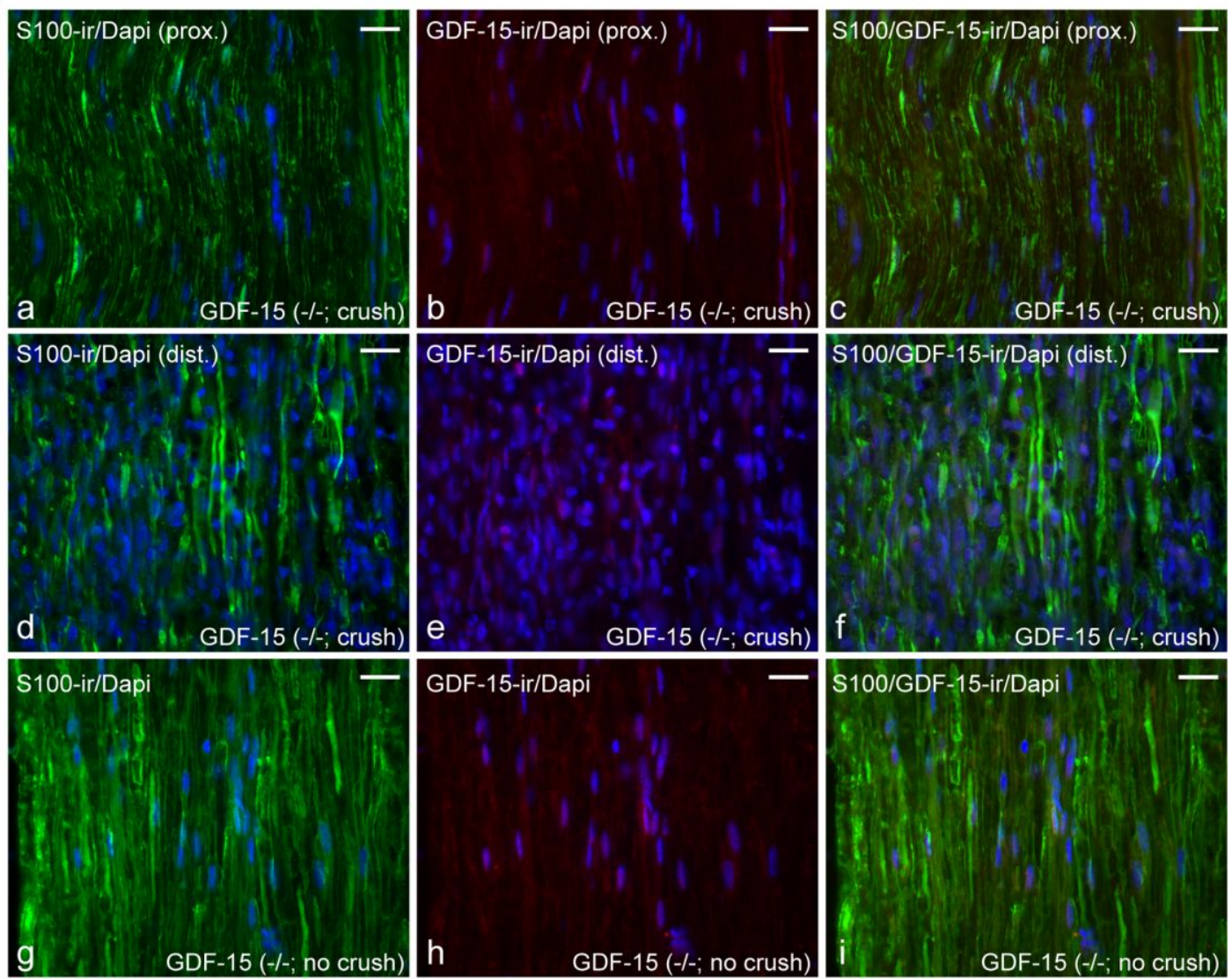

GDF-15-ir/Dap
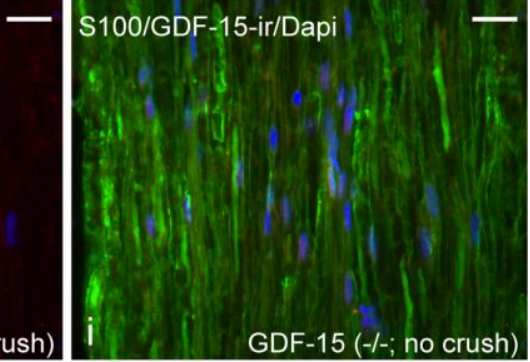

Fig 3.4 GDF-15 immunoreaction in SN after crush lesion. GDF-15/S100 $\beta$ 
immunohistochemistry in WT (A) and GDF-15 KO (B) SN at 7 days post crush lesion. (a-c) nerve proximal to lesion; (d-f) nerve distal to lesion; $(g-i)$ unlesioned nerve. GDF-15: red channel; S100ß: green channel; DAPI: blue channel. Bar=10 $\mu \mathrm{m}$.

In summary, in both SN crush and transection models, GDF-15 mRNA levels revealed an increase at 7 days, and subsequent decrease to control levels in DRG. GDF-15 peaked at 7 days and fell back in SN proximal to lesion, while it was greatly elevated at 7 days and kept at high levels until 28 days in SN distal to lesion.

\subsection{DRG neuron survival/death in WT and GDF-15 KO animals}

\subsubsection{Survival/death related genes in WT and GDF-15 KO animals}

When injuring the sciatic nerve, due to the depolarization of membrane and influx of ions, an "injury signal" is generated and retrogradely transported to the DRG neuron body, where it triggers downstream gene expression controlling cell survival/death (Abe and Cavalli, 2008; Chen et al., 2007). To investigate the role of GDF-15 on neuron survival/death after injury, representative candidate genes were chosen to be studied, including c-Jun for transcriptional control of regeneration (De Leon et al., 1995; Raivich et al., 2004), Galanin for neuroprotection (Coronel et al., 2008; Holmes et al., 2000; Raivich et al., 2004), Caspase 8 for apoptosis (Monnier et al., 2011) and Bad for promoting survival.

After SN crush lesion, DRGs of WT and GDF-15 KO animals were collected, and underwent either RNA isolation or cryo-sectioning $(10 \mu \mathrm{m})$. Upregulation of c-Jun mRNA was found at 1 day after injury, and then decreased, but still remained higher than control, at 7 days (Fig $3.5 \mathrm{~A}$ ). There was a trend that KO DRG had higher c-Jun levels after injury than WT, although this was not statistically significant (Fig 3.5 A). Galanin mRNA was dramatically elevated following the lesion (Fig $3.5 \mathrm{C}$ ), with significantly higher expression in $\mathrm{KO}$ than in WT animals (almost double level). As Galanin is transcriptionally controlled 
by c-Jun (Raivich et al., 2004), the higher Galanin level in KO might result from the higher c-Jun in $\mathrm{KO}$ animals. Caspase 8 mRNA was gradually leveled up in WT, $\sim 3$ times higher than control at 7 days (Fig $3.5 \mathrm{~B}$ ); however, it remained stable in $\mathrm{KO}$, being not significantly different to WT. Staining of phosphorylated Bad in WT DRG showed an upregulation of p-Bad ir in the nucleus, while, on the contrary, $\mathrm{KO}$ animals displayed constitutive expression before and after injury (Fig 3.5 E). 


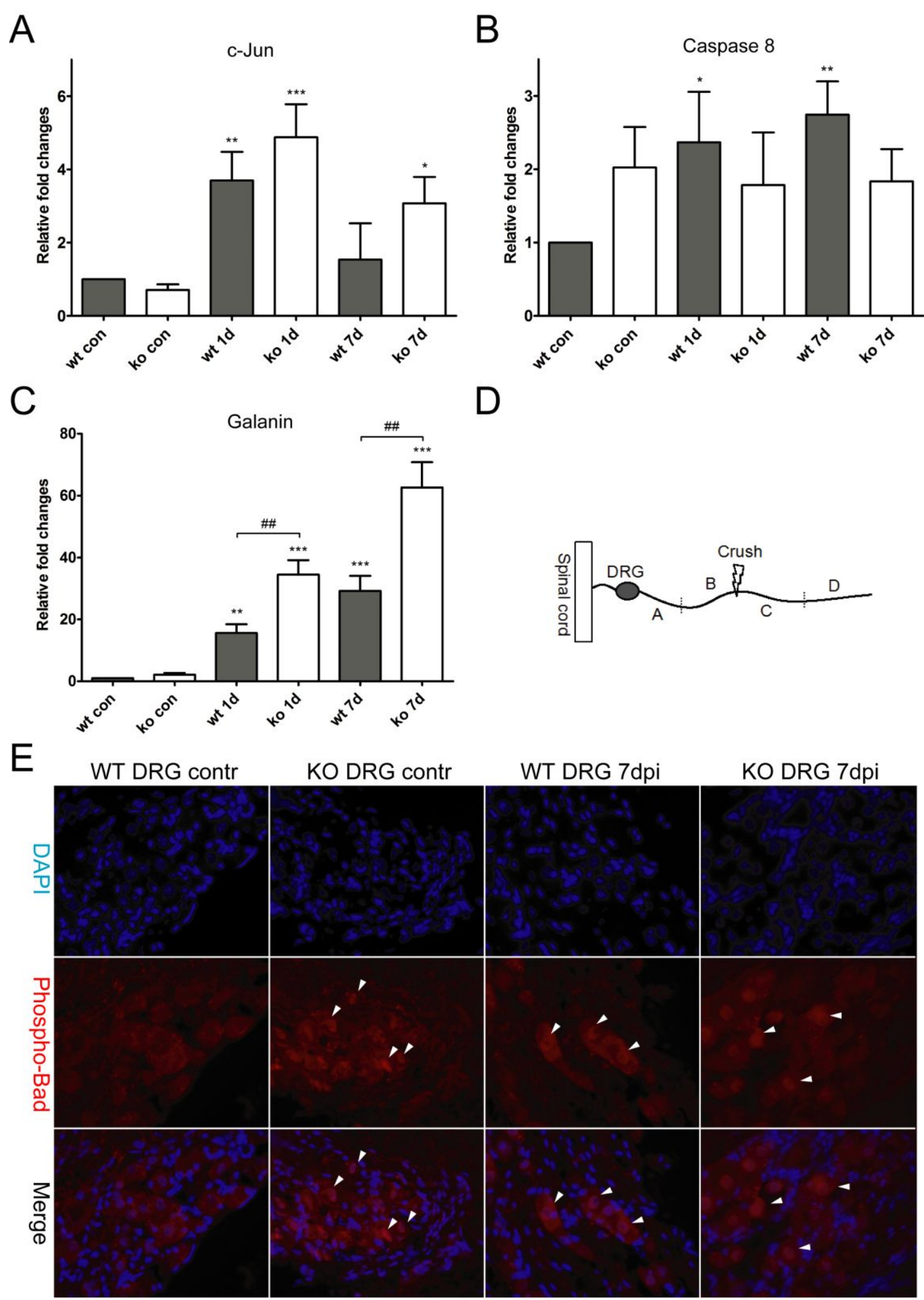

Fig 3.5 Neuron survival/death related genes in DRG. Survival-promoting gene c-Jun (A), Galanin (C) and cell-death related gene Caspase 8 (B). mRNA levels were determined by qRT-PCR in DRG at different time points after SN crush (normalized to GAPDH, n=3). (D) Schematic diagrams of lesion and tested tissue. (E) Phospho-Bad staining of DRG in WT and KO animals after SN crush lesion ( $p$-Bad: red channel; DPAl: blue channel; arrow head: $p$-Bad ir in the nucleus). Data are presented as mean \pm SD. 
P-values were calculated by One-Way ANOVA followed by Turkey post-hoc test, ${ }^{*} \mathrm{p}<0.05$, ${ }^{* *} p<0.01,{ }^{* * *} p<0.001$; or by unpaired t-test, \#p<0.01.

\subsubsection{DRG neuron quantification}

To further study whether GDF-15 was involved in neuron survival/death, L4 DRGs from WT and KO animals at 14 days and 28 days after SN transection were dissected, paraffin sectioned $(8 \mu \mathrm{m})$, Nissl stained and counted (Fig 3.6 C). In unlesioned conditions (Fig 3.6 A B, wt con/ko con), the KO had fewer neurons than WT (although not statistically significant), which coincided with previous observations that KO DRG underwent a mild postnatal neuron loss (Strelau et al., 2009). At 14 days after SN transection, DRG neuron numbers of the lesion side revealed a reduction of $\sim 25 \%$, without an imparity between WT and $\mathrm{KO}$ (Fig $3.6 \mathrm{~A}$ ). At 28 days after transection, the reduction reached 50 60\%, however, both genotypes showed no difference (Fig 3.6 B).

A

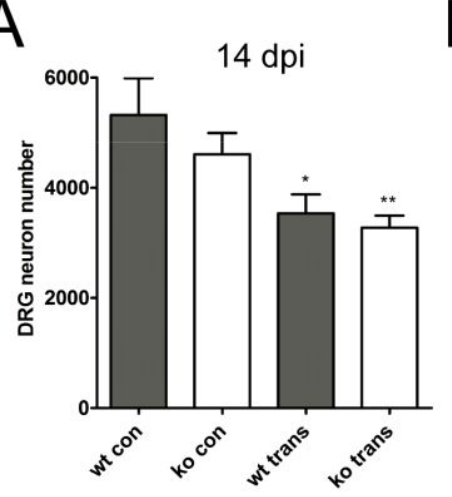

B

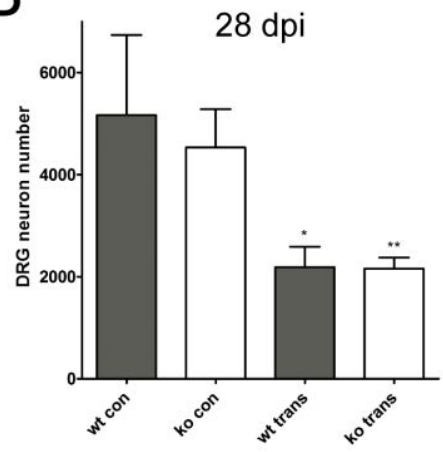

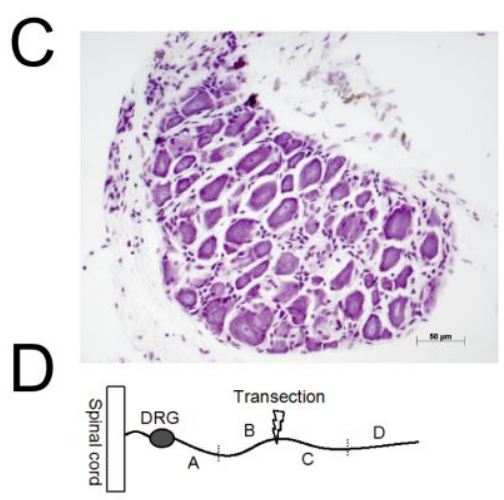

Fig 3.6 L4 DRG neuron quantification after SN transection. L4 DRGs from WT and GDF-15 KO animals were sectioned, Nissl stained and analyzed at 14 days ( $A, n=3)$ or 28 days $(B, n=3)$ after $S N$ transection. (C) Representative DRG Nissl staining. (D) Schematic diagrams of lesion and tested tissue. Data are shown as mean \pm SD. P-values were calculated by unpaired t-test, ${ }^{*} p<0.05,{ }^{* *} p<0.01$.

In summary, survival-promoting molecules as e.g. c-Jun, Galanin, and Bad were distinctly expressed in DRGs of WT and KO animals, however, the final fate of DRG neurons after lesion was similar in the two genotypes. GDF-15 did not alter neuron survival/death. 


\subsection{GDF-15 and axonal regeneration}

\subsubsection{Demyelination and regeneration related genes in WT and GDF-15} KO animals

After SN lesion, the distal nerve segment undergoes complex molecular and morphological changes called Wallerian degeneration. During this process, myelination related genes are repressed, while cell adhesion related and neurotrophic genes are promoted (Navarro et al., 2007; Stoll and Muller, 1999). To investigate whether there was a difference between WT and KO animals in terms of demyelination and regeneration, representative genes were studied, including Krox-20 for demyelination (Jessen and Mirsky, 2008), NF-kB for activation of glial cells (Nickols et al., 2003; Smith et al., 2009), MAC-2 for macrophage-Schwann cell interaction (Saada et al., 1996; Stoll and Muller, 1999) and NCAM for SC migration (Hansen et al., 2008; Thomaidou et al., 2001). After SN crush, the distal Segments C from WT and KO animals were collected at different time points, RNAs and proteins were isolated for qRT-PCR and Western blot analysis. Krox-20 mRNAs decreased following crush injury in both genotypes, while under unlesioned conditions and at 1 day after lesion, the KO showed a significantly higher expression than WT (Fig 3.7 A) (this might be related to the hypermyelination phenotype of $\mathrm{KO}$ animals, unpublished data). MAC-2 mRNA was upregulated after lesion in both genotypes, however, the KO showed higher expression at all time points compared to WT (Fig 3.7 B). NCAM mRNA in WT was increased in a time-dependent manner, in contrast to the $\mathrm{KO}$, which remained stable at the tested time points (Fig 3.7 C). In control and 1 day after injury, KO had higher NCAM mRNA levels, but in the late stage, which is more important for the regrowing axon, it did not show significant disparity to WT. NF-kB mRNA levels in $\mathrm{KO}$ were always higher than in WT, while both decreased over time (Fig 3.7 D). An opposite result was obtained in NF-kB Western blots, which revelaed that the protein was up-regulated over time, and at 1 and 7 days, the KO 
tended to express more NF-kB than WT (Fig 3.7 E F).

A

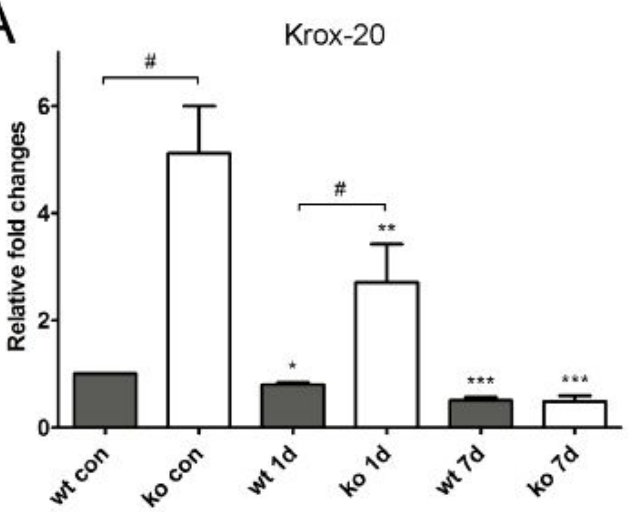

C

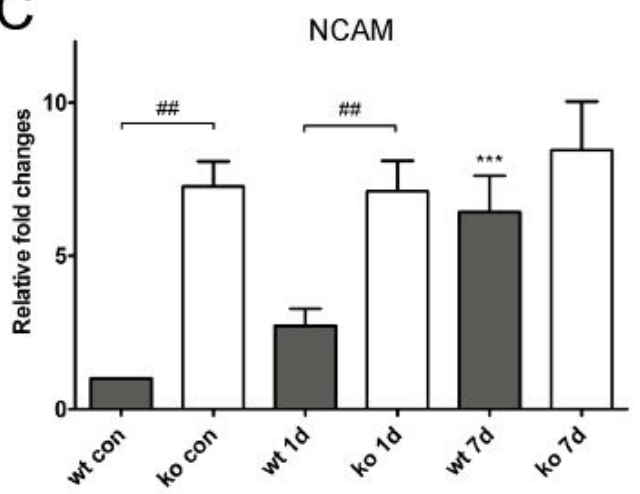

E

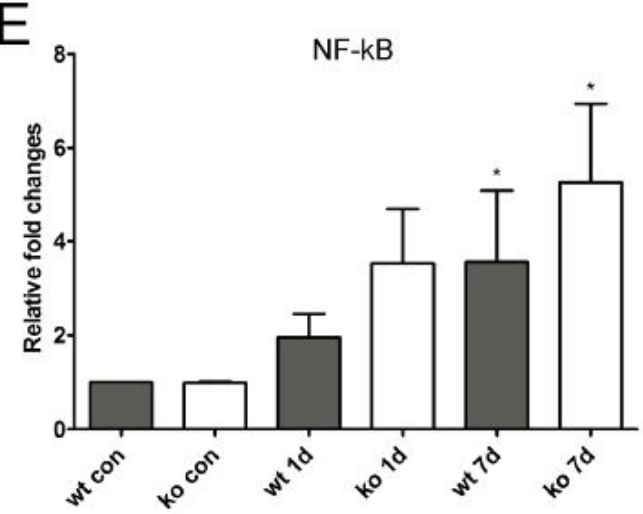

B

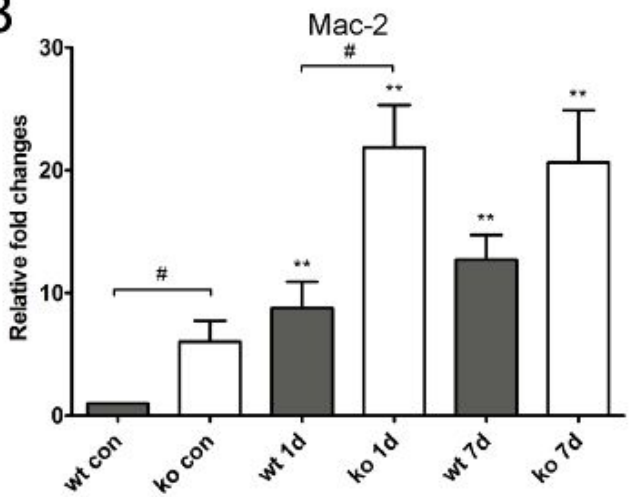

D

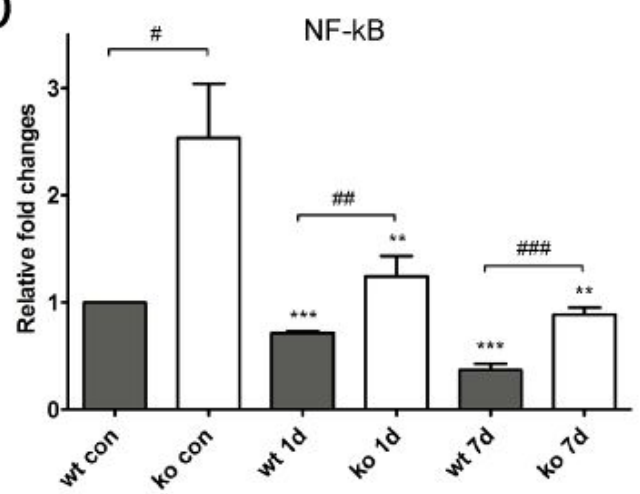

$\mathrm{F}$

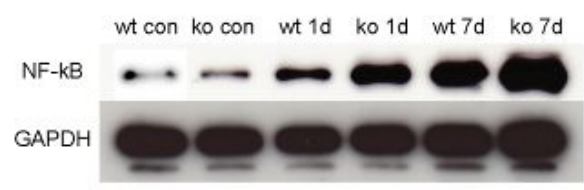

G

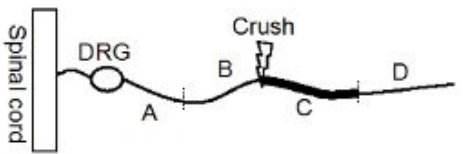

Fig 3.7 Regeneration-related genes in SN Segment C. (A) Krox-20, (B) MAC-2, (C) NCAM, (D) NF-KB mRNA levels from WT and GDF-15 KO animals were determined by qRT-PCR at different time points after SN crush in Segment $C$ (normalized by GAPDH, $\mathrm{n}=3$ ). (E) NF-kB (p65) protein regulation in Segment $C$ after $S N$ crush was quantified based on Western blot (normalized by GAPDH, $n=3$ ). ( $F$ ) Representative photograph of NF-kB Western blot. (G) Schematic diagrams of lesion and tested tissue. Data are shown as mean \pm SD. P-values were calculated by One-Way ANOVA followed by Tukey post-hoc test, ${ }^{*} p<0.05,{ }^{* *} p<0.01,{ }^{* * *} p<0.001$; or by unpaired t-test, $\# p<0.05, \quad \# p<0.01$, $\# \#$ \# $<0.001$. 


\subsubsection{Inflammatory genes and macrophage recruitment in WT and GDF-15 KO animals}

As the clearance of degraded axon debris after lesion is a critical step for effective regeneration, inflammation after injury and recruitment of circulating macrophages is of particular interest (Martini et al., 2008; Stoll and Muller, 1999). To verify whether GDF-15 had an impact on inflammation, immune mediators such as MCP-1, IL-1 $\beta$, IL-6 (Shamash et al., 2002; Taskinen and Roytta, 2000; Ydens et al., 2012), and alternative immune pathway markers such as Arg 1, Fizz 1 and Ym1 were chosen for analysis (Arora et al., 2006; Cai et al., 2002; Teng et al., 2003). After SN crush lesion, distal Segments C from WT and KO animals were collected at different time points, RNAs and proteins were isolated for qRT-PCR and Western blot analysis. MCP-1 mRNA followed an up-and-down pattern after lesion, from 1 day to 7 days, there was a 5 8 fold increase over basal levels, but no difference between the genotypes was observed (Fig 3.8 A). IL-1 $\beta$ mRNA exhibited two peaks, at $6 \mathrm{~h} / 1$ day (30 40 fold), and at 7 days (10 20 fold)(Fig 3.8 B). At all time points, higher levels of IL-1 $\beta$ were seen in the KO than in WT, especially at 1 day and 7 days. IL-6 mRNA also revealed two waves of upregulation, at $6 \mathrm{~h} / 1$ day (10 20 fold), and at $3 / 7$ day $(5 \sim 15$ fold), while levels in the KO significantly surpassed the WT at 3 and 7 days (Fig 3.8 C). Arg 1 mRNA levels were 150 250 fold elevated at 1 day, and then started to drop (Fig 3.8 D). Arg 1 mRNA levels in the $\mathrm{KO}$ tended to exceed those in the WT at all time points (not statistically significant). Fizz 1 mRNA was first decreased and then increased again, without difference between the genotypes (Fig 3.8 E). The pattern of Ym1 mRNA was similar to Arg 1, levels in the KO exceeded those in the WT at all time points, especially at 1 day (Fig 3.8 F). The Ym1 result was reinforced by Western blot (Fig 3.8 H). 

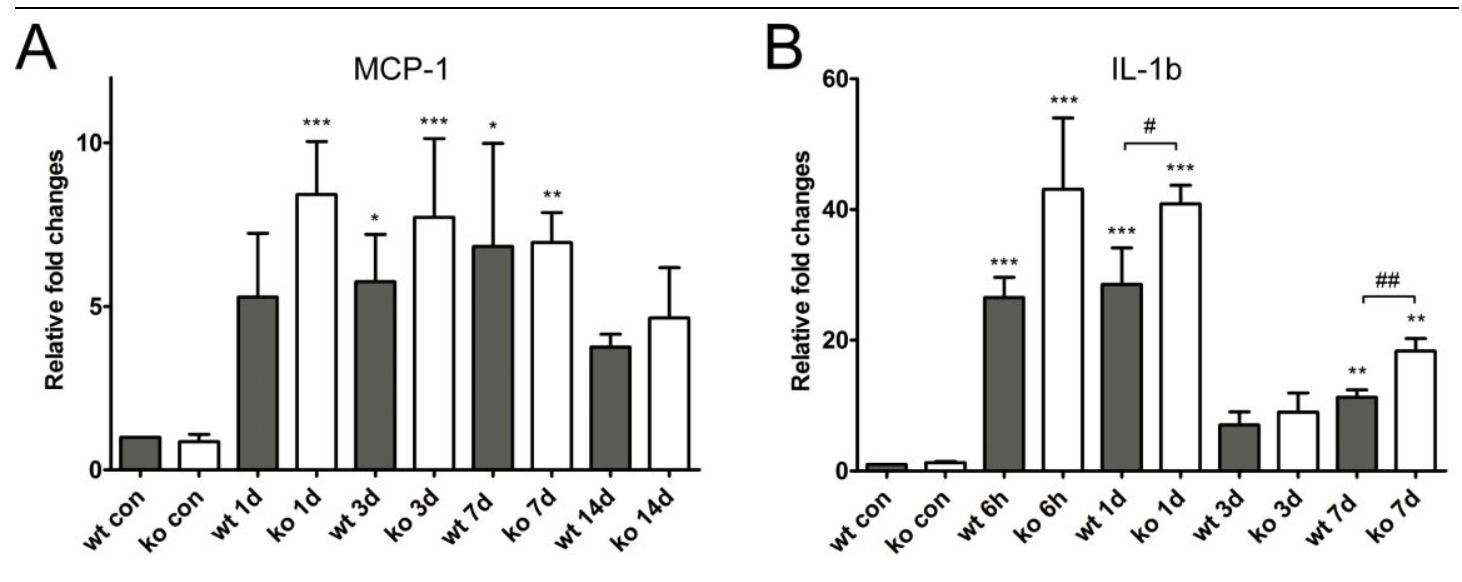

$\mathrm{C}$

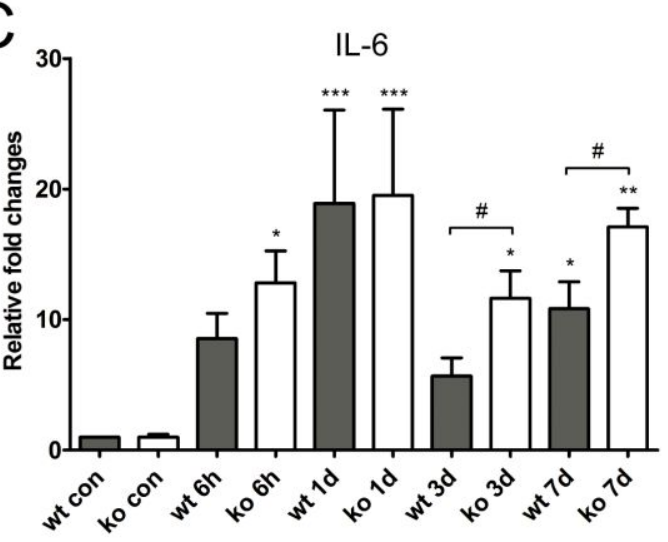

$\mathrm{D}$

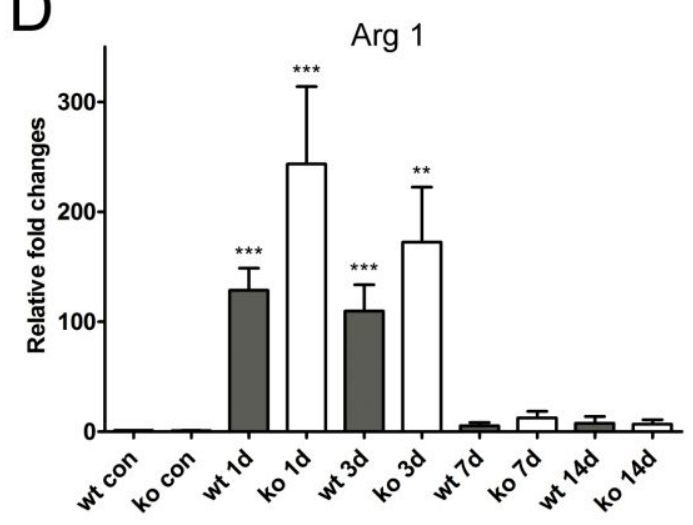

$\mathrm{E}$

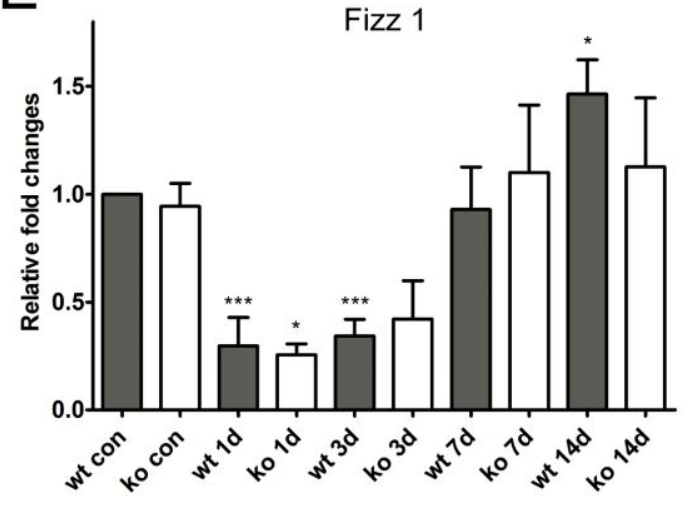

G

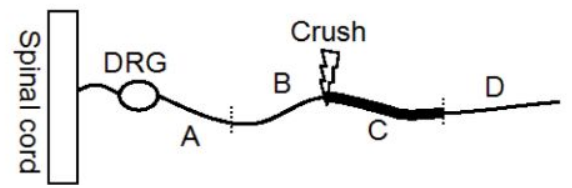

$\mathrm{F}$

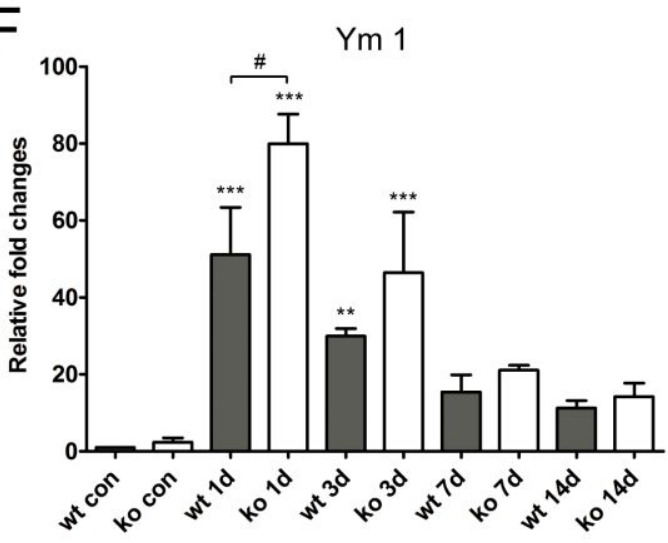

$\mathrm{H}$

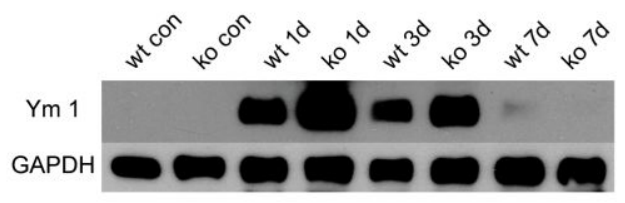

Fig 3.8 Inflammation related genes in SN Segment $C$ from WT and GDF-15 KO animals after crush lesion. (A) MCP-1, (B) IL-1 , (C) IL-6, (D) Arg 1, (E) Fizz 1, (F) Ym1 mRNA levels were determined by qRT-PCR (normalized by GAPDH, $n=3$ ). (G) Schematic diagrams of lesion and tested tissue. $(\mathrm{H})$ Representative photograph of Ym1 Western blot. Data are shown as mean \pm SD. P-values were calculated by One-Way ANOVA followed by Tukey post-hoc test, ${ }^{*} p<0.05,{ }^{* *} p<0.01,{ }^{* * *} p<0.001$; or by unpaired t-test, $\# p<0.05$, $\#$ \#p $<0.01$. 
Macrophage markers $\mathrm{CD} 11 \mathrm{~b}$ and $\mathrm{F} 4 / 80$ were used to compare the macrophage recruitment in the nerve distal to the lesion (Mueller et al., 2003; Murray and Wynn, 2011). CD11b and F4/80 mRNA patterns were similar, increased during time, indicating accumulation of macrophages distal to the lesion (Fig 3.9 A B). Both graphs show that expression in the $\mathrm{KO}$ was consistently higher than in WT (especially at 14 days for CD11b, at 1 and 7 days for F4/80). Western blot of F4/80 corroborated the qRT-PCR result (Fig $3.9 \mathrm{C} \mathrm{D}$ ). IHC of $\mathrm{F} 4 / 80$ in the distal nerve further verified the phenotype suggesting that more macrophages were present after injury in the KO (Fig 3.9 F). 

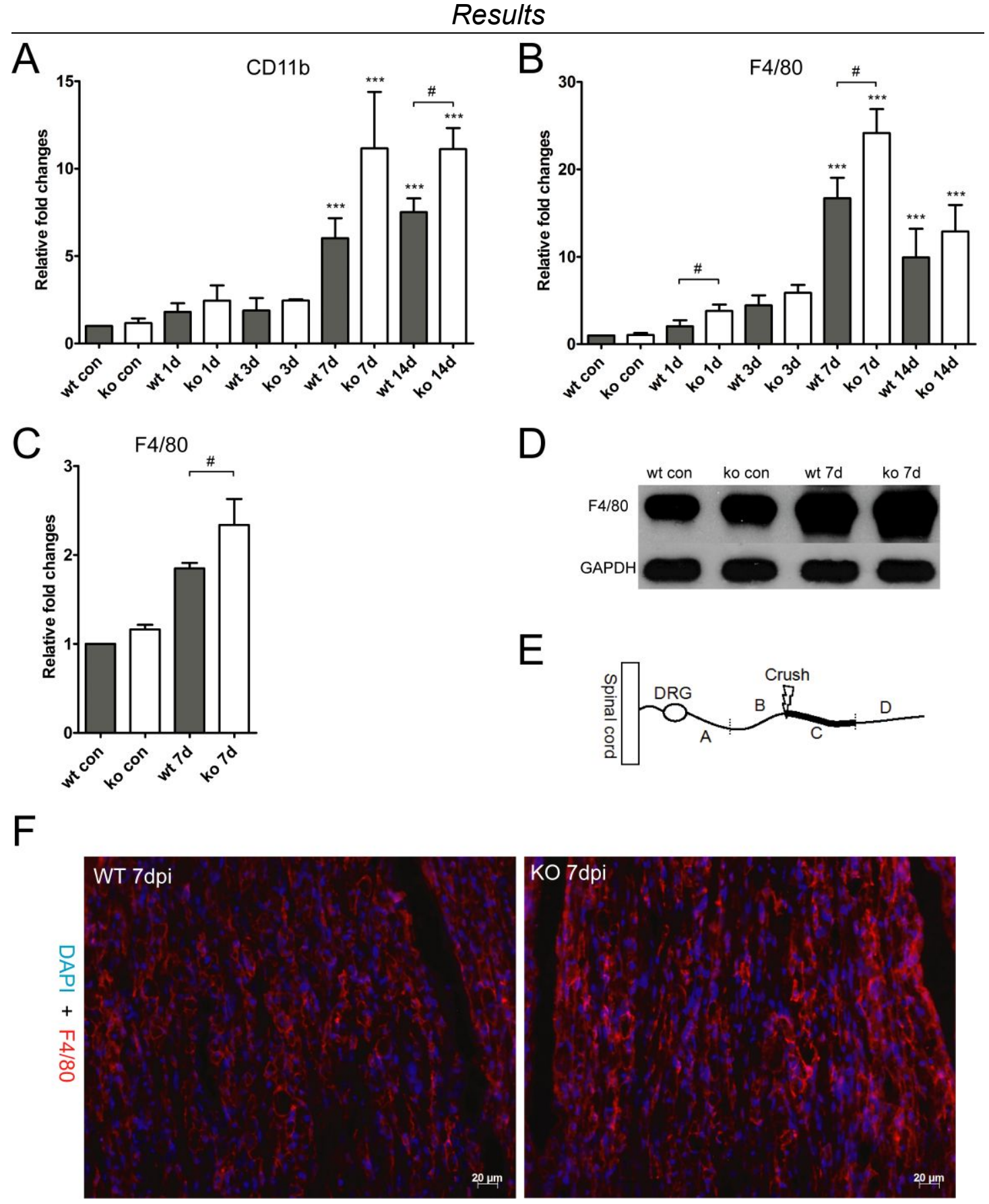

Fig 3.9 Macrophage markers in SN Segment $C$ from WT and GDF-15 KO animals after crush. (A) CD11b, (B) F4/80 mRNA levels (normalized to GAPDH, n=3). (C) Regulation of $F 4 / 80$ protein levels based on Western blot in WT and KO Segment $C$ after $\mathrm{SN}$ crush (normalized to GAPDH, n=3). (D) Representative photograph of F4/80 Western blot. (E) Schematic diagram of lesion and tested tissue. (F) Immunohistochemistry of F4/80 in SN Segment C, 7 day post crush lesion (F4/80: red channel; DAPI: blue channel). Data are shown as mean \pm SD. P-values were calculated by One-Way ANOVA followed by Tukey post-hoc test, ${ }^{* * *} p<0.001$; or by unpaired t-test, $\# p<0.05$. 
3.3.3. Fibroblast and Schwann cell activation in WT and GDF-15 KO animals

Fibroblasts and SCs also contribute to the rapid and successful regeneration, as the former provide favorable extracellular matrix conditions and guide Schwann cells across the lesion site, while the latter participate in phagocytosis, guidance of axon and remyelination (Griffin and Thompson, 2008; Parrinello et al., 2010; Stoll and Muller, 1999). To clarify whether deletion of GDF-15 leads to alterations in fibroblast or SC performance, fibroblast markers Fibronectin, alpha-smooth muscle actin ( $\alpha-S M A)$ and Collagen 1 (Parrinello et al., 2010), as well as SC activation markers sonic hedgehog $(\mathrm{SHH})$, Olig1 and S100ß were tested (Arthur-Farraj et al., 2012). After SN crush lesion, distal Segments C from WT and KO animals were collected at different time points, RNAs were isolated for qRT-PCR. Fibronectin mRNA, after a delay period at 1 day, was upregulated and remained at high levels from 3 to 14 days, without revealing differences between WT and KO (Fig 3.10 A). All other markers, a-SMA (Fig 3.10 B), Collagen 1 (Fig 3.10 C), SHH (Fig 3.10 D), Olig1 (Fig $3.10 \mathrm{E}$ ) and $\mathrm{S} 100 \beta$ (Fig 3.10 F) shared the same regulatory mode and were upregulated at 7 days, but showed no difference between WT and $\mathrm{KO}$. 


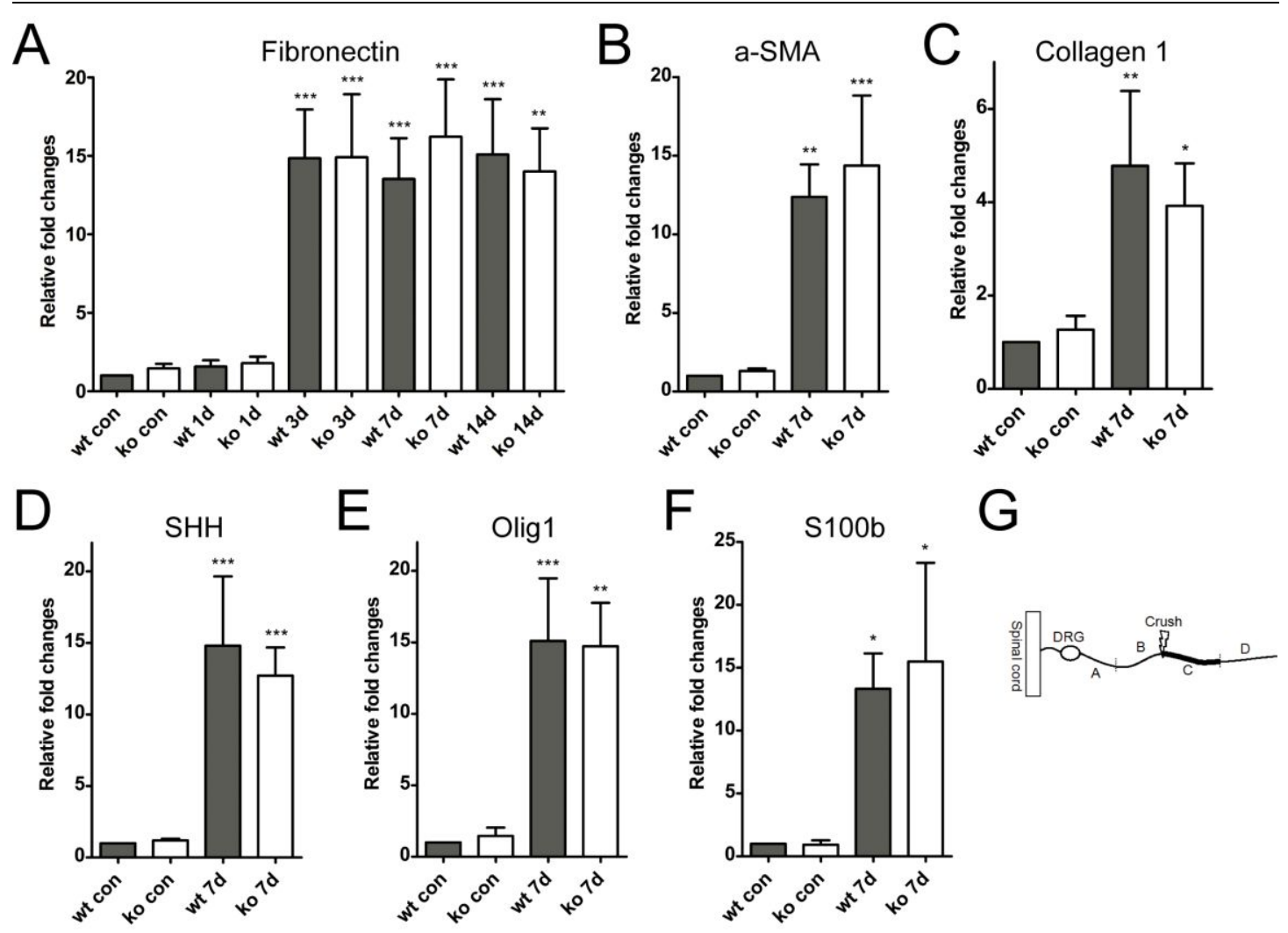

Fig 3.10 Fibroblast and SC markers in SN Segment $C$ from WT and GDF-15 KO animals after crush. (A) Fibronectin, (B) a-SMA, (C) Collagen 1, (D) SHH, (E) Olig1, (F) $S 100 \beta$ mRNA levels are shown (normalized to GAPDH, $n=3$ ). (G) Schematic diagram of lesion and tested tissue. Data were shown as mean \pm SD. P-values were calculated by One-Way ANOVA followed by Tukey post-hoc test, ${ }^{*} p<0.05,{ }^{* *} p<0.01,{ }^{* *} p<0.001$.

\subsubsection{Remyelination analysis of regrowing axons in WT and GDF-15 KO} animals

Although some regeneration-related genes showed discrepancies in WT and KO (see above), morphological evaluation was essential to determine the impact of molecular changes on structural regeneration. To identify the maturation/remyelination of regenerating axons, unlesioned and crushed sciatic nerves were dissected at 28 days after injury from both WT and KO animals. Samples were $\mathrm{OsO}_{4}$ fixed, resin-embedded and cut into $60 \mathrm{~nm}$ ultrathin section to determine the g-ratio (Fig 3.11 A). As shown in Fig 3.11 B, on the non-lesioned side, the KO nerve had a smaller g-ratio than the WT indicating a relatively thicker myelin sheath which corrorborated the previously 
documented hypermyelination phenotype (Strelau et al., unpublished). However, after lesion, when the original myelin sheath was broken down and the new axon was enwrapped by myelin, both genotypes showed a similar g-ratio of the new myelin sheath.

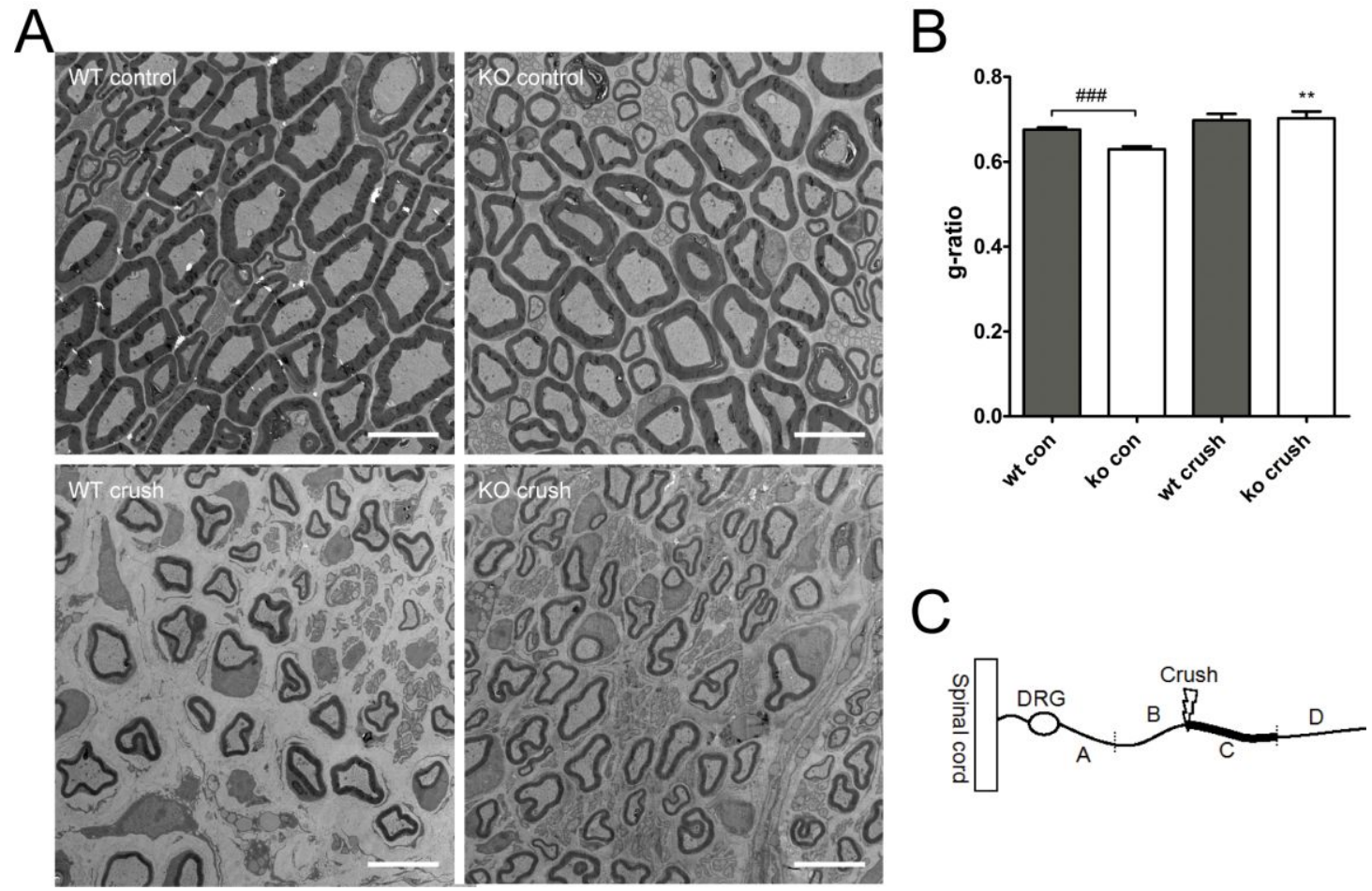

Fig 3.11 Remyelination and g-ratio of regenerating axons. (A) Representative photograph of ultrathin sections from sciatic nerve of WT and GDF-15 KO animals, at 28 days after $\mathrm{SN}$ crush. (B) g-ratio of axons is given ( $\mathrm{n}=3, \sim 100$ axons measured per nerve). (C) Schematic diagrams of lesion and tested tissue. Data are shown as mean \pm SD. P-values were calculated by unpaired t-test, ${ }^{* *} p<0.01, \# \# p<0.001$. Bar $=5 \mu \mathrm{m}$.

\subsubsection{Regenerating axon quantification in WT and GDF-15 KO animals}

Highly efficient regeneration can be assumed to lead to a faster axon regrowth from the lesion site towards distal targets. To determine axon regrowth, unlesioned and crushed sciatic nerves/tibial nerves were collected from WT and $\mathrm{KO}$ animals at 5 and 9 weeks after injury. Samples were PFA fixed, paraffin embedded and cut into $10 \mu \mathrm{m}$ sections, at $0.5 \mathrm{~cm}, 1.2 \mathrm{~cm}$ and $2.0 \mathrm{~cm}$ distal to crush site. Sections were stained with antibodies against Tuj1 for axons and S100ß for SCs (Nikolaev et al., 2009; Saijilafu et al., 2011)(Fig 3.12 
G). Axon numbers in tibial nerve or in the tibial bundle of sciatic nerve were recorded (Fig 3.12 A-F). As previously reported, KO animals have a progressive motor-/sensory neuron loss phenotype (Strelau et al., 2009), which would result in a reduced axon number in $\mathrm{KO}$ animals. Thus, as expected, the KO control group had fewer axons than WT control group throughout. After lesion, axon numbers on the WT crush side were similar to the WT control side (only except Fig 3.12 E). However, numbers of axons on the $\mathrm{KO}$ crush side were slightly reduced as compared to the $\mathrm{KO}$ control side (Fig 3.12 B C E F). This reduction was more prominent in the more distal part of the nerve, suggesting a retarded protrusion of axons towards the distal nerve end in the $\mathrm{KO}$.

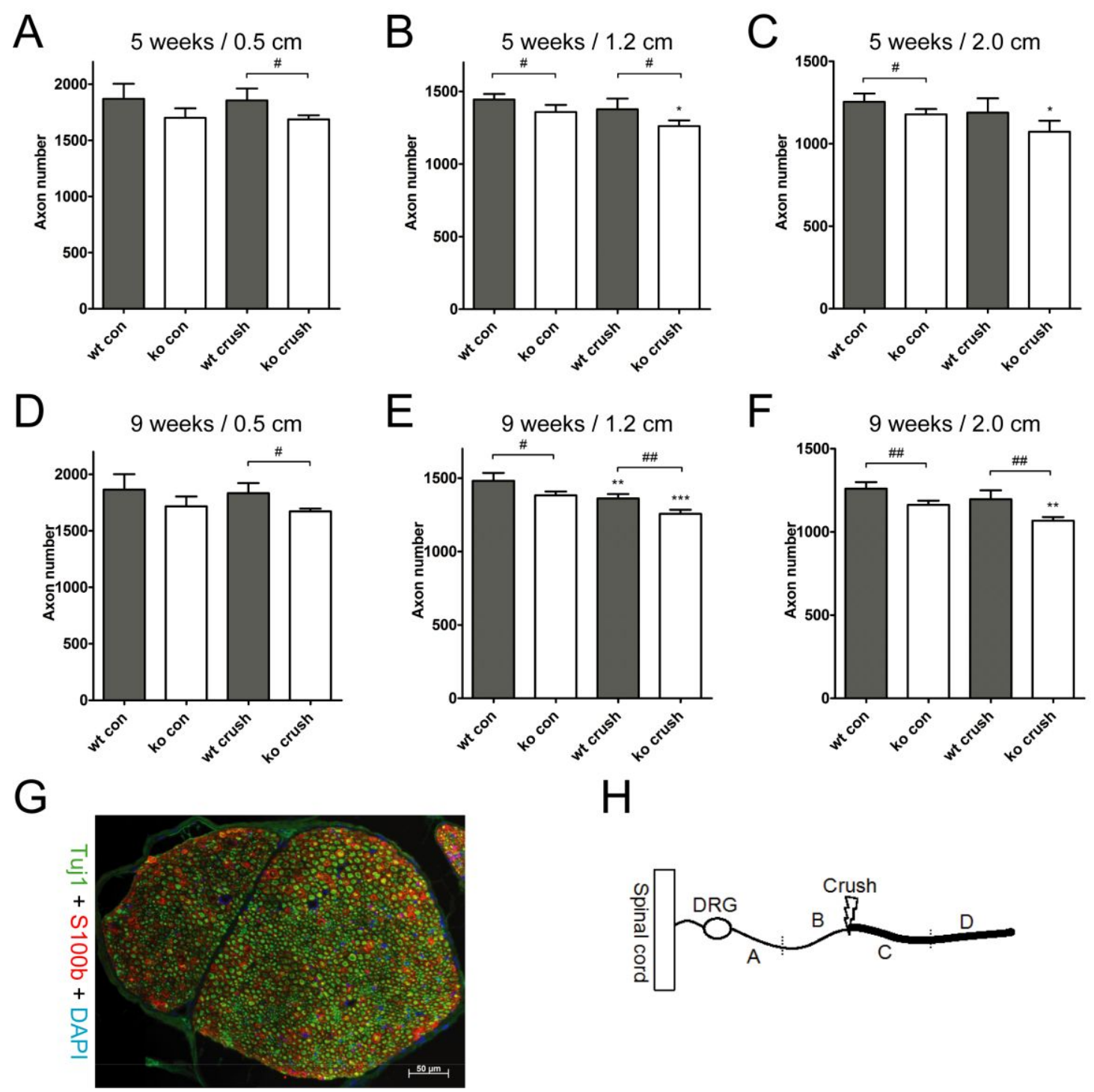

Fig 3.12 Axon quantification of tibial nerve from WT and GDF-15 KO animals at 5 
and 9 weeks after SN crush. Total axon numbers are shown at 5 weeks after crush in tibial nerve at $0.5 \mathrm{~cm}(A), 1.2 \mathrm{~cm}(B), 2.0 \mathrm{~cm}(C)$ distal to lesion $(n=4)$. Total axon numbers are shown at 9 weeks after crush in tibial nerve at $0.5 \mathrm{~cm}(D), 1.2 \mathrm{~cm}(\mathrm{E}), 2.0 \mathrm{~cm}(\mathrm{~F})$ distal to lesion ( $n=4)$. (G) Representative photograph of tibial nerve (Tuj1: green channel; S100ß: red channel; DAPI: blue channel). $(\mathrm{H})$ Schematic diagrams of lesion and tested tissue. Data are presented as mean \pm SD. P-values were calculated by unpaired t-test, ${ }^{*} p<0.05$, ${ }^{* *} p<0.01,{ }^{* * *} p<0.001 ; \# p<0.05, \# \# p<0.01$

\subsubsection{Regenerating axon diameter distribution in WT and GDF-15 KO animals}

For regeneration, efficiency, speed and maturation/diameter of the regrowing axon are all essential. Conduction velocity is correlated to the axon diameter (Kriz et al., 2000; Waxman, 1980). To determine the axon size distribution, an identical experiment as described in Chapter 3.3.5. was performed, but axon numbers were recorded and subdivided in three groups: axon diameter larger than $5 \mu \mathrm{m}$; diameter between 2 and $5 \mu \mathrm{m}$; diameter less than $2 \mu \mathrm{m}$. Two time points were analyzed, at 5 (Fig 3.13) and 9 weeks after injury (Fig 3.14). In Fig 3.13 A, E, I show overall diameter distribution: under control conditions, middle-sized $(2 \sim 5 \mu \mathrm{m})$ axons constituted the majority of axons, but after lesion, small-sized (less than $2 \mu \mathrm{m}$ ) axons formed a larger portion in the most distal part while middle-sized axons still predominated in the nerve portion close to the lesion. This may be due to the maturation process, which starts from the proximal nerve portion. Although a tendency was noted that WT nerves had more regenerating axons in all groups than $\mathrm{KO}$, only the small diameter regrown axons $0.5 \mathrm{~cm}$ away from the lesion showed statistical significance (Fig $3.13 \mathrm{D})$. 


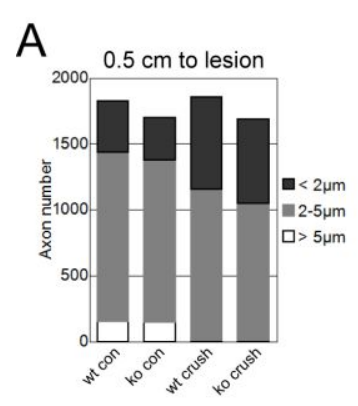

$\mathrm{E}$
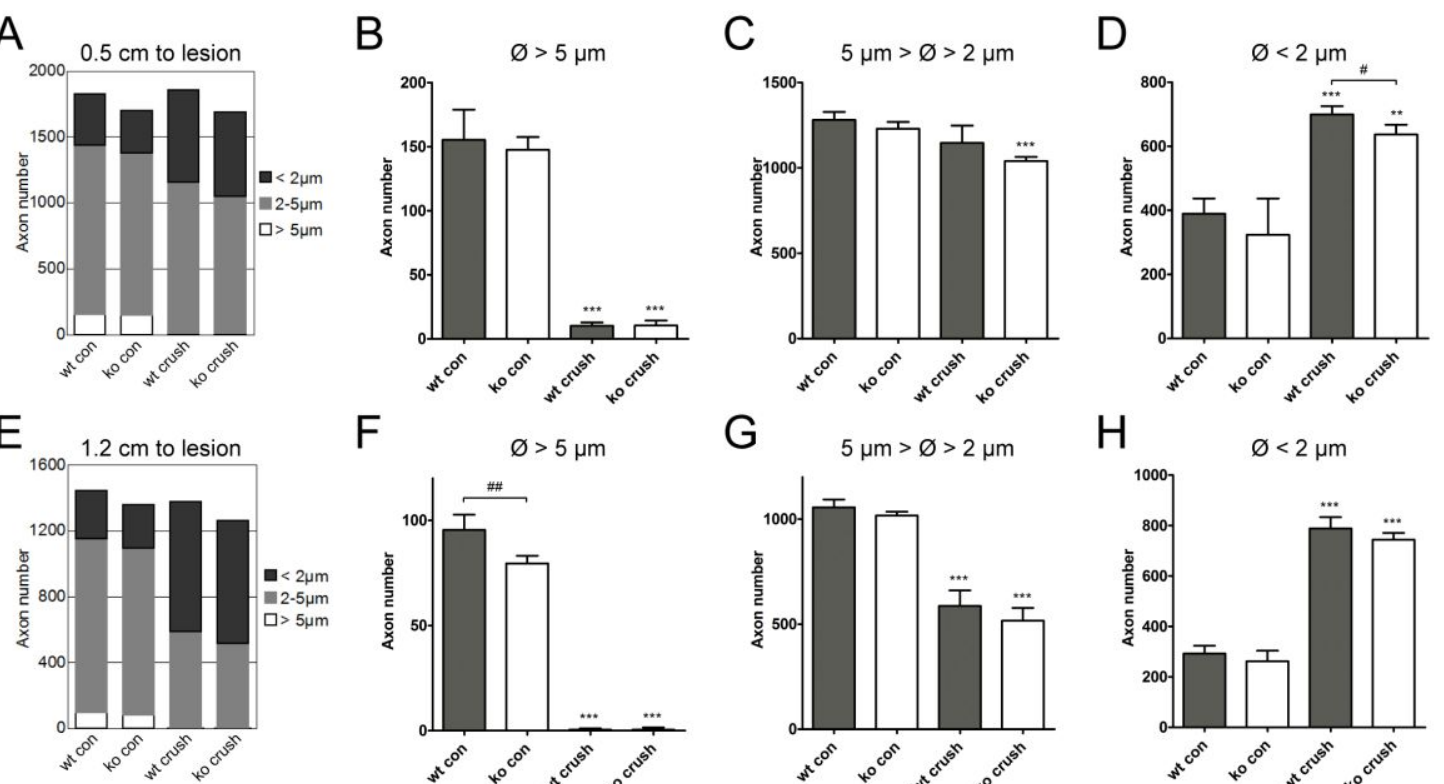

$\mathrm{F}$

G

$\mathrm{H}$
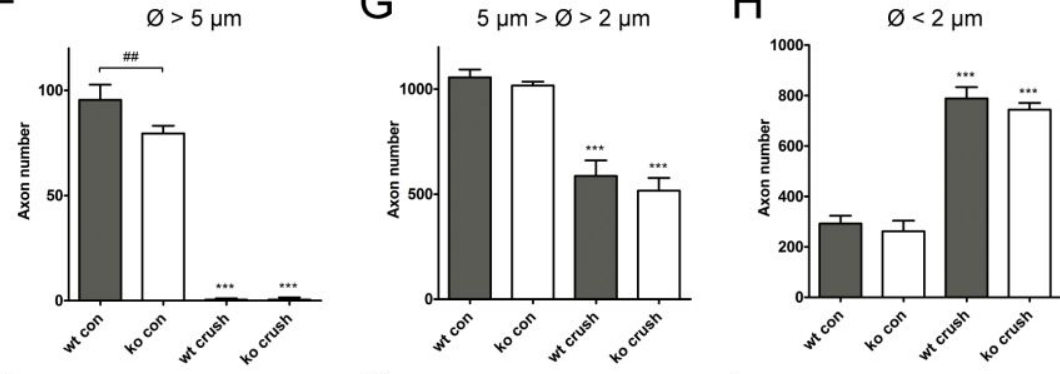

I
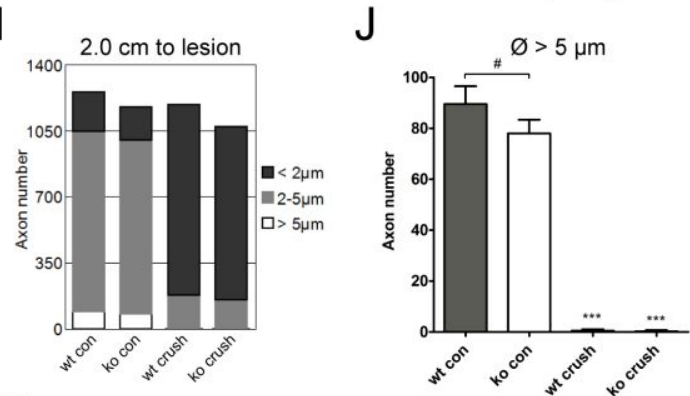

$\mathrm{K}$
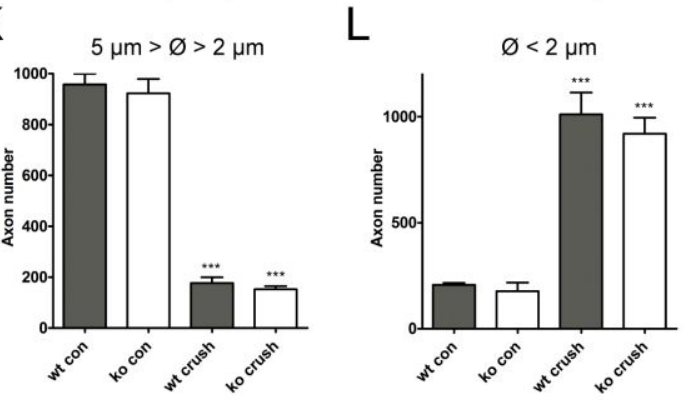

$\mathrm{M}$

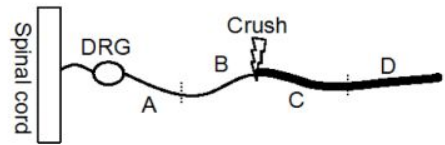

Fig 3.13 Tibial nerve axon diameter distribution in WT and GDF-15 KO animals 5 weeks after $\mathbf{S N}$ crush. (A-D) Tibial nerve axon diameter distribution at $0.5 \mathrm{~cm}$ distal to lesion $(n=4) .(E-H)$ Tibial nerve axon diameter distribution at $1.2 \mathrm{~cm}$ distal to lesion $(n=4)$. (I-L) Tibial nerve axon diameter distribution at $2.0 \mathrm{~cm}$ distal to lesion $(n=4)$. (M) Schematic diagrams of lesion and tested tissue. Data are shown as mean $\pm \mathrm{SD}$. P-values were calculated by unpaired t-test, ${ }^{* *} p<0.01,{ }^{* * *} p<0.001 ; \# p<0.05, \# \#<0.01$.

9 weeks after lesion, the axon size distribution was quite similar to that of 5 weeks (Fig 3.14). Of particular interest was that the middle-sized regrown axons (grey bar) at 9 weeks occupied a slightly larger portion compared to 5 weeks (Fig 3.13 A E I vs Fig 3.14 A E I), suggesting an improved maturation at a later time point. Another finding was that 9 weeks after lesion, in all three locations, WT displayed more middle-sized axons than the KOs (Table 3.1). As axons thicker than $2 \mu \mathrm{m}$ were mostly myelinated, this category could be the main contributor to improved impulse conduction (see physiological tests, 
below).
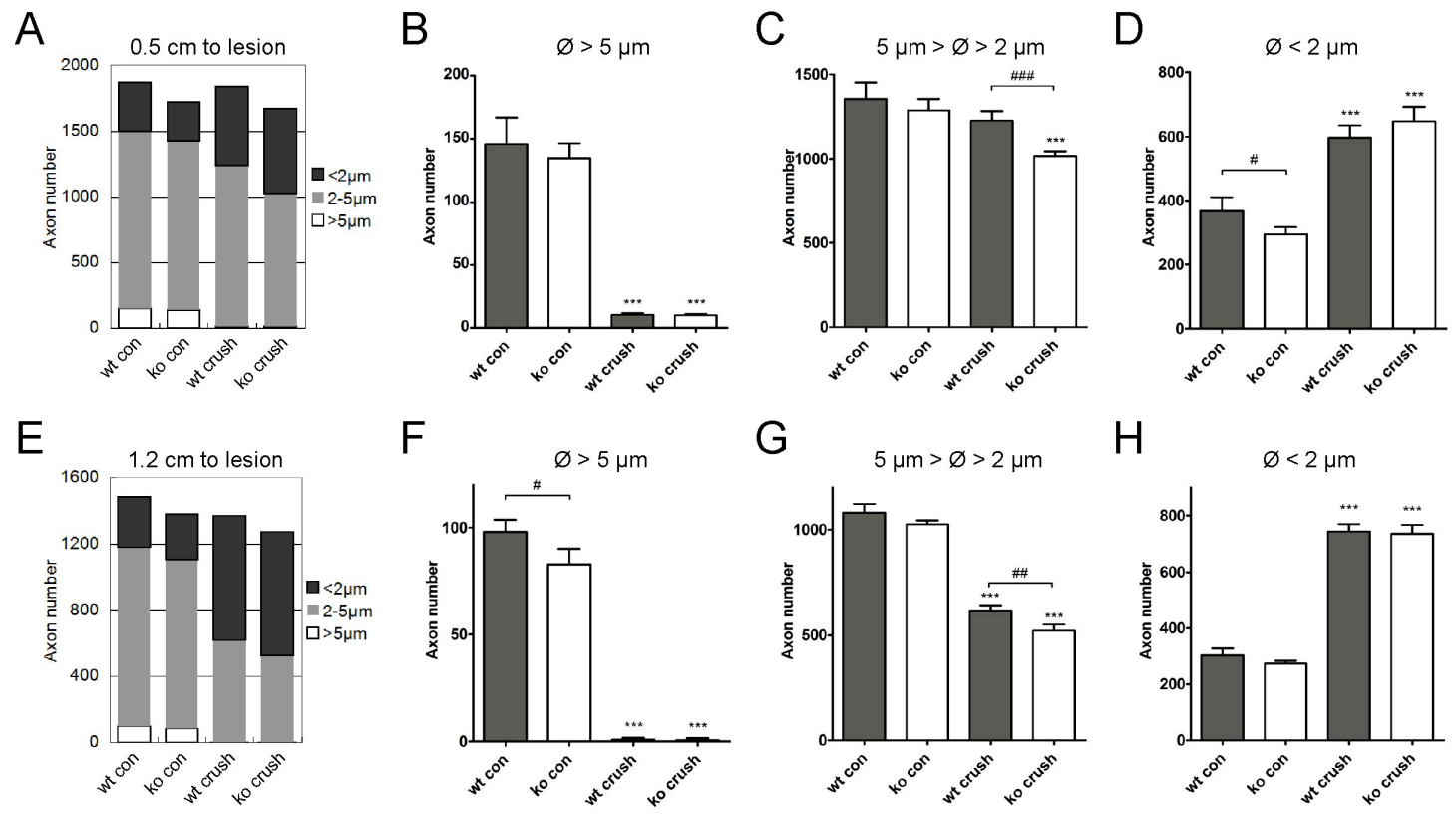

$\mathrm{H}$
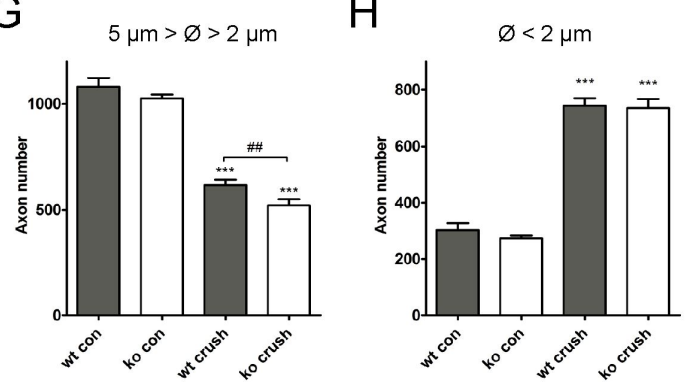

I

$\mathrm{J}$

K
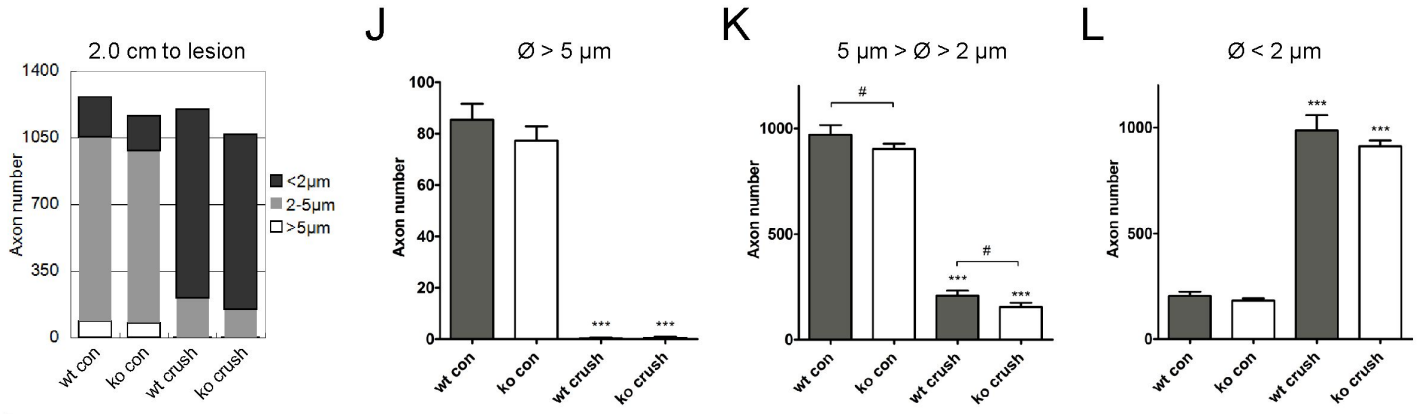

M

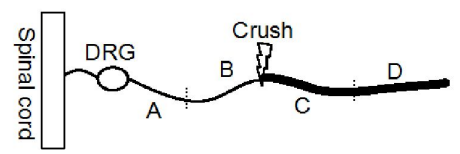

Fig 3.14 Tibial nerve axon diameter distribution in WT and GDF-15 KO animals 9 weeks after $\mathbf{S N}$ crush. (A-D) Tibial nerve axon diameter distribution at $0.5 \mathrm{~cm}$ distal to lesion $(n=4)$. $(E-H)$ Tibial nerve axon diameter distribution at $1.2 \mathrm{~cm}$ distal to lesion $(n=4)$. (I-L) Tibial nerve axon diameter distribution at $2.0 \mathrm{~cm}$ distal to lesion $(n=4)$. (M) Schematic diagram of lesion and tested tissue. Data are shown as mean \pm SD. P-values were calculated by unpaired t-test, ${ }^{* * *} p<0.001 ; \# p<0.05, \# \# p<0.01, \# \# p<0.001$. 
Table 3.1: Percentage of middle size axon $(2 \sim 5 \mu \mathrm{m})$ in WT and KO crushed nerve, 9 weeks after lesion.

\begin{tabular}{|l|l|l|l|}
\hline \multirow{2}{*}{$\begin{array}{l}\text { Percentage of } 2 \sim 5 \\
\text { um axon }\end{array}$} & \multicolumn{3}{|c|}{ Distance to crush site } \\
\cline { 2 - 4 } WT lesion & $0.5 \mathrm{~cm}$ & $1.2 \mathrm{~cm}$ & $2.0 \mathrm{~cm}$ \\
\hline KO lesion & $66.92 \% \pm 0.64 \%$ & $45.31 \% \pm 1.55 \%$ & $17.57 \% \pm 2.60 \%$ \\
\hline WT vs KO & $60.74 \% \pm 2.26 \%$ & $41.44 \% \pm 2.15 \%$ & $14.60 \% \pm 1.83 \%$ \\
\hline
\end{tabular}

$n=4$. Data are shown as mean \pm SD. P-values were calculated by unpaired t-test, ${ }^{*} p<0.05$; ${ }^{* *} p<0.01 ; n s=$ not significant.

In summary, at molecular levels, GDF-15 KO animals showed higher expression of axon regeneration related genes, inflammatory genes, and a tendency towards more macrophage recruitment, but no indication of increased fibroblast and SC activation. On a morphological level, the myelin sheath of regrown axons was similar in the 2 genotypes (g-ratio), while at 9 week after crush, WT showed significantly more middle-sized $(2 \sim 5 \mu \mathrm{m})$ regrown axons than the $\mathrm{KO}$ animals.

\subsection{Functional recovery in WT and GDF-15 KO animals after SN crush lesion}

The above morphological and molecular investigations were supplemented by electrophysiological studies. To determine the functional outcome of axon regeneration in WT and KO animals, electromyography (EMG) was performed at 5 and 9 weeks after SN crush. EMG provided information on velocity and strength of impulse conduction from nerve to muscle (Pattichis et al., 1999). 5 weeks after crush, both WT and KO showed a significant reduction of conduction velocity (CV) (Fig 3.15 A). Nevertheless, the amplitude was significantly decreased when comparing the control side to crush lesion side (Fig 3.15 C). However, there were no significant differences between WT control vs KO control or WT lesion vs KO lesion sides. 9 weeks after lesion, both $\mathrm{CV}$ and amplitude patterns resembled the 5 weeks pattern, with 
significant changes between control and lesion sides, but not between WT and KO (Fig 3.15 B D).

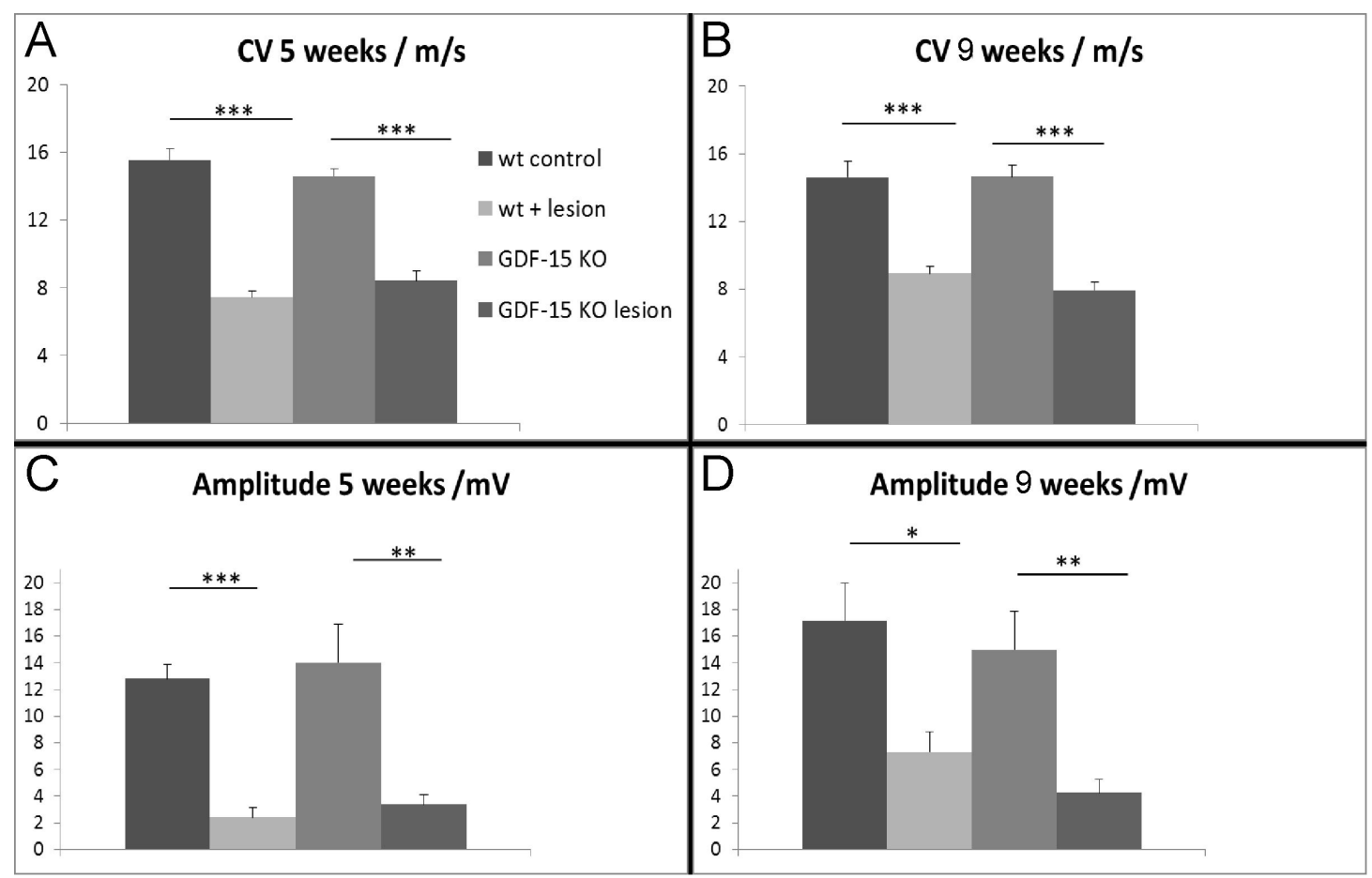

Fig 3.15 Electromyography analysis of WT and GDF-15 KO animals after sciatic nerve crush lesion. Conduction velocity recovery from sciatic nerve to musculus digitorum brevis was shown at 5 weeks after $S N$ crush $(A)(n=6)$, and 9 weeks after $S N$ crush $(B)(n=6)$. Amplitude changes were shown at 5 weeks after $S N$ crush $(C)(n=6)$, and 9 weeks after $S N$ crush $(D)(n=6)$. Data are shown as mean \pm SEM. P-values were calculated by unpaired t-test, ${ }^{*} p<0.05,{ }^{* *} p<0.01,{ }^{* * *} p<0.001$.

Interestingly, when comparing data between 5 and 9 weeks post-injury, a significant difference in the lesioned WT EMG was observed, in contrast to the lesioned GDF-15 KO EMG, where no significant differences were detected (Table 3.1). In the lesioned WT, the CV was increased after 9 weeks by $20 \%$ (p $<0.05)$ and the amplitude was increased by $204 \%(p<0.05)$. In the lesioned GDF-15 KO, the CV was decreased by $6 \%$ and the amplitude was increased by $27 \%$, but no statistical differences between the two time points were observed. The difference in functional recovery might result from the better maturation of regenerated axons in WT (Fig 3.14 C G K), which contributed to better impulse conduction. 
Results

Table 3.2: Comparison of conduction velocity (CV) and amplitude at 5 and 9 weeks of lesioned WT and GDF-15 KO mice (unpaired t-test, ${ }^{*} p<0.05$ ).

\begin{tabular}{|l|l|l|}
\hline $5 \rightarrow 9$ weeks & wt lesion & GDF-15 KO lesion \\
\hline CV & $+20 \%$ * & $-6 \%$ \\
\hline Amplitude & $+204 \%$ * & $+27 \%$ \\
\hline
\end{tabular}

In summary, at an early time point after lesion (5 weeks), there was no significant discrepancy between WT and KO animals in terms of conduction velocity and amplitude. However, at 9 weeks the WT displayed more robust functional recovery compared to $\mathrm{KO}$. 


\section{Discussion}

\subsection{GDF-15 expression pattern}

GDF-15 is expressed ubiquitously in animal organs and tissues, as described previously, including the nervous system (Böttner et al., 1999; Charalambous et al., 2013; Strelau et al., 2009; Strelau et al., 2000). Here we have shown the mRNA level of GDF-15 in DRG to be slightly upregulated at 3 and 7 days after $\mathrm{SN}$ crush and transection lesion (Fig 3.1 A B). However, the protein levels do not follow the same pattern (Fig 3.1 C D), possibly resulting from the mild change in transcriptional levels. In the brain, GDF-15 is highly expressed predominantly by the neurons in both cortex cryolesion and cerebral ischemia models, but also expressed by a small proportion of microglial cells (Schindowski et al., 2011; Schober et al., 2001). Another study on optic nerve showed that GDF-15 is mainly expressed in retinal ganglion cells and neurons in the inner nuclear layer after optic nerve crush (Charalambous et al., 2013). It remains unclear which type of cell is the main source for GDF-15 in DRG after sciatic nerve lesion. As active macrophages have a notion of being producers of GDF-15 (Böttner et al., 1999; de Jager et al., 2011), and macrophages infiltrate the DRG after lesioning, macrophages might be a source of GDF-15 after lesion (Hu and McLachlan, 2003; Vega-Avelaira et al., 2009). However, satellite glia cells and DRG neurons should also be considered as production sites of GDF-15.

A previous article points out that GDF-15 is expressed by SCs (Strelau et al., 2009), which could help to interpret our findings in the SN lesion models. After $\mathrm{SN}$ lesion, the distal nerve undergoes Wallerian degeneration, myelin sheaths break down, SCs become dedifferentiated, proliferate and enter a "debris removing" phase. This active stage starts within $24 \mathrm{~h}$; SCs proliferation peaks at $3 \sim 7$ days, can last until they contact the regrowing axons, and finally triples 
SC cell numbers (Griffin and Thompson, 2008; Navarro et al., 2007). In addition to proliferation, SCs also gain phagocytic ability when being stimulated by myelin break down products, such as lysophosphotidylcholine (LPS). Thus, SCs may be considered to be the major executor of phagocytosis, before macrophage invasion occurs on a large scale (Ousman and David, 2000).

Macrophages also play an important role in cleaning up the debris from degradation of axon and myelin. Circulating macrophages infiltrate the lesion and distal nerve, together with the proliferating local resident macrophages, starting phagocytosis no later than day 2 , and reaching their peaks at day $4 \sim 7$ (Rosenberg et al., 2012; Stoll and Muller, 1999; Tofaris et al., 2002). The increasing activation of SCs and macrophages could explain the gradual upregulation of GDF-15 in lesioned $\mathrm{SN}$, as numerical increase and phagocytotic activity of both cell types match the growth curve of GDF-15 (Fig $3.2,3.3)$. At the late time points $(14,28$ days, Fig 3.2 B C), the SN crush model shows a downregulation of GDF-15, which could be a consequence of the renewed contact of axon and SCs. At a speed of 1 3 mm per day, regenerating axons reach the distal stump and re-contact the dedifferentiated SCs. The latter then re-enter the myelinating phase (Arthur-Farraj et al., 2012; Giger et al., 2010; Napoli et al., 2012; Navarro et al., 2007). However, in the $\mathrm{SN}$ transection model, due to the ligation of the nerve stumps, the contact of axons and dedifferentiated SCs is forbidden, thus the SCs remain active, and the GDF-15 expression stays at a relative high level after 7 days (Fig 3.3 B C).

\subsection{GDF-15 and DRG neuron survival}

Lesion in SN could lead to DRG neuron death. Depending on the distance between lesion and cell body and the type of injury, the percentage of cell death varies, from $5 \sim 30 \%$ in distal crush lesion to $\sim 50 \%$ in a more proximal 
transection model (Groves et al., 1999; Shi et al., 2001; Tandrup et al., 2000). A couple of transcription factors, as well as survival/death mediators orchestrate for the final outcome. Neurotrophic factors including NT-3, BDNF, and NGF are known to promote cell survival and induce axonal regrowth, via a precisely controlled activation of $\mathrm{PI} 3 \mathrm{~K}$ at the frontier of the proximal axon, and inactivation of GSK-3 $\beta$ (Chen et al., 2007). c-Jun in the DRG neurons is among the most important factors in the context of promoting survival, and is also one of the first responding genes after peripheral nerve lesion (Kenney and Kocsis, 1998). Lesion induces local activation and retrograde transport of several MAPKs, e.g. Erk, JNK, protein kinase G (Hanz et al., 2003; Lindwall and Kanje, 2005; Perlson et al., 2005; Sung et al., 2006). JNK then phosphorylates C-Jun, and the latter transcriptionally switches on/promotes the expression of trophic factors and survival mediators, such as Integrin $\alpha 7 \beta 1$, CD44, Galanin, NPY (Frey et al., 2000; Hirata et al., 2002; Lindwall et al., 2004; Raivich et al., 2004; Son et al., 2007).

A recent study demonstrated that the survival mechanisms in c-Jun null DRG are impaired, leading to extensive cell death after SN crush (Arthur-Farraj et al., 2012). Galanin, a neuropeptide with a protective and pro-regeneration function, is controlled by c-Jun, and has three G-protein coupled receptors, GALR1, GALR2, and GALR3, among which, GALR2 is believed to mediate the sensory neuron survival and regeneration (Burazin and Gundlach, 1998; Webling et al., 2012; Xu et al., 2012). After axotomy of SN, Galanin-expressing DRG neuron counts go up to $40 \sim 50 \%$ of all DRG neurons, compared with $2 \sim 3 \%$ in unlesioned DRG. Deletion of Galanin results in a reduction of peripheral nerve regeneration and long-term functional deficiency (Holmes et al., 2000; Wynick et al., 2001).

Bad is a pro-apoptotic member in the Bcl-2 family, it can be rapidly phosphorylated by serine-threonine kinases in non-apoptotic conditions. 
Phospho-Bad then binds to 14-3-3, instead of binding to $\mathrm{Bcl}-\mathrm{xL}$ and $\mathrm{Bcl}-2$. The free $\mathrm{Bcl}-\mathrm{xL}$ and $\mathrm{Bcl}-2$ can then inhibit cytochrome $\mathrm{C}$ release and therefore inhibits the activation of the caspase cascade (Fang et al., 1999; Springer et al., 2000).

As described in previous paper, GDF-15 KO mice undergo a progressive postnatal reduction in DRG neuron numbers resulting in the loss of $\sim 20 \%$ neurons between P90 and P180. GDF-15 in cell culture media can promote the survival of cultured neurons (Strelau et al., 2009). Thus, GDF-15 seems to be connected to neuron survival. However, GDF-15 knock out animals failed to show a significant difference to WT animals with regard to selected survival/death molecules, including c-Jun and Caspase 8 (Fig 3.5 A B). Phospho-Bad expression differs between genotypes (Fig 3.5 E). Expression of p-Bad in unlesioned KO DRG, in contrast to WT, may suggest that endogenous GDF-15 suppresses p-BAD. However, after injury, the KOs and WTs have a similar $p-B A D$ immunoreactivity suggesting involvement of other regulatory mechanisms.

GDF-15 KO mice have higher expression levels of Galanin than WT mice (Fig $3.5 \mathrm{C}$ ), further supporting the notion that GDF-15 is a physiological regulator of Galanin (Charalambous et al., 2013). Given that Galanin is a potent neurotrophic molecule, it was surprising that no survival rate difference could be seen in the DRG neuron quantifications between genotypes (Fig 3.6). Although its receptors have been identified, the Galanin-mediated neuronal protective pathway is largely unknown. Especially the downstream effectors are not known. It could be speculated that some still unidentified molecule(s) neutralize(s) the downstream function of Galanin. As a summary to this part of the discussion, endogenous GDF-15, despite the observed alterations in Galanin and phospho-Bad, does not play a role in lesion-associated DRG neuron survival. 


\subsection{GDF-15 and $\mathrm{SN}$ regeneration}

\subsubsection{GDF-15 and axon myelination/remyelination}

GDF-15 KO mice have a hypermyelination phenotype, and have higher expression levels of myelin-related genes, e.g. P0, MBP (Strelau et al., unpublished data). Zinc finger transcription factor Krox-20 is known to be a key positive regulator of myelin related genes, which drives the myelination program and maintains the myelin sheath in a physiological condition (Topilko et al., 1994; Zorick et al., 1996). In case of nerve lesions, negative regulators, such as c-Jun and Pax-3, are upregulated, while Krox-20 is downregulated to suppress myelination. SCs enter the dedifferentiation phase for phagocytosis (Jessen and Mirsky, 2008; Kioussi et al., 1995; Parkinson et al., 2008; Pham et al., 2009). Krox-20 is re-expressed again, when the regenerating axons enter the distal stump and establish contact with local SCs for remyelination (LeBlanc and Poduslo, 1990; Zorick et al., 1996). In the present study, I could show that in unlesioned GDF-15 KO mice the background level of Krox-20 is higher than it in WT mice (Fig 3.7 A). Possibly, this might explain the hypermyelination phenotype, making GDF-15 a key regulator of Krox-20.

After lesionings, the myelin sheath breaks down and the debris is phagocytosed by active (dedifferentiated) SCs and macrophages. Active SCs form the Bands of Büngner guide the axons. When regenerating axons contact SCs, SCs wrap the axon and start the remyelination process (Navarro et al., 2007; Stoll and Muller, 1999). NF-KB is a multiple-function transcription factor, which participates in neuroinflammation, neural plasticity, cell survival and apoptosis (Pollock et al., 2005). Through TNFR1, NF-kB is activated by TNF- $\alpha$, leading to a pro-inflammatory process. NF-KB is a key modulator of Wallerian degeneration for successful axon regeneration (Smith et al., 2009). Furthermore, inhibition of NF-kB activation results in a delayed sensory axon bundle formation and delayed compact remyelination (Morton et al., 2012). In 
our study, the analysis of Krox-20 and NF-KB was terminated at 7 days after lesion, which leaves the role of these genes at later time points open.

Analysis of the g-ratio at 28 day after crush lesion did not reveal obvious differences between the two genotypes studied. We could speculate that at day 28 , the Krox-20 levels in both genotypes may be still comparable to each other, since myelin sheath thickness is similar. Considering that remyelination after lesion might be a longer process, perhaps at an even later time points, the small discrepancy in myelin thickness between the genotypes might become re-established.

\subsubsection{GDF-15 and Schwann cells/fibroblasts/macrophages}

Fibroblasts are another player during nerve regeneration. They accumulate at the lesion site, mediate SC sorting via ephrin-B/EphB2 signaling and Sox2, $\mathrm{N}$-cadherin relocalization, finally orchestrate SC migration and formation of Bands of Büngner, and eventually guide the regrowing axon (Parrinello et al., 2010). In our study, markers such as Fibronectin, a-SMA were determined as a measure of fibroblast activity (Kalluri and Zeisberg, 2006; Parrinello et al., 2010). However, we did not detect differences between GDF-15 KO and WT littermates (Fig 3.10 A B C). It is not clear whether fibroblasts are a source of GDF-15, but apparently their phenotype is not prominently affected in the GDF-15 gene knock out.

SCs are main players during the PNS lesion and regeneration (Chen et al., 2007; Navarro et al., 2007; Stoll and Muller, 1999). Immediately after lesion, they exhibit an early response, including alterations in calcium fluxes. cAMP conducts the injury signal via ERK/MAPK, JNK/c-Jun, Notch, JAK-STAT to the nucleus for transcriptional remodulation (Newbern and Snider, 2012). Increased cAMP levels trigger PKA, which activates CREB and downstream 
genes such as Arginase 1 (Cai et al., 2002; Gao et al., 2004). cAMP also promotes immune regulators such as IL-6 via the STAT3 pathway, which further leads to expression of GAP-43, promoting axon regrowth.

c-Jun is a central molecule in the orchestration of axon regeneration (Blom et al., 2014; Ishii et al., 2013; McDonald et al., 2006; Monje et al., 2010; Parkinson et al., 2004; Yang et al., 2012). The activation of c-Jun inhibits Krox-20, thereby suppressing myelination. c-Jun also promotes the level of transcription factor $\mathrm{SHH}$, trophic factors such as GDNF and BDNF, cell surface molecules such as NCAM, N-cadherin, and the neurotrophin receptor $p 75^{\mathrm{NTR}}$ (Ahmad et al., 2014; Arthur-Farraj et al., 2012; Coulson et al., 2000; Coulson et al., 1999; Fontana et al., 2012; Hashimoto et al., 2008; Jiang et al., 2005; Klein et al., 2014; Parkinson et al., 2008; Pham et al., 2009; Shy et al., 1996; Topilko et al., 1997; Topilko et al., 1994). SCs are then entering a unique active stage normally named dedifferentiation. As markers for the active SCs, the SHH and Olig1 levels were not significantly changed when comparing GDF-15 KO to WT (Fig 3.10 D E). This suggests that the activation of Schwann cells in the lesion condition is not markedly influenced by GDF-15. However, the proliferation and phagocytosis of SCs, two additional aspects of SC activity, were not analyzed in the present study.

SCs are one of the first cells to react to the injury, they detect the axon degradation products via Toll-like receptors (TLR2/3/4) and MyD88 signaling (Boivin et al., 2007; Karanth et al., 2006; Lee et al., 2006), and switch on the expression of pro-inflammatory cytokines including IL-1 $\beta, I L-1 \alpha, M C P-1$ and TNF- $\alpha$ within hours after lesion, followed by the expression of IL-6 and IL-10 (Bolin et al., 1995; Perrin et al., 2005; Reichert et al., 1996; Saada et al., 1996; Shamash et al., 2002; Taskinen et al., 2000). Fibroblasts in the lesion site also secret GM-CSF, which promotes the expression of MAC-2 for the attraction of phagocytosing macrophages (Saada et al., 1996). The degraded lipid 
components in the myelin sheath and axon membrane need to be recycled, thus apolipoproteins are upregulated for binding of lipids. ApoD is mainly expressed by fibroblasts while ApoE is generated by invading macrophages (Spreyer et al., 1990; Stoll and Muller, 1986b). Schwann cell-derived MCP-1, $\mathrm{IL}-1 \beta$ and MIP-1 $\alpha$ contribute to the macrophage recruitment, as neutralizing these factors leads to a severe reduction of phagocytic macrophages (Perrin et al., 2005). MAC-1 and MAC-2 are also crucial for the myelin phagocytosis by macrophages and SCs (Makranz et al., 2004; Makranz et al., 2006; Saada et al., 1996). In the present study, I observed that MAC-2, IL-1 $\beta$ and IL-6 are significantly higher expressed in GDF-15 KO nerve, furthermore, MCP-1 levels in the $\mathrm{KO}$ also showed a trend to surpass its expression in WT (Fig 3.7 B, Fig 3.8 A B C). These observations possibly indicate stronger macrophage recruitment in the $\mathrm{KO}$ animals. This was in part supported by the mRNA analysis and staining of macrophages marker CD11b and F4/80 (Fig 3.9) (Murray and Wynn, 2011).

A previous publication on an atherosclerosis model had shown that GDF-15 deficiency impairs the expression of CCR2, attenuates MCP-1 mediated macrophage migration, and as a consequence, leads to reduced macrophage recruitment (de Jager et al., 2011). Interestingly, another study on the polymorphonuclear leukocytes (PMNs) demonstrates an increased PMNs recruitment into the infracted myocardium in GDF-15 deficient animals (Kempf et al., 2011). This phenotype may result from the activation of small GTPase Cdc42 and inhibition of the small GTPase Rap1, which leads to the conformation and clustering change of $\beta_{2}$ integrin (Kempf et al., 2011). The results are contradictory concerning the immunocell response to GDF-15, however, the underlying mechanism for macrophages and PMNs must not be the same. A further question concerning macrophages has not been answered in my study, namely whether the excess macrophages in GDF-15 animals are a consequence of reinforced recruitment or proliferation. 
Controlled SN lesion is a type of "sterile inflammation", as there is no pathogen to be removed by macrophages; instead, a more predominant task for macrophages is to restructure the damaged tissue. Pro-inflammatory cytokines recruiting macrophage are necessary, but the magnitude of inflammation needs to be carefully limited by negative feedback loops, or switched to a T helper 2 cytokines, such as IL-4 and IL-13, mediated pathway, preventing excessive tissue damage (Gordon and Martinez, 2010; Murray and Wynn, 2011). Classical activation of macrophages (M1) is triggered by interferon- $y$ (IFNy) and TNF, leading to an enhanced anti-microbe and anti-tumor activity, as well as reinforced pro-inflammatory cytokine secretion of, e.g. IL-1, IL-6 (O'Shea and Murray, 2008). On the other hand, IL-4 and IL-13 are the most important cytokines to mediate an alternative activation pathway (Gordon and Martinez, 2010). Fizz1 and Arginase 1 (Arg 1) have been shown to decrease the magnitude of inflammation and be beneficial for tissue healing (Herbert et al., 2010; Sutherland et al., 2009). Although the secondary pathway is still not fully clarified, several studies demonstrate that the T help 2 cytokine pathway (alternative activation of macrophage, M2 pathway) promotes nerve regeneration (Kigerl et al., 2009; Pannu et al., 2005; Ydens et al., 2012). Our results possibly suggest a higher degree of alternative activation of macrophages in GDF-15 KO animals, as they expressed higher levels of Arg 1 and Ym1 (Fig 3.8 D F), which are signature molecules for the M2 pathway (Gordon and Martinez, 2010; Murray and Wynn, 2011). A recent study showed that in the M2 pathway macrophages undergo massive local proliferation, rather than infiltration from the circulation (Jenkins et al., 2011). This might also be applicable to the sciatic nerve lesion issue (Jenkins et al., 2011; Ydens et al., 2012) (Fig 3.9).

\subsubsection{GDF-15 and regenerated axons}

The relation between $\mathrm{SN}$ lesion and neuron death has been investigated for 
many years, and several factors, including age, severity of injury and distance of injury to the cell body are believed to influence the neuron fate (Navarro et al., 2007). In general, the percentage of DRG sensory neuron death varies between 5 and $30 \%$, and the death rate of motoneurons amounts to $0 \sim 10 \%$ (Arvidsson et al., 1986; Groves et al., 2003; Lowrie et al., 1994; Tandrup et al., 2000; Valero-Cabre et al., 2001; Vanden et al., 1993; Vestergaard et al., 1997). As graphed in Fig 3.12, there is a difference in axon number in control conditions between GDF-15 KO and WT, which can be interpreted as resulting from the progressive postnatal neuron loss (up to $20 \%$ ) in the $\mathrm{KO}$ animals (Strelau et al., 2009). Interestingly, at 5 weeks or 9 weeks after crush lesion, the difference in axon number between $\mathrm{KO}$ and WT remains, which demonstrates there is no additional neuron loss after crush lesion; thus, GDF-15 deficiency does not change the neuron fate after lesion. Nevertheless, the measurement of axon number in different loci distal to the lesion site shows that the axonal regrowth velocity towards the distal nerve part is similar in both genotypes (Fig 3.12).

Regenerated axons, however, normally have a small diameter, which is a consequence of downregulation and reduced transport of neurofilament proteins (Fawcett and Keynes, 1990; Fenrich and Gordon, 2004). Nevertheless, upregulation of tubulin and actin permits a relatively high speed of neurite outgrowth, but in turn, further reduce the axonal caliber (Gordon et al., 1991; Tetzlaff et al., 1991; Tetzlaff et al., 1996). At late time points of regeneration, myelination of newly formed axons could induce the phosphorylation of neurofilament $\mathrm{M}$ and $\mathrm{H}$, which leads to a larger interfilament space and finally an increase in axonal diameter (Hisanaga and Hirokawa, 1989; Hoffman et al., 1987; Kriz et al., 2000). In the present study I could show that at a late time point (9 weeks post lesion), WT nerves contain a larger proportion of mid-caliber $(2 \sim 5 \mu \mathrm{m})$ axons than $\mathrm{KO}$ nerves, as well as a lower proportion of small caliber (smaller than $2 \mu \mathrm{m}$ ) axons than $\mathrm{KO}$ nerves (Fig 3.13, 
3.14, Table 3.1). The axon size distribution result is also supported by the electromyography study, which shows from 5 weeks post lesion to 9 weeks post lesion, that there is significant improvement in terms of conduction velocity and amplitude in WT animals, with magnitude of $+20 \%$ and $+204 \%$, respectively. On the contrary, the change in $\mathrm{KO}$ animals is only $-6 \%$ and $+27 \%$ respectively (Table 3.2). This is a proof of better functional recovery in WT animals (Kriz et al., 2000). Our result is also supported by a previous study on a local substitution of GDF-15 in a sciatic nerve after gap lesion, where animals with exogenous GDF-15 applied into the nerve gap exhibited a lower density of myelinated axons and larger axon diameters, meaning that GDF-15 could promote the maturity of newly regenerated axons (Mensching et al., 2012). This could be the result of GDF-15-controlled production or phosphorylation of neurofilaments. However, this issue needs further investigation. 


\section{Conclusion}

In this study, I used GDF-15 KO mice as a model organism, and introduced SN crush or transection plus stump ligation to analyze the potential role of GDF-15 in peripheral nerve lesion and regeneration. I have found that GDF-15 does not finally alter the DRG neurons' fate after SN transection. GDF-15 expression in the distal nerve after lesion reaches the peak at 7 days post lesion, the putative source is very likely the activated macrophages and SCs. GDF-15 KO animals show a stronger expression of inflammatory modulators, M2 pathway markers and more macrophages in lesioned nerve. However, the activation of fibroblasts and SCs is not significantly changed between genotypes. The GDF-15 KO exhibits a higher level of Krox-20 in physiological (unlesioned) conditions, possibly accounting for the hypermyelination phenotype, but failed to obtain significant hypermyelination after axonal regeneration. Both $\mathrm{KO}$ and WT animals show a similar axon protruding speed, but WT animals exhibit better axon maturation after lesion, as they gain a larger axonal caliber. Thus the WT mice show a better improvement in the conduction velocity and signal amplitude in the electromyography test. 


\section{Acknowledgement:}

I would like to express my sincere appreciation to Prof. Dr. Klaus Unsicker, my supervisor in the Ph.D. project. I learnt a lot from him about how to do a research, from logic thinking to solving problem, from experiment planning to thesis writing. He is not only my teacher in scientific research, but also an elder taking care of my life in Freiburg.

I would like to sincerely thank Prof. Dr. Irmgard Merfort for giving me chance to be an external student in her laboratory, and a registered Ph.D. candidate in the Faculty of Pharmacy, University of Freiburg, and also for scientific support to the project.

I would like to sincerely thank Prof. Dr. Kerstin Krieglstein, for giving me permission to work in Institute of Anatomy and Cell Biology, University of Freiburg, and give me financial support in my hard time.

I would like to sincerely thank Prof. Hans-Werner Müller, Dr. Frank Bosse, and Dipl. Julia Krebbers for the animal surgery, as well as suggestions and performance of the electrophysiological experiments.

I would like to sincerely thank Frau. Sigrun Nestel and Frau. Barbara Joch for their help on the Electron microscopy.

I would like to express my appreciation to Dr. Petar Charalambous, Dr. Xiaolai Zhou, Dr. Stella Shtukmaster and Venissa Machado, who act as my brothers and sisters in the scientific field as well as in my daily life.

I would like to express my appreciation to Dr. Andreas Schober, Dr. Attila 
Magyar, Dr. Veronica La Padula, Dr. Xiaolai Zhou, Dr. Björn Spittau and Venissa Machado, M.Sc., for their technical support and scientific discussions in the project.

I warmly thank Frau. Ute Baur and Herr. Günter Frank for their kind technical help in my experiments.

I would also express my gratitude to Herr. Helmut Gerlach for the IT support and solving problems I met in my daily life.

Of course I am grateful to all the members in our department: Dr. Stella Shtukmaster, Dr. Amparo Tolosa, Dr. Ahmed Sharaf, Dr. Priyanka Anantha Narasimhan, Dr. Sopie Koszinowski, Dr. Katalin Zajzon, Dr. Oliver Öhlke, Dr. Jan Spear, Christian Bohrer, Sabrina Purr, Sagar, Riccardo Vezzali, Nicole Hellbach, Sebastian Schildge, Shalaka Wahane..... We experienced a great time together in Freiburg, we are a big family.

I am grateful for the China Scholarship Council (CSC) and Northwest Agriculture \& Forestry Universty, as they give me the chance to perform my Ph.D. study in Germany.

At last, I would like to show my great appreciation to my parents, my wife Lihui Yang, and all my family members in China for all types of help to support my study. I love you all forever.

Xiaolong Wang

November 2014

Freiburg, Germany 


\section{References:}

Abe, N., and Cavalli, V. (2008). Nerve injury signaling. Curr Opin Neurobiol 18, 276-283.

Ahmad, I., Yue, W.Y., Fernando, A., Clark, J.J., Woodson, E.A., and Hansen, M.R. (2014). p75NTR is highly expressed in vestibular schwannomas and promotes cell survival by activating nuclear transcription factor kappaB. Glia 62, 1699-1712.

Arora, M., Chen, L., Paglia, M., Gallagher, I., Allen, J.E., Vyas, Y.M., Ray, A., and Ray, P. (2006). Simvastatin promotes Th2-type responses through the induction of the chitinase family member Ym1 in dendritic cells. Proc Natl Acad Sci U S A 103, 7777-7782.

Arthur-Farraj, P.J., Latouche, M., Wilton, D.K., Quintes, S., Chabrol, E., Banerjee, A., Woodhoo, A., Jenkins, B., Rahman, M., and Turmaine, M., et al. (2012). c-Jun reprograms Schwann cells of injured nerves to generate a repair cell essential for regeneration. Neuron $75,633-647$.

Arvidsson, J., Ygge, J., and Grant, G. (1986). Cell loss in lumbar dorsal root ganglia and transganglionic degeneration after sciatic nerve resection in the rat. Brain Res 373 , 15-21.

Averill, S., Michael, G.J., Shortland, P.J., Leavesley, R.C., King, V.R., Bradbury, E.J., McMahon, S.B., and Priestley, J.V. (2004). NGF and GDNF ameliorate the increase in ATF3 expression which occurs in dorsal root ganglion cells in response to peripheral nerve injury. Eur J Neurosci 19, 1437-1445.

Baek, K.E., Yoon, S.R., Kim, J.T., Kim, K.S., Kang, S.H., Yang, Y., Lim, J.S., Choi, I., Nam, M.S., Yoon, M., and Lee, H.G. (2009). Upregulation and secretion of macrophage inhibitory cytokine-1 (MIC-1) in gastric cancers. Clin Chim Acta 401, 128-133.

Baek, S.J., Horowitz, J.M., and Eling, T.E. (2001). Molecular cloning and characterization of human nonsteroidal anti-inflammatory drug-activated gene promoter. Basal transcription is mediated by Sp1 and Sp3. J Biol Chem 276, 33384-33392.

Bendszus, M., and Stoll, G. (2003). Caught in the act: in vivo mapping of macrophage infiltration in nerve injury by magnetic resonance imaging. $J$ Neurosci 23 , 10892-10896.

Blanchard, A.D., Sinanan, A., Parmantier, E., Zwart, R., Broos, L., Meijer, D., Meier, C., Jessen, K.R., and Mirsky, R. (1996). Oct-6 (SCIP/Tst-1) is expressed in Schwann cell precursors, embryonic Schwann cells, and postnatal myelinating Schwann cells: comparison with Oct-1, Krox-20, and Pax-3. J Neurosci Res 46, 630-640.

Blom, C.L., Martensson, L.B., and Dahlin, L.B. (2014). Nerve injury-induced c-Jun activation in Schwann cells is JNK independent. Biomed Res Int 2014, 392971.

Boivin, A., Pineau, I., Barrette, B., Filali, M., Vallieres, N., Rivest, S., and Lacroix, S. 
(2007). Toll-like receptor signaling is critical for Wallerian degeneration and functional recovery after peripheral nerve injury. J Neurosci 27, 12565-12576.

Bolin, L.M., Verity, A.N., Silver, J.E., Shooter, E.M., and Abrams, J.S. (1995). Interleukin-6 production by Schwann cells and induction in sciatic nerve injury. J Neurochem 64 850-858.

Bonaterra, G.A., Zugel, S., Thogersen, J., Walter, S.A., Haberkorn, U., Strelau, J., and Kinscherf, R. (2012). Growth differentiation factor-15 deficiency inhibits atherosclerosis progression by regulating interleukin-6-dependent inflammatory response to vascular injury. J Am Heart Assoc 1, e2550.

Bootcov, M.R., Bauskin, A.R., Valenzuela, S.M., Moore, A.G., Bansal, M., He, X.Y., Zhang, H.P., Donnellan, M., Mahler, S., and Pryor, K., et al. (1997). MIC-1, a novel macrophage inhibitory cytokine, is a divergent member of the TGF-beta superfamily. Proc Natl Acad Sci U S A 94, 11514-11519.

Böttner, M., Laaff, M., Schechinger, B., Rappold, G., Unsicker, K., and Suter-Crazzolara, C. (1999). Characterization of the rat, mouse, and human genes of growth/differentiation factor-15/macrophage inhibiting cytokine-1 (GDF-15/MIC-1) Gene 237, 105-111.

Böttner, M., Suter-Crazzolara, C., Schober, A., and Unsicker, K. (1999). Expression of a novel member of the TGF-beta superfamily, growth/differentiation factor-15/macrophage-inhibiting cytokine-1 (GDF-15/MIC-1) in adult rat tissues. Cell Tissue Res 297, 103-110.

Boyle, G.M., Pedley, J., Martyn, A.C., Banducci, K.J., Strutton, G.M., Brown, D.A., Breit, S.N., and Parsons, P.G. (2009). Macrophage inhibitory cytokine-1 is overexpressed in malignant melanoma and is associated with tumorigenicity. J Invest Dermatol 129, 383-391.

Britsch, S., Goerich, D.E., Riethmacher, D., Peirano, R.I., Rossner, M., Nave, K.A., Birchmeier, C., and Wegner, M. (2001). The transcription factor Sox10 is a key regulator of peripheral glial development. Genes Dev 15, 66-78.

Bronner-Fraser, M. (1994). Neural crest cell formation and migration in the developing embryo. Faseb J 8, 699-706.

Bronner-Fraser, M. (1995). Origins and developmental potential of the neural crest. Exp Cell Res 218, 405-417.

Brown, D.A., Ward, R.L., Buckhaults, P., Liu, T., Romans, K.E., Hawkins, N.J., Bauskin, A.R., Kinzler, K.W., Vogelstein, B., and Breit, S.N. (2003). MIC-1 serum level and genotype: associations with progress and prognosis of colorectal carcinoma. Clin Cancer Res 9, 2642-2650.

Burazin, T.C., and Gundlach, A.L. (1998). Inducible galanin and GalR2 receptor system in motor neuron injury and regeneration. J Neurochem 71, 879-882. 
Cafferty, W.B., Gardiner, N.J., Gavazzi, I., Powell, J., McMahon, S.B., Heath, J.K., Munson, J., Cohen, J., and Thompson, S.W. (2001). Leukemia inhibitory factor determines the growth status of injured adult sensory neurons. J Neurosci 21, 7161-7170.

Cafferty, W.B., McGee, A.W., and Strittmatter, S.M. (2008). Axonal growth therapeutics: regeneration or sprouting or plasticity? Trends Neurosci 31, 215-220.

Cai, D., Deng, K., Mellado, W., Lee, J., Ratan, R.R., and Filbin, M.T. (2002). Arginase I and polyamines act downstream from cyclic AMP in overcoming inhibition of axonal growth MAG and myelin in vitro. Neuron 35, 711-719.

Chang, C., and Hemmati-Brivanlou, A. (1998). Cell fate determination in embryonic ectoderm. J Neurobiol 36, 128-151.

Charalambous, P., Wang, X., Thanos, S., Schober, A., and Unsicker, K. (2013). Regulation and effects of GDF-15 in the retina following optic nerve crush. Cell Tissue Res 353, 1-8.

Chen, Y.Y., McDonald, D., Cheng, C., Magnowski, B., Durand, J., and Zochodne, D.W. (2005). Axon and Schwann cell partnership during nerve regrowth. J Neuropathol Exp Neurol 64, 613-622.

Chen, Z., Yu, W., and Strickland, S. (2007). Peripheral regeneration. Annu. Rev. Neurosci. 30, 209-233.

Chen, Z.L., and Strickland, S. (2003). Laminin gamma1 is critical for Schwann cell differentiation, axon myelination, and regeneration in the peripheral nerve. $J$ Cell Biol 163, 889-899.

Cheng, H.L., Steinway, M., Delaney, C.L., Franke, T.F., and Feldman, E.L. (2000). IGF-I promotes Schwann cell motility and survival via activation of Akt. Mol Cell Endocrinol 170, 211-215.

Cheng, J.C., Chang, H.M., and Leung, P.C. (2011). Wild-type p53 attenuates cancer cell motility by inducing growth differentiation factor-15 expression. Endocrinology 152, 2987-2995.

Chernousov, M.A., Yu, W.M., Chen, Z.L., Carey, D.J., and Strickland, S. (2008). Regulation of Schwann cell function by the extracellular matrix. Glia 56, 1498-1507.

Chey, S., Claus, C., and Liebert, U.G. (2011). Improved method for simultaneous isolation of proteins and nucleic acids. Anal Biochem 411, 164-166.

Cornejo, M., Nambi, D., Walheim, C., Somerville, M., Walker, J., Kim, L., Ollison, L., Diamante, G., Vyawahare, S., and de Bellard, M.E. (2010). Effect of NRG1, GDNF, EGF and NGF in the migration of a Schwann cell precursor line. Neurochem Res 35, 1643-1651.

Coronel, M.F., Brumovsky, P.R., Hokfelt, T., and Villar, M.J. (2008). Differential galanin upregulation in dorsal root ganglia and spinal cord after graded single ligature nerve 
constriction of the rat sciatic nerve. J Chem Neuroanat 35, 94-100.

Coulson, E.J., Reid, K., Murray, S.S., Cheema, S.S., and Bartlett, P.F. (2000). Role of neurotrophin receptor p75NTR in mediating neuronal cell death following injury. Clin Exp Pharmacol Physiol 27, 537-541.

Coulson, E.J., Reid, K., and Bartlett, P.F. (1999). Signaling of neuronal cell death by the p75NTR neurotrophin receptor. Mol Neurobiol 20, 29-44.

Cowen, T., and Gavazzi, I. (1998). Plasticity in adult and ageing sympathetic neurons. Prog Neurobiol 54, 249-288.

Dai, Y., Sun, X., and Chen, Q. (2009). Differential induction of c-Fos and c-Jun in the lateral geniculate nucleus of rats following unilateral optic nerve injury with contralateral retinal blockade. Exp Brain Res 193, 9-18.

David, S., Fry, E.J., and Lopez-Vales, R. (2008). Novel roles for Nogo receptor in inflammation and disease. Trends Neurosci 31, 221-226.

de Jager, S.C., Bermudez, B., Bot, I., Koenen, R.R., Bot, M., Kavelaars, A., de Waard, V., Heijnen, C.J., Muriana, F.J., and Weber, C., et al. (2011). Growth differentiation factor 15 deficiency protects against atherosclerosis by attenuating CCR2-mediated macrophage chemotaxis. J Exp Med 208, 217-225.

De Leon, M., Nahin, R.L., Molina, C.A., De Leon, D.D., and Ruda, M.A. (1995). Comparison of $c$-jun, junB, and junD mRNA expression and protein in the rat dorsal root ganglia following sciatic nerve transection. J Neurosci Res 42, 391-401.

Decker, L., Desmarquet-Trin-Dinh, C., Taillebourg, E., Ghislain, J., Vallat, J.M., and Charnay, P. (2006). Peripheral myelin maintenance is a dynamic process requiring constant Krox20 expression. J Neurosci 26, 9771-9779.

Delcroix, J.D., Valletta, J.S., Wu, C., Hunt, S.J., Kowal, A.S., and Mobley, W.C. (2003). NGF signaling in sensory neurons: evidence that early endosomes carry NGF retrograde signals. Neuron $39,69-84$.

Dominguez, E., Mauborgne, A., Mallet, J., Desclaux, M., and Pohl, M. (2010). SOCS3-mediated blockade of JAK/STAT3 signaling pathway reveals its major contribution to spinal cord neuroinflammation and mechanical allodynia after peripheral nerve injury. J Neurosci 30, 5754-5766.

Donnerer, J. (2003). Regeneration of primary sensory neurons. Pharmacology 67, 169-181.

Dowsing, B.J., Morrison, W.A., Nicola, N.A., Starkey, G.P., Bucci, T., and Kilpatrick, T.J. (1999). Leukemia inhibitory factor is an autocrine survival factor for Schwann cells. J Neurochem 73, 96-104.

Dubey, S., Vanveldhuizen, P., Holzbeierlein, J., Tawfik, O., Thrasher, J.B., and Karan, D. (2012). Inflammation-associated regulation of the macrophage inhibitory cytokine (MIC-1) gene in prostate cancer. Oncol Lett 3, 1166-1170. 
Duprat, A.M., Saint-Jeannet, J.P., Pituello, F., Huang, S., Boudannaoui, S., Kan, P., and Gualandris, L. (1990). From presumptive ectoderm to neural cells in an amphibian. Int J Dev Biol 34, 149-156.

Einheber, S., Hannocks, M.J., Metz, C.N., Rifkin, D.B., and Salzer, J.L. (1995). Transforming growth factor-beta 1 regulates axon/Schwann cell interactions. J Cell Biol 129, 443-458.

Elenkov, I.J., Wilder, R.L., Chrousos, G.P., and Vizi, E.S. (2000). The sympathetic nerve--an integrative interface between two supersystems: the brain and the immune system. Pharmacol Rev 52, 595-638.

Fairlie, W.D., Moore, A.G., Bauskin, A.R., Russell, P.K., Zhang, H.P., and Breit, S.N. (1999). MIC-1 is a novel TGF-beta superfamily cytokine associated with macrophage activation. J Leukoc Biol 65, 2-5.

Fang, X., Yu, S., Eder, A., Mao, M., Bast, R.J., Boyd, D., and Mills, G.B. (1999). Regulation of BAD phosphorylation at serine 112 by the Ras-mitogen-activated protein kinase pathway. Oncogene 18, 6635-6640.

Fawcett, J.W., and Keynes, R.J. (1990). Peripheral nerve regeneration. Annu Rev Neurosci 13, 43-60.

Feltri, M.L., Graus Porta, D., Previtali, S.C., Nodari, A., Migliavacca, B., Cassetti, A., Littlewood-Evans, A., Reichardt, L.F., Messing, A., and Quattrini, A., et al. (2002). Conditional disruption of beta 1 integrin in Schwann cells impedes interactions with axons. J Cell Biol 156, 199-209.

Fenrich, K., and Gordon, T. (2004). Canadian Association of Neuroscience review: axonal regeneration in the peripheral and central nervous systems--current issues and advances. Can J Neurol Sci 31, 142-156.

Fex, S.A., Colman, D.R., and Pedraza, L. (2004). Satellite cells of dorsal root ganglia are multipotential glial precursors. Neuron Glia Biol 1, 85-93.

Flores, A.J., Lavernia, C.J., and Owens, P.W. (2000). Anatomy and physiology of peripheral nerve injury and repair. Am J Orthop (Belle Mead NJ) 29, 167-173.

Flugel, A., Hager, G., Horvat, A., Spitzer, C., Singer, G.M., Graeber, M.B., Kreutzberg, G.W., and Schwaiger, F.W. (2001). Neuronal MCP-1 expression in response to remote nerve injury. J Cereb Blood Flow Metab 21, 69-76.

Fontana, X., Hristova, M., Da, C.C., Patodia, S., Thei, L., Makwana, M., Spencer-Dene, B., Latouche, M., Mirsky, R., and Jessen, K.R., et al. (2012). c-Jun in Schwann cells promotes axonal regeneration and motoneuron survival via paracrine signaling. J Cell Biol 198, 127-141.

Francis, N.J., and Landis, S.C. (1999). Cellular and molecular determinants of sympathetic neuron development. Annu Rev Neurosci 22, 541-566.

Frey, D., Laux, T., Xu, L., Schneider, C., and Caroni, P. (2000). Shared and unique roles 
of CAP23 and GAP43 in actin regulation, neurite outgrowth, and anatomical plasticity. J Cell Biol 149, 1443-1454.

Friese, M.A., Wischhusen, J., Wick, W., Weiler, M., Eisele, G., Steinle, A., and Weller, M. (2004). RNA interference targeting transforming growth factor-beta enhances NKG2D-mediated antiglioma immune response, inhibits glioma cell migration and invasiveness, and abrogates tumorigenicity in vivo. Cancer Res 64, 7596-7603.

Fry, E.J., Ho, C., and David, S. (2007). A role for Nogo receptor in macrophage clearance from injured peripheral nerve. Neuron 53, 649-662.

Fu, S.Y., and Gordon, T. (1997). The cellular and molecular basis of peripheral nerve regeneration. Mol Neurobiol 14, 67-116.

Gan, W.B., Wong, V.Y., Phillips, A., Ma, C., Gershon, T.R., and Macagno, E.R. (1999). Cellular expression of a leech netrin suggests roles in the formation of longitudinal nerve tracts and in regional innervation of peripheral targets. J Neurobiol 40, 103-115.

Gao, Y., Deng, K., Hou, J., Bryson, J.B., Barco, A., Nikulina, E., Spencer, T., Mellado, W., Kandel, E.R., and Filbin, M.T. (2004). Activated CREB is sufficient to overcome inhibitors in myelin and promote spinal axon regeneration in vivo. Neuron 44, 609-621.

Garratt, A.N., Britsch, S., and Birchmeier, C. (2000). Neuregulin, a factor with many functions in the life of a schwann cell. Bioessays 22, 987-996.

Ghazvini, M., Mandemakers, W., Jaegle, M., Piirsoo, M., Driegen, S., Koutsourakis, M., Smit, X., Grosveld, F., and Meijer, D. (2002). A cell type-specific allele of the POU gene Oct- 6 reveals Schwann cell autonomous function in nerve development and regeneration. Embo J 21, 4612-4620.

Giger, R.J., Hollis, E.R., and Tuszynski, M.H. (2010). Guidance molecules in axon regeneration. Cold Spring Harbor perspectives in biology 2.

Gillespie, M.J., and Stein, R.B. (1983). The relationship between axon diameter, myelin thickness and conduction velocity during atrophy of mammalian peripheral nerves. Brain Res 259, 41-56.

Gordon, S., and Martinez, F.O. (2010). Alternative activation of macrophages: mechanism and functions. Immunity 32, 593-604.

Gordon, T., Gillespie, J., Orozco, R., and Davis, L. (1991). Axotomy-induced changes in rabbit hindlimb nerves and the effects of chronic electrical stimulation. J Neurosci 11 , 2157-2169.

Griffin, J.W., and Thompson, W.J. (2008). Biology and pathology of nonmyelinating Schwann cells. Glia 56, 1518-1531.

Grose, R., Harris, B.S., Cooper, L., Topilko, P., and Martin, P. (2002). Immediate early genes krox-24 and krox-20 are rapidly up-regulated after wounding in the embryonic and adult mouse. Dev Dyn 223, 371-378. 
Groves, M.J., An, S.F., Giometto, B., and Scaravilli, F. (1999). Inhibition of sensory neuron apoptosis and prevention of loss by NT-3 administration following axotomy. Exp Neurol 155, 284-294.

Groves, M.J., Schanzer, A., Simpson, A.J., An, S.F., Kuo, L.T., and Scaravilli, F. (2003). Profile of adult rat sensory neuron loss, apoptosis and replacement after sciatic nerve crush. J Neurocytol 32, 113-122.

Gupta, R., Rummler, L.S., Palispis, W., Truong, L., Chao, T., Rowshan, K., Mozaffar, T., and Steward, O. (2006). Local down-regulation of myelin-associated glycoprotein permits axonal sprouting with chronic nerve compression injury. Exp Neurol 200, 418-429.

Haas, C.A., Hofmann, H.D., and Kirsch, M. (1999). Expression of CNTF/LIF-receptor components and activation of STAT3 signaling in axotomized facial motoneurons: evidence for a sequential postlesional function of the cytokines. J Neurobiol 41, 559-571.

Hall, S. (1997). Axonal regeneration through acellular muscle grafts. J Anat 190 (Pt 1), 57-71.

Hansen, S.M., Berezin, V., and Bock, E. (2008). Signaling mechanisms of neurite outgrowth induced by the cell adhesion molecules NCAM and N-cadherin. Cell Mol Life Sci 65, 3809-3821.

Hanz, S., Perlson, E., Willis, D., Zheng, J.Q., Massarwa, R., Huerta, J.J., Koltzenburg, M., Kohler, M., Van-Minnen, J., Twiss, J.L., and Fainzilber, M. (2003). Axoplasmic importins enable retrograde injury signaling in lesioned nerve. Neuron 40, 1095-1104.

Hashimoto, M., Ishii, K., Nakamura, Y., Watabe, K., Kohsaka, S., and Akazawa, C. (2008). Neuroprotective effect of sonic hedgehog up-regulated in Schwann cells following sciatic nerve injury. J Neurochem 107, 918-927.

Herbert, D.R., Orekov, T., Roloson, A., Ilies, M., Perkins, C., O'Brien, W., Cederbaum, S., Christianson, D.W., Zimmermann, N., Rothenberg, M.E., and Finkelman, F.D. (2010). Arginase I suppresses IL-12/IL-23p40-driven intestinal inflammation during acute schistosomiasis. J Immunol 184, 6438-6446.

Hinoi, E., Ochi, H., Takarada, T., Nakatani, E., lezaki, T., Nakajima, H., Fujita, H., Takahata, Y., Hidano, S., and Kobayashi, T., et al. (2012). Positive regulation of osteoclastic differentiation by growth differentiation factor 15 upregulated in osteocytic cells under hypoxia. J Bone Miner Res 27, 938-949.

Hirata, A., Masaki, T., Motoyoshi, K., and Kamakura, K. (2002). Intrathecal administration of nerve growth factor delays GAP 43 expression and early phase regeneration of adult rat peripheral nerve. Brain Res 944, 146-156.

Hisanaga, S., and Hirokawa, N. (1989). The effects of dephosphorylation on the structure of the projections of neurofilament. J Neurosci 9, 959-966. 
Hoffman, P.N., Cleveland, D.W., Griffin, J.W., Landes, P.W., Cowan, N.J., and Price, D.L. (1987). Neurofilament gene expression: a major determinant of axonal caliber. Proc Natl Acad Sci U S A 84, 3472-3476.

Hoke, A., Ho, T., Crawford, T.O., LeBel, C., Hilt, D., and Griffin, J.W. (2003). Glial cell line-derived neurotrophic factor alters axon schwann cell units and promotes myelination in unmyelinated nerve fibers. J Neurosci 23, 561-567.

Holland, N.R., Crawford, T.O., Hauer, P., Cornblath, D.R., Griffin, J.W., and McArthur, J.C. (1998). Small-fiber sensory neuropathies: clinical course and neuropathology of idiopathic cases. Ann Neurol 44, 47-59.

Holmes, F.E., Mahoney, S., King, V.R., Bacon, A., Kerr, N.C., Pachnis, V., Curtis, R., Priestley, J.V., and Wynick, D. (2000). Targeted disruption of the galanin gene reduces the number of sensory neurons and their regenerative capacity. Proc Natl Acad Sci U S A 97, 11563-11568.

Hromas, R., Hufford, M., Sutton, J., Xu, D., Li, Y., and Lu, L. (1997). PLAB, a novel placental bone morphogenetic protein. Biochim Biophys Acta 1354, 40-44.

Hu, P., and McLachlan, E.M. (2003). Distinct functional types of macrophage in dorsal root ganglia and spinal nerves proximal to sciatic and spinal nerve transections in the rat. Exp Neurol 184, 590-605.

Hudson, T.W., Evans, G.R., and Schmidt, C.E. (2000). Engineering strategies for peripheral nerve repair. Orthop Clin North Am 31, 485-498.

Huh, S.J., Chung, C.Y., Sharma, A., and Robertson, G.P. (2010). Macrophage inhibitory cytokine-1 regulates melanoma vascular development. Am J Pathol 176, 2948-2957.

Ichikawa, T., Suenaga, Y., Koda, T., Ozaki, T., and Nakagawara, A. (2008). TAp63-dependent induction of growth differentiation factor 15 (GDF15) plays a critical role in the regulation of keratinocyte differentiation. Oncogene $27,409-420$.

Irwin, M. (1993). Stress-induced immune suppression. Role of the autonomic nervous system. Ann N Y Acad Sci 697, 203-218.

Ishii, A., Furusho, M., and Bansal, R. (2013). Sustained activation of ERK1/2 MAPK in oligodendrocytes and schwann cells enhances myelin growth and stimulates oligodendrocyte progenitor expansion. J Neurosci 33, 175-186.

Jaegle, M., Ghazvini, M., Mandemakers, W., Piirsoo, M., Driegen, S., Levavasseur, F., Raghoenath, S., Grosveld, F., and Meijer, D. (2003). The POU proteins Brn-2 and Oct-6 share important functions in Schwann cell development. Genes Dev 17, 1380-1391.

Jagalur, N.B., Ghazvini, M., Mandemakers, W., Driegen, S., Maas, A., Jones, E.A., Jaegle, M., Grosveld, F., Svaren, J., and Meijer, D. (2011). Functional dissection of the Oct6 Schwann cell enhancer reveals an essential role for dimeric Sox10 binding. J Neurosci 31, 8585-8594. 
Jenkins, S.J., Ruckerl, D., Cook, P.C., Jones, L.H., Finkelman, F.D., van Rooijen, N., MacDonald, A.S., and Allen, J.E. (2011). Local macrophage proliferation, rather than recruitment from the blood, is a signature of $\mathrm{TH} 2$ inflammation. Science 332, 1284-1288.

Jergova, S., Kolesar, D., and Cizkova, D. (2008). Expression of c-Fos in the parabrachial nucleus following peripheral nerve injury in rats. Eur J Pain 12, 172-179.

Jessen, K.R., and Mirsky, R. (2005). The origin and development of glial cells in peripheral nerves. Nat Rev Neurosci 6, 671-682.

Jessen, K.R., and Mirsky, R. (2008). Negative regulation of myelination: relevance for development, injury, and demyelinating disease. Glia 56, 1552-1565.

Ji, B., Case, L.C., Liu, K., Shao, Z., Lee, X., Yang, Z., Wang, J., Tian, T., Shulga-Morskaya, S., and Scott, M., et al. (2008). Assessment of functional recovery and axonal sprouting in oligodendrocyte-myelin glycoprotein (OMgp) null mice after spinal cord injury. Mol Cell Neurosci 39, 258-267.

Jiang, Y., Zhang, J.S., and Jakobsen, J. (2005). Differential effect of p75 neurotrophin receptor on expression of pro-apoptotic proteins c-jun, p38 and caspase-3 in dorsal root ganglion cells after axotomy in experimental diabetes. Neuroscience 132, 1083-1092.

Johnen, H., Lin, S., Kuffner, T., Brown, D.A., Tsai, V.W., Bauskin, A.R., Wu, L., Pankhurst, G., Jiang, L., and Junankar, S., et al. (2007). Tumor-induced anorexia and weight loss are mediated by the TGF-beta superfamily cytokine MIC-1. Nat Med 13, 1333-1340.

Johnson, E.J., Taniuchi, M., and DiStefano, P.S. (1988). Expression and possible function of nerve growth factor receptors on Schwann cells. Trends Neurosci 11, 299-304.

Julien, J.P., and Mushynski, W.E. (1983). The distribution of phosphorylation sites among identified proteolytic fragments of mammalian neurofilaments. J Biol Chem 258, 4019-4025.

Kadara, H., Schroeder, C.P., Lotan, D., Pisano, C., and Lotan, R. (2006). Induction of GDF-15/NAG-1/MIC-1 in human lung carcinoma cells by retinoid-related molecules and assessment of its role in apoptosis. Cancer Biol Ther 5, 518-522.

Kalluri, R., and Zeisberg, M. (2006). Fibroblasts in cancer. Nat Rev Cancer 6, 392-401.

Karanth, S., Yang, G., Yeh, J., and Richardson, P.M. (2006). Nature of signals that initiate the immune response during Wallerian degeneration of peripheral nerves. Exp Neurol 202, 161-166.

Kehl, D.W., lqbal, N., Fard, A., Kipper, B.A., De La Parra, L.A., and Maisel, A.S. (2012). Biomarkers in acute myocardial injury. Transl Res 159, 252-264.

Kempf, T., Bjorklund, E., Olofsson, S., Lindahl, B., Allhoff, T., Peter, T., Tongers, J., Wollert, K.C., and Wallentin, L. (2007). Growth-differentiation factor-15 improves risk stratification in ST-segment elevation myocardial infarction. Eur Heart $\mathrm{J} 28$, 
2858-2865.

Kempf, T., Eden, M., Strelau, J., Naguib, M., Willenbockel, C., Tongers, J., Heineke, J., Kotlarz, D., Xu, J., and Molkentin, J.D., et al. (2006). The transforming growth factor-beta superfamily member growth-differentiation factor-15 protects the heart from ischemia/reperfusion injury. Circ Res 98, 351-360.

Kempf, T., von Haehling, S., Peter, T., Allhoff, T., Cicoira, M., Doehner, W., Ponikowski, P., Filippatos, G.S., Rozentryt, P., and Drexler, H., et al. (2007). Prognostic utility of growth differentiation factor-15 in patients with chronic heart failure. J Am Coll Cardiol $50,1054-1060$.

Kempf, T., Zarbock, A., Widera, C., Butz, S., Stadtmann, A., Rossaint, J., Bolomini-Vittori, M., Korf-Klingebiel, M., Napp, L.C., and Hansen, B., et al. (2011). GDF-15 is an inhibitor of leukocyte integrin activation required for survival after myocardial infarction in mice. Nat Med 17, 581-588.

Kenney, A.M., and Kocsis, J.D. (1998). Peripheral axotomy induces long-term c-Jun amino-terminal kinase-1 activation and activator protein-1 binding activity by c-Jun and junD in adult rat dorsal root ganglia In vivo. J Neurosci 18, 1318-1328.

Kigerl, K.A., Gensel, J.C., Ankeny, D.P., Alexander, J.K., Donnelly, D.J., and Popovich, P.G. (2009). Identification of two distinct macrophage subsets with divergent effects causing either neurotoxicity or regeneration in the injured mouse spinal cord. $J$ Neurosci 29, 13435-13444.

Kim, J.S., Baek, S.J., Sali, T., and Eling, T.E. (2005). The conventional nonsteroidal anti-inflammatory drug sulindac sulfide arrests ovarian cancer cell growth via the expression of NAG-1/MIC-1/GDF-15. Mol Cancer Ther 4, 487-493.

Kim, K.K., Lee, J.J., Yang, Y., You, K.H., and Lee, J.H. (2008). Macrophage inhibitory cytokine-1 activates AKT and ERK-1/2 via the transactivation of ErbB2 in human breast and gastric cancer cells. Carcinogenesis 29, 704-712.

Kioussi, C., Gross, M.K., and Gruss, P. (1995). Pax3: a paired domain gene as a regulator in PNS myelination. Neuron 15, 553-562.

Kiryu-Seo, S., Kato, R., Ogawa, T., Nakagomi, S., Nagata, K., and Kiyama, H. (2008). Neuronal injury-inducible gene is synergistically regulated by ATF3, c-Jun, and STAT3 through the interaction with Sp1 in damaged neurons. J Biol Chem 283, 6988-6996.

Klein, D., Groh, J., Wettmarshausen, J., and Martini, R. (2014). Nonuniform molecular features of myelinating Schwann cells in models for CMT1: distinct disease patterns are associated with NCAM and c-Jun upregulation. Glia 62, 736-750.

Kluger, H.M., Hoyt, K., Bacchiocchi, A., Mayer, T., Kirsch, J., Kluger, Y., Sznol, M., Ariyan, S., Molinaro, A., and Halaban, R. (2011). Plasma markers for identifying patients with metastatic melanoma. Clin Cancer Res 17, 2417-2425. 
Kriz, J., Zhu, Q., Julien, J.P., and Padjen, A.L. (2000). Electrophysiological properties of axons in mice lacking neurofilament subunit genes: disparity between conduction velocity and axon diameter in absence of NF-H. Brain Res 885, 32-44.

Kubu, C.J., Orimoto, K., Morrison, S.J., Weinmaster, G., Anderson, D.J., and Verdi, J.M. (2002). Developmental changes in Notch1 and numb expression mediated by local cell-cell interactions underlie progressively increasing delta sensitivity in neural crest stem cells. Dev Biol 244, 199-214.

Kuspert, M., Weider, M., Muller, J., Hermans-Borgmeyer, I., Meijer, D., and Wegner, M. (2012). Desert hedgehog links transcription factor Sox10 to perineurial development. J Neurosci 32, 5472-5480.

Lajer, M., Jorsal, A., Tarnow, L., Parving, H.H., and Rossing, P. (2010). Plasma growth differentiation factor-15 independently predicts all-cause and cardiovascular mortality as well as deterioration of kidney function in type 1 diabetic patients with nephropathy. Diabetes Care 33, 1567-1572.

Larsen, P.H., Wells, J.E., Stallcup, W.B., Opdenakker, G., and Yong, V.W. (2003). Matrix metalloproteinase- 9 facilitates remyelination in part by processing the inhibitory NG2 proteoglycan. J Neurosci 23, 11127-11135.

Lawton, L.N., Bonaldo, M.F., Jelenc, P.C., Qiu, L., Baumes, S.A., Marcelino, R.A., de Jesus, G.M., Wellington, S., Knowles, J.A., and Warburton, D., et al. (1997). Identification of a novel member of the TGF-beta superfamily highly expressed in human placenta. Gene 203, 17-26.

Le, N., Nagarajan, R., Wang, J.Y., Araki, T., Schmidt, R.E., and Milbrandt, J. (2005). Analysis of congenital hypomyelinating Egr2Lo/Lo nerves identifies Sox2 as an inhibitor of Schwann cell differentiation and myelination. Proc Natl Acad Sci U S A 102, 2596-2601.

LeBlanc, A.C., and Poduslo, J.F. (1990). Axonal modulation of myelin gene expression in the peripheral nerve. J Neurosci Res 26, 317-326.

Lee, H., Jo, E.K., Choi, S.Y., Oh, S.B., Park, K., Kim, J.S., and Lee, S.J. (2006). Necrotic neuronal cells induce inflammatory Schwann cell activation via TLR2 and TLR3: implication in Wallerian degeneration. Biochem Biophys Res Commun 350, 742-747.

Li, F.Q., Fowler, K.A., Neil, J.E., Colton, C.A., and Vitek, M.P. (2010). An apolipoprotein E-mimetic stimulates axonal regeneration and remyelination after peripheral nerve injury. J Pharmacol Exp Ther 334, 106-115.

Li, Y., Rao, P.K., Wen, R., Song, Y., Muir, D., Wallace, P., van Horne, S.J., Tennekoon, G.I., and Kadesch, T. (2004). Notch and Schwann cell transformation. Oncogene 23, 1146-1152.

Lieberman, A.R. (1971). The axon reaction: a review of the principal features of perikaryal responses to axon injury. Int Rev Neurobiol 14, 49-124. 
$\overline{\text { Lim, Y.S., Mallapur, S., Kao, G., Ren, X.C., and Wadsworth, W.G. (1999). Netrin UNC-6 }}$ and the regulation of branching and extension of motoneuron axons from the ventral nerve cord of Caenorhabditis elegans. J Neurosci 19, 7048-7056.

Lindwall, C., Dahlin, L., Lundborg, G., and Kanje, M. (2004). Inhibition of c-Jun phosphorylation reduces axonal outgrowth of adult rat nodose ganglia and dorsal root ganglia sensory neurons. Mol Cell Neurosci 27, 267-279.

Lindwall, C., and Kanje, M. (2005). Retrograde axonal transport of JNK signaling molecules influence injury induced nuclear changes in p-c-Jun and ATF3 in adult rat sensory neurons. Mol Cell Neurosci 29, 269-282.

Liu, H.M. (1996). Growth factors and extracellular matrix in peripheral nerve regeneration, studied with a nerve chamber. J Peripher Nerv Syst 1, 97-110.

Livesey, F.J., O'Brien, J.A., Li, M., Smith, A.G., Murphy, L.J., and Hunt, S.P. (1997). A Schwann cell mitogen accompanying regeneration of motor neurons. Nature 390, 614-618.

Lowrie, M.B., Lavalette, D., and Davies, C.E. (1994). Time course of motoneurone death after neonatal sciatic nerve crush in the rat. Dev Neurosci 16, 279-284.

Lustig, M., Zanazzi, G., Sakurai, T., Blanco, C., Levinson, S.R., Lambert, S., Grumet, M., and Salzer, J.L. (2001). Nr-CAM and neurofascin interactions regulate ankyrin $\mathrm{G}$ and sodium channel clustering at the node of Ranvier. Curr Biol 11, 1864-1869.

Mager, G.M., Ward, R.M., Srinivasan, R., Jang, S.W., Wrabetz, L., and Svaren, J. (2008). Active gene repression by the Egr2.NAB complex during peripheral nerve myelination. J Biol Chem 283, 18187-18197.

Makranz, C., Cohen, G., Baron A, Levidor, L., Kodama, T., Reichert, F., and Rotshenker, S. (2004). Phosphatidylinositol 3-kinase, phosphoinositide-specific phospholipase-Cgamma and protein kinase-C signal myelin phagocytosis mediated by complement receptor-3 alone and combined with scavenger receptor-Al/II in macrophages. Neurobiol Dis 15, 279-286.

Makranz, C., Cohen, G., Reichert, F., Kodama, T., and Rotshenker, S. (2006). cAMP cascade (PKA, Epac, adenylyl cyclase, $\mathrm{Gi}$, and phosphodiesterases) regulates myelin phagocytosis mediated by complement receptor-3 and scavenger receptor-AI/II in microglia and macrophages. Glia 53, 441-448.

Makwana, M., and Raivich, G. (2005). Molecular mechanisms in successful peripheral regeneration. FEBS J 272, 2628-2638.

Mandemakers, W., Zwart, R., Jaegle, M., Walbeehm, E., Visser, P., Grosveld, F., and Meijer, D. (2000). A distal Schwann cell-specific enhancer mediates axonal regulation of the Oct-6 transcription factor during peripheral nerve development and regeneration. Embo J 19, 2992-3003.

Martini, R., Fischer, S., Lopez-Vales, R., and David, S. (2008). Interactions between 
Schwann cells and macrophages in injury and inherited demyelinating disease. Glia 56, 1566-1577.

McConnell, S.K. (1995). Strategies for the generation of neuronal diversity in the developing central nervous system. J Neurosci 15, 6987-6998.

McDonald, D., Cheng, C., Chen, Y., and Zochodne, D. (2006). Early events of peripheral nerve regeneration. Neuron Glia Biol 2, 139-147.

Meier, C., Parmantier, E., Brennan, A., Mirsky, R., and Jessen, K.R. (1999). Developing Schwann cells acquire the ability to survive without axons by establishing an autocrine circuit involving insulin-like growth factor, neurotrophin-3, and platelet-derived growth factor-BB. J Neurosci 19, 3847-3859.

Mensching, L., Borger, A.K., Wang, X., Charalambous, P., Unsicker, K., and Haastert-Talini, K. (2012). Local substitution of GDF-15 improves axonal and sensory recovery after peripheral nerve injury. Cell Tissue Res 350, 225-238.

Mercier, G., Turque, N., and Schumacher, M. (2001). Early activation of transcription factor expression in Schwann cells by progesterone. Brain Res Mol Brain Res 97, 137-148.

Meyer, D., and Birchmeier, C. (1995). Multiple essential functions of neuregulin in development. Nature 378, 386-390.

Meyer, M., Matsuoka, I., Wetmore, C., Olson, L., and Thoenen, H. (1992). Enhanced synthesis of brain-derived neurotrophic factor in the lesioned peripheral nerve: different mechanisms are responsible for the regulation of BDNF and NGF mRNA. J Cell Biol 119, 45-54.

Micera, A., Lambiase, A., Stampachiacchiere, B., Bonini, S., and Levi-Schaffer, F. (2007). Nerve growth factor and tissue repair remodeling: trkA(NGFR) and p75(NTR), two receptors one fate. Cytokine Growth Factor Rev 18, 245-256.

Miller, L.C., Freter, S., Liu, F., Taylor, J.S., Patient, R., and Begbie, J. (2010). Separating early sensory neuron and blood vessel patterning. Dev Dyn 239, 3297-3302.

Mirski, R., Reichert, F., Klar, A., and Rotshenker, S. (2003). Granulocyte macrophage colony stimulating factor (GM-CSF) activity is regulated by a GM-CSF binding molecule in Wallerian degeneration following injury to peripheral nerve axons. $J$ Neuroimmunol 140, 88-96.

Mirsky, R., Dubois, C., Morgan, L., and Jessen, K.R. (1990). 04 and A007-sulfatide antibodies bind to embryonic Schwann cells prior to the appearance of galactocerebroside; regulation of the antigen by axon-Schwann cell signals and cyclic AMP. Development 109, 105-116.

Mirsky, R., Woodhoo, A., Parkinson, D.B., Arthur-Farraj, P., Bhaskaran, A., and Jessen, K.R. (2008). Novel signals controlling embryonic Schwann cell development, myelination and dedifferentiation. J Peripher Nerv Syst 13, 122-135. 
Monje, P.V., Soto, J., Bacallao, K., and Wood, P.M. (2010). Schwann cell dedifferentiation is independent of mitogenic signaling and uncoupled to proliferation: role of cAMP and JNK in the maintenance of the differentiated state. J Biol Chem 285, 31024-31036.

Monnier, P.P., D'Onofrio, P.M., Magharious, M., Hollander, A.C., Tassew, N., Szydlowska, K., Tymianski, M., and Koeberle, P.D. (2011). Involvement of caspase-6 and caspase-8 in neuronal apoptosis and the regenerative failure of injured retinal ganglion cells. J Neurosci 31, 10494-10505.

Morest, D.K., and Silver, J. (2003). Precursors of neurons, neuroglia, and ependymal cells in the CNS: what are they? Where are they from? How do they get where they are going? Glia 43, 6-18.

Morrison, S.J., Perez, S.E., Qiao, Z., Verdi, J.M., Hicks, C., Weinmaster, G., and Anderson, D.J. (2000). Transient Notch activation initiates an irreversible switch from neurogenesis to gliogenesis by neural crest stem cells. Cell 101, 499-510.

Morton, P.D., Johnstone, J.T., Ramos, A.Y., Liebl, D.J., Bunge, M.B., and Bethea, J.R. (2012). Nuclear factor-kappaB activation in Schwann cells regulates regeneration and remyelination. Glia 60, 639-650.

Mueller, M., Leonhard, C., Wacker, K., Ringelstein, E.B., Okabe, M., Hickey, W.F., and Kiefer, R. (2003). Macrophage response to peripheral nerve injury: the quantitative contribution of resident and hematogenous macrophages. Lab Invest 83, 175-185.

Murakami, M., Nakatani, Y., Atsumi, G., Inoue, K., and Kudo, I. (1997). Regulatory functions of phospholipase A2. Crit Rev Immunol 17, 225-283.

Murinson, B.B., and Griffin, J.W. (2004). C-fiber structure varies with location in peripheral nerve. J Neuropathol Exp Neurol 63, 246-254.

Murray, P.J., and Wynn, T.A. (2011). Protective and pathogenic functions of macrophage subsets. Nat Rev Immunol 11, 723-737.

Nadeau, S., Filali, M., Zhang, J., Kerr, B.J., Rivest, S., Soulet, D., Iwakura, Y., de Rivero, V.J., Keane, R.W., and Lacroix, S. (2011). Functional recovery after peripheral nerve injury is dependent on the pro-inflammatory cytokines IL-1beta and TNF: implications for neuropathic pain. J Neurosci 31, 12533-12542.

Nakamura, T., Scorilas, A., Stephan, C., Yousef, G.M., Kristiansen, G., Jung, K., and Diamandis, E.P. (2003). Quantitative analysis of macrophage inhibitory cytokine-1 (MIC-1) gene expression in human prostatic tissues. Br J Cancer 88, 1101-1104.

Napoli, I., Noon, L.A., Ribeiro, S., Kerai, A.P., Parrinello, S., Rosenberg, L.H., Collins, M.J., Harrisingh, M.C., White, I.J., Woodhoo, A., and Lloyd, A.C. (2012). A central role for the ERK-signaling pathway in controlling Schwann cell plasticity and peripheral nerve regeneration in vivo. Neuron $73,729-742$.

Nascimento, R.S., Santiago, M.F., Marques, S.A., Allodi, S., and Martinez, A.M. (2008). Diversity among satellite glial cells in dorsal root ganglia of the rat. Braz $\mathrm{J}$ Med Biol 
Res 41, 1011-1017.

Navarro, X., Viv O, M., and Valero-Cabr E, A. (2007). Neural plasticity after peripheral nerve injury and regeneration. Prog Neurobiol 82, 163-201.

Nave, K.A. (2010). Myelination and the trophic support of long axons. Nat Rev Neurosci $11,275-283$.

Newbern, J., and Birchmeier, C. (2010). Nrg1/ErbB signaling networks in Schwann cell development and myelination. Semin Cell Dev Biol 21, 922-928.

Newbern, J.M., and Snider, W.D. (2012). Bers-ERK Schwann cells coordinate nerve regeneration. Neuron 73, 623-626.

Nickols, J.C., Valentine, W., Kanwal, S., and Carter, B.D. (2003). Activation of the transcription factor NF-kappaB in Schwann cells is required for peripheral myelin formation. Nat Neurosci 6, 161-167.

Nikolaev, A., McLaughlin, T., O Leary, D.D.M., and Tessier-Lavigne, M. (2009). APP binds DR6 to trigger axon pruning and neuron death via distinct caspases. Nature 457, 981-989.

Ohbayashi, N., Ikeda, O., Taira, N., Yamamoto, Y., Muromoto, R., Sekine, Y., Sugiyama, K., Honjoh, T., and Matsuda, T. (2007). LIF- and IL-6-induced acetylation of STAT3 at Lys-685 through PI3K/Akt activation. Biol Pharm Bull 30, 1860-1864.

Omura, T., Sano, M., Omura, K., Hasegawa, T., Doi, M., Sawada, T., and Nagano, A. (2005). Different expressions of BDNF, NT3, and NT4 in muscle and nerve after various types of peripheral nerve injuries. J Peripher Nerv Syst 10, 293-300.

O'Shea, J.J., and Murray, P.J. (2008). Cytokine signaling modules in inflammatory responses. Immunity $28,477-487$.

Ousman, S.S., and David, S. (2000). Lysophosphatidylcholine induces rapid recruitment and activation of macrophages in the adult mouse spinal cord. Glia 30, 92-104.

Pagany, M., Jagodic, M., Schubart, A., Pham-Dinh, D., Bachelin, C., Baron van Evercooren, A., Lachapelle, F., Olsson, T., and Linington, C. (2003). Myelin oligodendrocyte glycoprotein is expressed in the peripheral nervous system of rodents and primates. Neurosci Lett 350, 165-168.

Pannese, E. (2010). The structure of the perineuronal sheath of satellite glial cells (SGCs) in sensory ganglia. Neuron Glia Biol 6, 3-10.

Pannu, R., Barbosa, E., Singh, A.K., and Singh, I. (2005). Attenuation of acute inflammatory response by atorvastatin after spinal cord injury in rats. J Neurosci Res $79,340-350$.

Paralkar, V.M., Vail, A.L., Grasser, W.A., Brown, T.A., Xu, H., Vukicevic, S., Ke, H.Z., Qi, H., Owen, T.A., and Thompson, D.D. (1998). Cloning and characterization of a novel member of the transforming growth factor-beta/bone morphogenetic protein family. $\mathrm{J}$ 
Biol Chem 273, 13760-13767.

Paratore, C., Goerich, D.E., Suter, U., Wegner, M., and Sommer, L. (2001). Survival and glial fate acquisition of neural crest cells are regulated by an interplay between the transcription factor Sox10 and extrinsic combinatorial signaling. Development 128 , 3949-3961.

Parkinson, D.B., Bhaskaran, A., Arthur-Farraj, P., Noon, L.A., Woodhoo, A., Lloyd, A.C., Feltri, M.L., Wrabetz, L., Behrens, A., Mirsky, R., and Jessen, K.R. (2008). c-Jun is a negative regulator of myelination. J Cell Biol 181, 625-637.

Parkinson, D.B., Bhaskaran, A., Droggiti, A., Dickinson, S., D'Antonio, M., Mirsky, R., and Jessen, K.R. (2004). Krox-20 inhibits Jun-NH2-terminal kinase/c-Jun to control Schwann cell proliferation and death. J Cell Biol 164, 385-394.

Parkinson, D.B., Dong, Z., Bunting, H., Whitfield, J., Meier, C., Marie, H., Mirsky, R., and Jessen, K.R. (2001). Transforming growth factor beta (TGFbeta) mediates Schwann cell death in vitro and in vivo: examination of c-Jun activation, interactions with survival signals, and the relationship of TGFbeta-mediated death to Schwann cell differentiation. J Neurosci 21, 8572-8585.

Parlato, R., Rieker, C., Turiault, M., Tronche, F., and Schutz, G. (2006). Survival of DA neurons is independent of CREM upregulation in absence of CREB. Genesis 44, 454-464.

Parrinello, S., Napoli, I., Ribeiro, S., Digby, P.W., Fedorova, M., Parkinson, D.B., Doddrell, R.D., Nakayama, M., Adams, R.H., and Lloyd, A.C. (2010). EphB signaling directs peripheral nerve regeneration through Sox2-dependent Schwann cell sorting. Cell $143,145-155$.

Pattichis, C.S., Schofield, I., Merletti, R., Parker, P.A., and Middleton, L.T. (1999). Introduction to this special issue. Intelligent data analysis in electromyography and electroneurography. Med Eng Phys 21, 379-388.

Perlson, E., Hanz, S., Ben-Yaakov, K., Segal-Ruder, Y., Seger, R., and Fainzilber, M. (2005). Vimentin-dependent spatial translocation of an activated MAP kinase in injured nerve. Neuron 45, 715-726.

Perrin, F.E., Lacroix, S., Aviles-Trigueros, M., and David, S. (2005). Involvement of monocyte chemoattractant protein-1, macrophage inflammatory protein-1alpha and interleukin-1 beta in Wallerian degeneration. Brain 128, 854-866.

Pham, K., Nassiri, N., and Gupta, R. (2009). c-Jun, krox-20, and integrin beta4 expression following chronic nerve compression injury. Neurosci Lett 465, 194-198.

Piirsoo, M., Kaljas, A., Tamm, K., and Timmusk, T. (2010). Expression of NGF and GDNF family members and their receptors during peripheral nerve development and differentiation of Schwann cells in vitro. Neurosci Lett 469, 135-140.

Pollock, G., Pennypacker, K.R., Memet, S., Israel, A., and Saporta, S. (2005). Activation 
of NF-kappaB in the mouse spinal cord following sciatic nerve transection. Exp Brain Res 165, 470-477.

Raivich, G., Bohatschek, M., Da, C.C., Iwata, O., Galiano, M., Hristova, M., Nateri, A.S., Makwana, M., Riera-Sans, L., and Wolfer, D.P., et al. (2004). The AP-1 transcription factor c-Jun is required for efficient axonal regeneration. Neuron 43, 57-67.

Reichert, F., Levitzky, R., and Rotshenker, S. (1996). Interleukin 6 in intact and injured mouse peripheral nerves. Eur J Neurosci 8, 530-535.

Reichert, F., Saada, A., and Rotshenker, S. (1994). Peripheral nerve injury induces Schwann cells to express two macrophage phenotypes: phagocytosis and the galactose-specific lectin MAC-2. J Neurosci 14, 3231-3245.

Reid, A.J., Welin, D., Wiberg, M., Terenghi, G., and Novikov, L.N. (2010). Peripherin and ATF3 genes are differentially regulated in regenerating and non-regenerating primary sensory neurons. Brain Res 1310, 1-7.

Reyes, O., Sosa, I., and Kuffler, D.P. (2005). Promoting neurological recovery following a traumatic peripheral nerve injury. P R Health Sci J 24, 215-223.

Rosenberg, A.F., Wolman, M.A., Franzini-Armstrong, C., and Granato, M. (2012). In vivo nerve-macrophage interactions following peripheral nerve injury. $\mathrm{J}$ Neurosci 32 , 3898-3909.

Roth, P., Junker, M., Tritschler, I., Mittelbronn, M., Dombrowski, Y., Breit, S.N., Tabatabai, G., Wick, W., Weller, M., and Wischhusen, J. (2010). GDF-15 contributes to proliferation and immune escape of malignant gliomas. Clin Cancer Res 16, 3851-3859.

Saada, A., Reichert, F., and Rotshenker, S. (1996). Granulocyte macrophage colony stimulating factor produced in lesioned peripheral nerves induces the up-regulation of cell surface expression of MAC-2 by macrophages and Schwann cells. J Cell Biol 133, 159-167.

Saijilafu, Hur, E.M., and Zhou, F.Q. (2011). Genetic dissection of axon regeneration via in vivo electroporation of adult mouse sensory neurons. Nat Commun 2, 543.

Sakurai, T., Lustig, M., Babiarz, J., Furley, A.J., Tait, S., Brophy, P.J., Brown, S.A., Brown, L.Y., Mason, C.A., and Grumet, M. (2001). Overlapping functions of the cell adhesion molecules Nr-CAM and L1 in cerebellar granule cell development. J Cell Biol 154, 1259-1273.

Saul, K.E., Koke, J.R., and Garcia, D.M. (2010). Activating transcription factor 3 (ATF3) expression in the neural retina and optic nerve of zebrafish during optic nerve regeneration. Comp Biochem Physiol A Mol Integr Physiol 155, 172-182.

Schäfer, M.K., and Frotscher, M. (2012). Role of L1CAM for axon sprouting and branching. Cell Tissue Res 349, 39-48.

Scherer, S.S., Xu, Y.T., Bannerman, P.G., Sherman, D.L., and Brophy, P.J. (1995). 
Periaxin expression in myelinating Schwann cells: modulation by axon-glial interactions and polarized localization during development. Development 121, 4265-4273.

Schindowski, K., von Bohlen, U.H.O., Strelau, J., Ridder, D.A., Herrmann, O., Schober, A., Schwaninger, M., and Unsicker, K. (2011). Regulation of GDF-15, a distant TGF-beta superfamily member, in a mouse model of cerebral ischemia. Cell Tissue Res 343, 399-409.

Schlittenhardt, D., Schober, A., Strelau, J., Bonaterra, G.A., Schmiedt, W., Unsicker, K., Metz, J., and Kinscherf, R. (2004). Involvement of growth differentiation factor-15/macrophage inhibitory cytokine-1 (GDF-15/MIC-1) in oxLDL-induced apoptosis of human macrophages in vitro and in arteriosclerotic lesions. Cell Tissue Res 318, 325-333.

Schmid, R.S., and Maness, P.F. (2008). L1 and NCAM adhesion molecules as signaling coreceptors in neuronal migration and process outgrowth. Curr Opin Neurobiol 18, 245-250.

Schober, A., Böttner, M., Strelau, J., Kinscherf, R., Bonaterra, G.A., Barth, M., Schilling, L., Fairlie, W.D., Breit, S.N., and Unsicker, K. (2001). Expression of growth differentiation factor-15/ macrophage inhibitory cytokine-1 (GDF-15/MIC-1) in the perinatal, adult, and injured rat brain. J Comp Neurol 439, 32-45.

Schwartz, S., Maquet, P., and Frith, C. (2002). Neural correlates of perceptual learning: a functional MRI study of visual texture discrimination. Proc Natl Acad Sci U S A 99, 17137-17142.

Sekikawa, A., Fukui, H., Fujii, S., Ichikawa, K., Tomita, S., Imura, J., Chiba, T., and Fujimori, T. (2008). REG lalpha protein mediates an anti-apoptotic effect of STAT3 signaling in gastric cancer cells. Carcinogenesis 29, 76-83.

Sendtner, M., Carroll, P., Holtmann, B., Hughes, R.A., and Thoenen, H. (1994). Ciliary neurotrophic factor. J Neurobiol 25, 1436-1453.

Shamash, S., Reichert, F., and Rotshenker, S. (2002). The cytokine network of Wallerian degeneration: tumor necrosis factor-alpha, interleukin-1alpha, and interleukin-1beta. $J$ Neurosci 22, 3052-3060.

Sharghi-Namini, S., Turmaine, M., Meier, C., Sahni, V., Umehara, F., Jessen, K.R., and Mirsky, R. (2006). The structural and functional integrity of peripheral nerves depends on the glial-derived signal desert hedgehog. J Neurosci 26, 6364-6376.

Sherman, D.L., and Brophy, P.J. (2005). Mechanisms of axon ensheathment and myelin growth. Nat Rev Neurosci 6, 683-690.

Shi, T.J., Tandrup, T., Bergman, E., Xu, Z.Q., Ulfhake, B., and Hokfelt, T. (2001). Effect of peripheral nerve injury on dorsal root ganglion neurons in the $\mathrm{C} 57 \mathrm{BL} / 6 \mathrm{~J}$ mouse: marked changes both in cell numbers and neuropeptide expression. Neuroscience 105, 249-263. 
Shibata, A., Zelivyanskaya, M., Limoges, J., Carlson, K.A., Gorantla, S., Branecki, C., Bishu, S., Xiong, H., and Gendelman, H.E. (2003). Peripheral nerve induces macrophage neurotrophic activities: regulation of neuronal process outgrowth, intracellular signaling and synaptic function. J Neuroimmunol 142, 112-129.

Shy, M.E., Shi, Y., Wrabetz, L., Kamholz, J., and Scherer, S.S. (1996). Axon-Schwann cell interactions regulate the expression of c-jun in Schwann cells. J Neurosci Res 43, 511-525.

Si, Y., Liu, X., Cheng, M., Wang, M., Gong, Q., Yang, Y., Wang, T., and Yang, W. (2011). Growth differentiation factor 15 is induced by hepatitis $C$ virus infection and regulates hepatocellular carcinoma-related genes. PLoS One 6, e19967.

Silva, D., Dikkes, P., Barnes, M., and Lopez, M.F. (2009). Decreased motoneuron survival in Igf2 null mice after sciatic nerve transection. Neuroreport 20, 1414-1418.

Smith, D., Tweed, C., Fernyhough, P., and Glazner, G.W. (2009). Nuclear factor-kappaB activation in axons and Schwann cells in experimental sciatic nerve injury and its role in modulating axon regeneration: studies with etanercept. J Neuropathol Exp Neurol $68,691-700$.

Smith, P.M., Sim, F.J., Barnett, S.C., and Franklin, R.J. (2001). SCIP/Oct-6, Krox-20, and desert hedgehog mRNA expression during CNS remyelination by transplanted olfactory ensheathing cells. Glia 36, 342-353.

Snider, W.D., Elliott, J.L., and Yan, Q. (1992). Axotomy-induced neuronal death during development. J Neurobiol 23, 1231-1246.

Snider, W.D., Zhou, F.Q., Zhong, J., and Markus, A. (2002). Signaling the pathway to regeneration. Neuron 35, 13-16.

Snipes, G.J., Orfali, W., Fraser, A., Dickson, K., and Colby, J. (1999). The anatomy and cell biology of peripheral myelin protein-22. Ann N Y Acad Sci 883, 143-151.

Son, S.J., Lee, K.M., Jeon, S.M., Park, E.S., Park, K.M., and Cho, H.J. (2007). Activation of transcription factor c-jun in dorsal root ganglia induces VIP and NPY upregulation and contributes to the pathogenesis of neuropathic pain. Exp Neurol 204, 467-472.

Son, Y.J., and Thompson, W.J. (1995). Schwann cell processes guide regeneration of peripheral axons. Neuron 14, 125-132.

Song, H., Yin, D., and Liu, Z. (2012). GDF-15 promotes angiogenesis through modulating p53/HIF-1alpha signaling pathway in hypoxic human umbilical vein endothelial cells. Mol Biol Rep 39, 4017-4022.

Spooren, A., Kooijman, R., Lintermans, B., Van Craenenbroeck, K., Vermeulen, L., Haegeman, G., and Gerlo, S. (2010). Cooperation of NFkappaB and CREB to induce synergistic IL-6 expression in astrocytes. Cell Signal 22, 871-881.

Spreyer, P., Schaal, H., Kuhn, G., Rothe, T., Unterbeck, A., Olek, K., and Muller, H.W. (1990). Regeneration-associated high level expression of apolipoprotein D mRNA in 
endoneurial fibroblasts of peripheral nerve. Embo J 9, 2479-2484.

Springer, J.E., Azbill, R.D., Nottingham, S.A., and Kennedy, S.E. (2000). Calcineurin-mediated BAD dephosphorylation activates the caspase-3 apoptotic cascade in traumatic spinal cord injury. J Neurosci 20, 7246-7251.

Stassart, R.M., Fledrich, R., Velanac, V., Brinkmann, B.G., Schwab, M.H., Meijer, D., Sereda, M.W., and Nave, K.A. (2013). A role for Schwann cell-derived neuregulin-1 in remyelination. Nat Neurosci 16, 48-54.

Stewart, H.J., Turner, D., Jessen, K.R., and Mirsky, R. (1997). Expression and regulation of alpha1beta1 integrin in Schwann cells. J Neurobiol 33, 914-928.

Stoll, G., and Muller, H.W. (1986). Macrophages in the peripheral nervous system and astroglia in the central nervous system of rat commonly express apolipoprotein $E$ during development but differ in their response to injury. Neurosci Lett 72, 233-238.

Stoll, G., and Muller, H.W. (1999). Nerve injury, axonal degeneration and neural regeneration: basic insights. Brain Pathol 9, 313-325.

Strelau, J., Strzelczyk, A., Rusu, P., Bendner, G., Wiese, S., Diella, F., Altick, A.L., von Bartheld, C.S., Klein, R., Sendtner, M., and Unsicker, K. (2009). Progressive postnatal motoneuron loss in mice lacking GDF-15. J Neurosci 29, 13640-13648.

Strelau, J., Sullivan, A., Böttner, M., Lingor, P., Falkenstein, E., Suter-Crazzolara, C., Galter, D., Jaszai, J., Krieglstein, K., and Unsicker, K. (2000). Growth/differentiation factor-15/macrophage inhibitory cytokine- 1 is a novel trophic factor for midbrain dopaminergic neurons in vivo. J Neurosci 20, 8597-8603.

Subramaniam, S., Strelau, J., and Unsicker, K. (2003). Growth differentiation factor-15 prevents low potassium-induced cell death of cerebellar granule neurons by differential regulation of Akt and ERK pathways. J Biol Chem 278, 8904-8912.

Sung, Y.J., Chiu, D.T., and Ambron, R.T. (2006). Activation and retrograde transport of protein kinase $G$ in rat nociceptive neurons after nerve injury and inflammation. Neuroscience 141, 697-709.

Sutherland, T.E., Maizels, R.M., and Allen, J.E. (2009). Chitinases and chitinase-like proteins: potential therapeutic targets for the treatment of T-helper type 2 allergies. Clin Exp Allergy 39, 943-955.

Syroid, D.E., Maycox, P.J., Soilu-Hanninen, M., Petratos, S., Bucci, T., Burrola, P., Murray, S., Cheema, S., Lee, K.F., Lemke, G., and Kilpatrick, T.J. (2000). Induction of postnatal schwann cell death by the low-affinity neurotrophin receptor in vitro and after axotomy. J Neurosci 20, 5741-5747.

Tacke, R., and Martini, R. (1990). Changes in expression of mRNA specific for cell adhesion molecules (L1 and NCAM) in the transected peripheral nerve of the adult rat. Neurosci Lett 120, 227-230.

Tanabe, Y., and Jessell, T.M. (1996). Diversity and pattern in the developing spinal cord. 
Science $274,1115-1123$.

Tandrup, T., Woolf, C.J., and Coggeshall, R.E. (2000). Delayed loss of small dorsal root ganglion cells after transection of the rat sciatic nerve. J Comp Neurol 422, 172-180.

Taskinen, H.S., Olsson, T., Bucht, A., Khademi, M., Svelander, L., and Roytta, M. (2000). Peripheral nerve injury induces endoneurial expression of IFN-gamma, IL-10 and TNF-alpha mRNA. J Neuroimmunol 102, 17-25.

Taskinen, H.S., and Roytta, M. (2000). Increased expression of chemokines (MCP-1, MIP-1alpha, RANTES) after peripheral nerve transection. J Peripher Nerv Syst 5, 75-81.

Teng, X., Li, D., Champion, H.C., and Johns, R.A. (2003). FIZZ1/RELMalpha, a novel hypoxia-induced mitogenic factor in lung with vasoconstrictive and angiogenic properties. Circ Res 92, 1065-1067.

Tetzlaff, W., Alexander, S.W., Miller, F.D., and Bisby, M.A. (1991). Response of facial and rubrospinal neurons to axotomy: changes in mRNA expression for cytoskeletal proteins and GAP-43. J Neurosci 11, 2528-2544.

Tetzlaff, W., Leonard, C., Krekoski, C.A., Parhad, I.M., and Bisby, M.A. (1996). Reductions in motoneuronal neurofilament synthesis by successive axotomies: a possible explanation for the conditioning lesion effect on axon regeneration. Exp Neurol 139, 95-106.

Thomaidou, D., Coquillat, D., Meintanis, S., Noda, M., Rougon, G., and Matsas, R. (2001). Soluble forms of NCAM and F3 neuronal cell adhesion molecules promote Schwann cell migration: identification of protein tyrosine phosphatases zeta/beta as the putative F3 receptors on Schwann cells. J Neurochem 78, 767-778.

Thornton, M.R., Mantovani, C., Birchall, M.A., and Terenghi, G. (2005). Quantification of $\mathrm{N}-\mathrm{CAM}$ and $\mathrm{N}$-cadherin expression in axotomized and crushed rat sciatic nerve. $J$ Anat 206, 69-78.

Thornton, M.R., Shawcross, S.G., Mantovani, C., Kingham, P.J., Birchall, M.A., and Terenghi, G. (2008). Neurotrophins 3 and 4 differentially regulate NCAM, L1 and $\mathrm{N}$-cadherin expression during peripheral nerve regeneration. Biotechnol Appl Biochem 49, 165-174.

Tofaris, G.K., Patterson, P.H., Jessen, K.R., and Mirsky, R. (2002). Denervated Schwann cells attract macrophages by secretion of leukemia inhibitory factor (LIF) and monocyte chemoattractant protein- 1 in a process regulated by interleukin- 6 and LIF. J Neurosci 22, 6696-6703.

Tolwani, R.J., Cosgaya, J.M., Varma, S., Jacob, R., Kuo, L.E., and Shooter, E.M. (2004). BDNF overexpression produces a long-term increase in myelin formation in the peripheral nervous system. J Neurosci Res 77, 662-669.

Topilko, P., Levi, G., Merlo, G., Mantero, S., Desmarquet, C., Mancardi, G., and Charnay, 
P. (1997). Differential regulation of the zinc finger genes Krox-20 and Krox-24 (Egr-1) suggests antagonistic roles in Schwann cells. J Neurosci Res 50, 702-712.

Topilko, P., Schneider-Maunoury, S., Levi, G., Baron-Van, E.A., Chennoufi, A.B., Seitanidou, T., Babinet, C., and Charnay, P. (1994). Krox-20 controls myelination in the peripheral nervous system. Nature 371, 796-799.

Trapp, B.D. (1988). Distribution of the myelin-associated glycoprotein and P0 protein during myelin compaction in quaking mouse peripheral nerve. J Cell Biol 107, 675-685.

Triolo, D., Dina, G., Lorenzetti, I., Malaguti, M., Morana, P., Del Carro, U., Comi, G., Messing, A., Quattrini, A., and Previtali, S.C. (2006). Loss of glial fibrillary acidic protein (GFAP) impairs Schwann cell proliferation and delays nerve regeneration after damage. J Cell Sci 119, 3981-3993.

Unsicker, K., Spittau, B., and Krieglstein, K. (2013). The multiple facets of the TGF- $\beta$ family cytokine growth/differentiation factor-15/macrophage inhibitory cytokine-1. Cytokine Growth F R 24, 373-384.

Valero-Cabre, A., Tsironis, K., Skouras, E., Perego, G., Navarro, X., and Neiss, W.F. (2001). Superior muscle reinnervation after autologous nerve graft or poly-L-lactide-epsilon-caprolactone (PLC) tube implantation in comparison to silicone tube repair. J Neurosci Res 63, 214-223.

Vanden, N.S., Wallace, N., Muccio, D., Turtz, A., and Pinter, M.J. (1993). Adult spinal motoneurons remain viable despite prolonged absence of functional synaptic contact with muscle. Exp Neurol 123, 147-156.

Vanhara, P., Lincova, E., Kozubik, A., Jurdic, P., Soucek, K., and Smarda, J. (2009). Growth/differentiation factor-15 inhibits differentiation into osteoclasts--a novel factor involved in control of osteoclast differentiation. Differentiation 78, 213-222.

Vega, J.A., Garcia-Suarez, O., Montano, J.A., Pardo, B., and Cobo, J.M. (2009). The Meissner and Pacinian sensory corpuscles revisited new data from the last decade. Microsc Res Tech 72, 299-309.

Vega-Avelaira, D., Geranton, S.M., and Fitzgerald, M. (2009). Differential regulation of immune responses and macrophage/neuron interactions in the dorsal root ganglion in young and adult rats following nerve injury. Mol Pain 5, 70 .

Venkatesh, K., Chivatakarn, O., Lee, H., Joshi, P.S., Kantor, D.B., Newman, B.A., Mage, R., Rader, C., and Giger, R.J. (2005). The Nogo-66 receptor homolog NgR2 is a sialic acid-dependent receptor selective for myelin-associated glycoprotein. J Neurosci 25, 808-822.

Vestergaard, S., Tandrup, T., and Jakobsen, J. (1997). Effect of permanent axotomy on number and volume of dorsal root ganglion cell bodies. J Comp Neurol 388, 307-312.

Wallquist, W., Patarroyo, M., Thams, S., Carlstedt, T., Stark, B., Cullheim, S., and 
Hammarberg, H. (2002). Laminin chains in rat and human peripheral nerve: Distribution and regulation during development and after axonal injury. The Journal of Comparative Neurology 454, 284-293.

Wanner, I.B., Guerra, N.K., Mahoney, J., Kumar, A., Wood, P.M., Mirsky, R., and Jessen, K.R. (2006). Role of N-cadherin in Schwann cell precursors of growing nerves. Glia 54, 439-459.

Waxman, S.G. (1980). Determinants of conduction velocity in myelinated nerve fibers. Muscle Nerve 3, 141-150.

Webling, K.E., Runesson, J., Bartfai, T., and Langel, U. (2012). Galanin receptors and ligands. Front Endocrinol (Lausanne) 3, 146.

Webster, H.D., Martin, R., and O'Connell, M.F. (1973). The relationships between interphase Schwann cells and axons before myelination: a quantitative electron microscopic study. Dev Biol 32, 401-416.

Weiner, J.A., and Chun, J. (1999). Schwann cell survival mediated by the signaling phospholipid lysophosphatidic acid. Proc Natl Acad Sci U S A 96, 5233-5238.

Welsh, J.B., Sapinoso, L.M., Kern, S.G., Brown, D.A., Liu, T., Bauskin, A.R., Ward, R.L., Hawkins, N.J., Quinn, D.I., and Russell, P.J., et al. (2003). Large-scale delineation of secreted protein biomarkers overexpressed in cancer tissue and serum. Proc Natl Acad Sci U S A 100, 3410-3415.

Wilhelm, J.C., Xu, M., Cucoranu, D., Chmielewski, S., Holmes, T., Lau, K.S., Bassell, G.J., and English, A.W. (2012). Cooperative roles of BDNF expression in neurons and Schwann cells are modulated by exercise to facilitate nerve regeneration. $\mathrm{J}$ Neurosci 32, 5002-5009.

Willison, H.J., Trapp, B.D., Bacher, J.D., and Quarles, R.H. (1988). The expression of myelin-associated glycoprotein in regenerating cat sciatic nerve. Brain Res 444, 10-16.

Wollmann, W., Goodman, M.L., Bhat-Nakshatri, P., Kishimoto, H., Goulet, R.J., Mehrotra, S., Morimiya, A., Badve, S., and Nakshatri, H. (2005). The macrophage inhibitory cytokine integrates AKT/PKB and MAP kinase signaling pathways in breast cancer cells. Carcinogenesis 26, 900-907.

Wolpowitz, D., Mason, T.B., Dietrich, P., Mendelsohn, M., Talmage, D.A., and Role, L.W. (2000). Cysteine-rich domain isoforms of the neuregulin-1 gene are required for maintenance of peripheral synapses. Neuron 25, 79-91.

Woodhoo, A., Alonso, M.B., Droggiti, A., Turmaine, M., D'Antonio, M., Parkinson, D.B., Wilton, D.K., Al-Shawi, R., Simons, P., and Shen, J., et al. (2009). Notch controls embryonic Schwann cell differentiation, postnatal myelination and adult plasticity. Nat Neurosci 12, 839-847.

Woodhoo, A., and Sommer, L. (2008). Development of the Schwann cell lineage: from the 
neural crest to the myelinated nerve. Glia 56, 1481-1490.

Wynick, D., Thompson, S.W., and McMahon, S.B. (2001). The role of galanin as a multi-functional neuropeptide in the nervous system. Curr Opin Pharmacol 1, 73-77.

Xiao, J., Wong, A.W., Willingham, M.M., Kaasinen, S.K., Hendry, I.A., Howitt, J., Putz, U., Barrett, G.L., Kilpatrick, T.J., and Murray, S.S. (2009). BDNF exerts contrasting effects on peripheral myelination of NGF-dependent and BDNF-dependent DRG neurons. J Neurosci 29, 4016-4022.

Xu, J., Kimball, T.R., Lorenz, J.N., Brown, D.A., Bauskin, A.R., Klevitsky, R., Hewett, T.E., Breit, S.N., and Molkentin, J.D. (2006). GDF15/MIC-1 functions as a protective and antihypertrophic factor released from the myocardium in association with SMAD protein activation. Circ Res 98, 342-350.

Xu, X., Jiang, H., Liu, H., Zhang, W., Xu, X., and Li, Z. (2012). The effects of galanin on dorsal root ganglion neurons with high glucose treatment in vitro. Brain Res Bull 87, 85-93.

Yamauchi, J., Chan, J.R., and Shooter, E.M. (2004). Neurotrophins regulate Schwann cell migration by activating divergent signaling pathways dependent on Rho GTPases. Proc Natl Acad Sci U S A 101, 8774-8779.

Yanaba, K., Asano, Y., Tada, Y., Sugaya, M., Kadono, T., and Sato, S. (2012). Clinical significance of serum growth differentiation factor-15 levels in systemic sclerosis: association with disease severity. Mod Rheumatol 22, 668-675.

Yang, D.P., Kim, J., Syed, N., Tung, Y.J., Bhaskaran, A., Mindos, T., Mirsky, R., Jessen, K.R., Maurel, P., Parkinson, D.B., and Kim, H.A. (2012). p38 MAPK activation promotes denervated Schwann cell phenotype and functions as a negative regulator of Schwann cell differentiation and myelination. J Neurosci 32, 7158-7168.

Ydens, E., Cauwels, A., Asselbergh, B., Goethals, S., Peeraer, L., Lornet, G., Almeida-Souza, L., Van Ginderachter, J.A., Timmerman, V., and Janssens, S. (2012). Acute injury in the peripheral nervous system triggers an alternative macrophage response. J Neuroinflammation 9, 176.

Ygge, J. (1989). Neuronal loss in lumbar dorsal root ganglia after proximal compared to distal sciatic nerve resection: a quantitative study in the rat. Brain Res 478, 193-195.

Yuan, Q., Su, H., Guo, J., Tsang, K.Y., Cheah, K.S., Chiu, K., Yang, J., Wong, W.M., So, K.F., and Huang, J.D., et al. (2012). Decreased C-Jun expression correlates with impaired spinal motoneuron regeneration in aged mice following sciatic nerve crush. Exp Gerontol 47, 329-336.

Yuan, Z., Gong, S., Luo, J., Zheng, Z., Song, B., Ma, S., Guo, J., Hu, C., Thiel, G., and Vinson, C., et al. (2009). Opposing roles for ATF2 and c-Fos in c-Jun-mediated neuronal apoptosis. Mol Cell Biol 29, 2431-2442.

Zhong, J., Dietzel, I.D., Wahle, P., Kopf, M., and Heumann, R. (1999). Sensory 
impairments and delayed regeneration of sensory axons in interleukin-6-deficient mice. J Neurosci 19, 4305-4313.

Zhou, X., Spittau, B., and Krieglstein, K. (2012). TGFbeta signalling plays an important role in IL4-induced alternative activation of microglia. J Neuroinflammation 9, 210.

Zorick, T.S., Syroid, D.E., Arroyo, E., Scherer, S.S., and Lemke, G. (1996). The Transcription Factors SCIP and Krox-20 Mark Distinct Stages and Cell Fates in Schwann Cell Differentiation. Mol Cell Neurosci 8, 129-145.

Zorick, T.S., Syroid, D.E., Brown, A., Gridley, T., and Lemke, G. (1999). Krox-20 controls SCIP expression, cell cycle exit and susceptibility to apoptosis in developing myelinating Schwann cells. Development 126, 1397-1406. 


\section{Curriculum Vitae}

Basic Information:

Name: Xiaolong Wang

Gender: Male

Birthday: Feb, 1982

Place of Birth: Xi'an, Shaanxi, China

Nationality: China

Marital status: Married

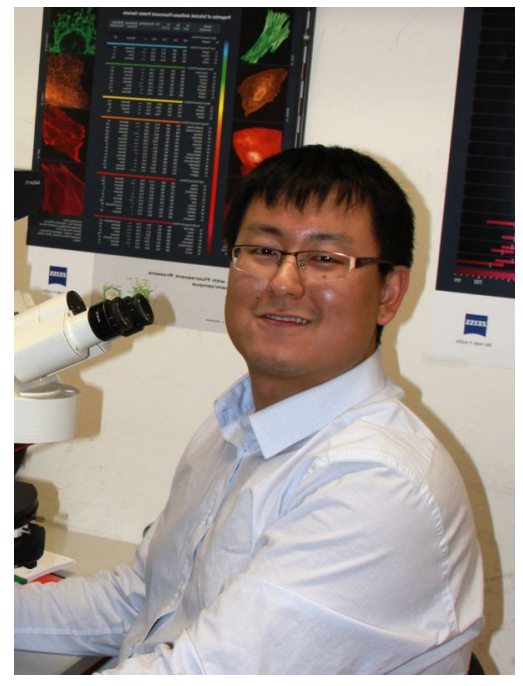

E-mail: xiaolong.wang225@gmail.com

\section{Educational Experience:}

Since 11/2009 Ph.D. candidate in Department of Pharmazia, Department of Molecular Embryology, Institute of Anatomy and Cell Biology, University of Freiburg, Germany.

09/2006-07/2009 M.Sc. in Biochemistry and Molecular Biology. College of Life Sciences, Northwest A\&F University, China.

09/2000-07/2004 B.Sc. in Biotechnology. College of Life Sciences, Zhejiang University, China.

\section{Work Experience:}

2005, Research assistant in Prof. Ming Zhang's lab, Department of Cell Biology, Zhejiang University. Work topic: Establishment and differentiation of mouse embryo stem cell. 